\title{
Fouling mitigation in Forward Osmosis and Membrane Distillation for Desalination
}

\author{
W.J. Lee ${ }^{1}$, Z.C. $\mathrm{Ng}^{1}$, S.K. Hubadillah ${ }^{1}$, P.S. Goh ${ }^{1}$, W.J. Lau ${ }^{1}$, M.H.D. Othman ${ }^{1}$, A.F. Ismail*1 \\ and N. Hilal ${ }^{2,3}$ \\ - ${ }^{1}$ Advanced Membrane Technology Research Centre, School of Chemical and Energy \\ Engineering, Faculty of Engineering, Universiti Teknologi Malaysia, 81310 Johor, Malaysia \\ ${ }^{2}$ Centre for Water Advanced Technologies and Environmental Research (CWATER), \\ College of Engineering, Swansea University, Swansea SA1 8EN, UK \\ ${ }^{3}$ NYUAD Water Research Center, New York University Abu Dhabi, Abu Dhabi, United \\ Arab Emirates
}

Corresponding author: afauzi@utm.my

\begin{abstract}
Freshwater scarcity is one of the grand challenges that has posed threats to the global economy, societal stability and ecosystem balance. Desalination has been long recognized as an effective approach for fresh water production from seawater and brackish water. Forward osmosis (FO) is currently one of the most studied technologies for seawater and brackish water desalination due to its intrinsic advantages compared to reverse osmosis. On the other hand, membrane distillation (MD) is an emerging technology to offer a potentially cost effective thermallydriven desalination process, especially when coupled with waste heat and solar thermal. One major and inevitable challenge for FO and MD is membrane fouling. For decades, fouling and its related topics have gained extensive attention from the desalination communities and various strategies have been implemented to tackle this long standing issue. In this contribution, the fouling mitigation strategies in terms of pretreatment, membrane surface modification and operating conditions for both FO and MD processes are comprehensively reviewed.
\end{abstract}

Keywords: forward osmosis; membrane distillation; desalination; fouling

\section{Table of Content}

1. Introduction

2. Emerging Membrane Technologies for Desalination

2.1 Forward Osmosis

2.2 Membrane Distillation

3. Brief Overview on Fouling Mechanisms in FO and MD

4. Fouling Mitigation Strategies

4.1 Pretreatment

4.1.1 Chemical-based Treatment

4.1.2 Microporous Membrane Separation

4.1.3 Curing Temperature

4.2 Membrane Surface Modification

4.2.1 Forward Osmosis

4.2.2 Membrane Distillation

4.3 Operating Conditions

4.3.1 Forward Osmosis 


\subsubsection{Draw Solution and Feed Solution Flowrates}

4.3.1.2 Draw Solution Concentration

\subsubsection{Membrane Distillation}

4.4 Membrane Cleaning

4.4.1 Forward Osmosis

5. Future Outlook and Conclusions

References

\section{Introduction}

Reverse osmosis (RO) technology currently dominates the market of both seawater and brackish water desalination. More than half of the total installed desalination capacity in the world is based on this technology [1]. The majority of installed desalination capacity is located in the Middle East where seawater is plentiful and freshwater is scarce. However, over the last decade, desalination has become increasingly important around the world with significant growth in Asia and the Americas [2]. Although the energy cost of RO technology for desalination process is getting closer to the fundamental limit (i.e., $\sim 1.06 \mathrm{~kW} \mathrm{~h} \mathrm{~m}^{-3}$ for desalination of seawater with $35,000 \mathrm{ppm}$ salt at typical recovery of $50 \%$ ) owing to the improvement in process efficiency [3], its energy consumption is still significantly higher compared to the conventional treatment process that purifies non saline water sources. Because of this reason, many developing countries particularly countries which can easily obtain water from catchment restrict to diversify national water supply system to desalination process.

The impacts of climate change coupled with growing population, however, would put pressure on the conventional water supply and thus, a low-energy desalination process is explored to address the growing demand on freshwater. Other emerging membrane technologies such as forward osmosis (FO) and membrane distillation (MD) are currently studied to desalinate water with the aim of offering alternative solution to purify saline water at lower energy cost [4]-[7]. Figure 1 compares the number of papers published in the peerreviewed journals in the fields of RO, FO and MD over the last decade. Although the number of papers published per year in the fields of FO and MD is much lower compared to the RO, the significant growth of these two emerging membrane technologies for desalination process has been witnessed particularly over the past several years. More than half of the total number of FO and MD related papers published over the recent past 10 years were recorded for the years between 2016 and 2019 (till Aug). This indicates that the strong research interest among the membrane scientists worldwide to seek alternative membrane processes with greater advantages in comparison to the conventional RO process. 


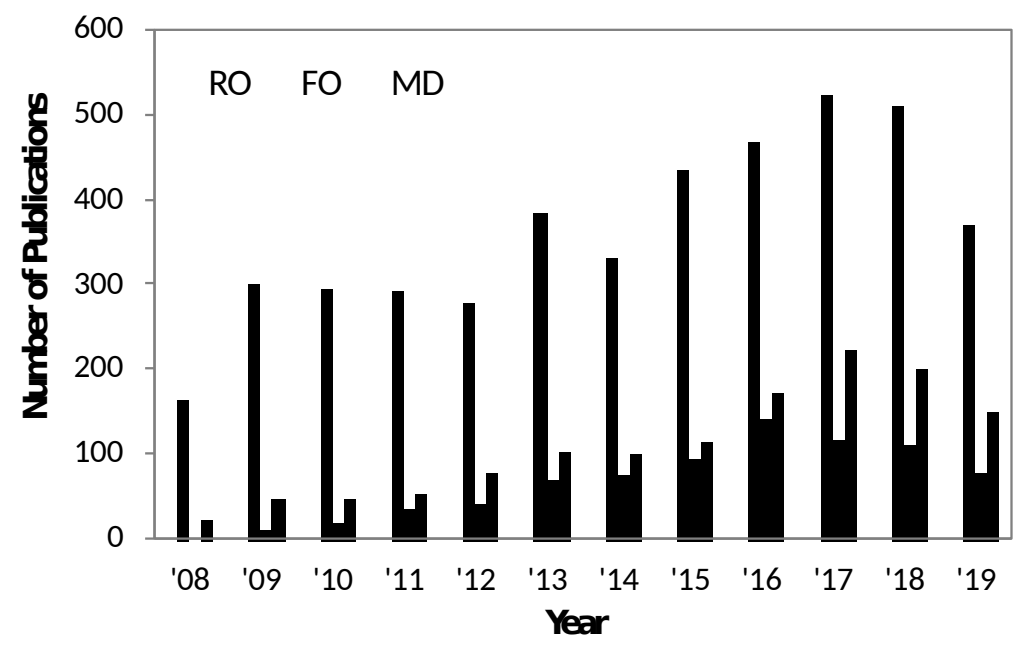

Figure 1. Number of research publications related to RO, FO and MD for desalination process for the period of 2008-2019 (Data from Scopus, Assessed on Dec 8, 2019)

Similar to the RO membrane process, membrane surface fouling is also one of the main problems encountered by FO and MD process. Since both FO and MD processes require minimum external hydraulic force during operation (mainly to circulate fluids within system), they in general experience lower degree of surface fouling in comparison to the high-pressure driven RO membrane process. Nevertheless, the fouling issues in the FO and MD process must not be neglected as the accumulation of foulants on the membrane surface and/or inside the membrane pores is associated with decline in membrane permeability, leading to inefficiency of the treatment process. The interaction between foulant and membrane however varies depending on the types of fouling (e.g., organic fouling, inorganic fouling, scaling and microbial fouling) and the membrane surface characteristics (e.g., functional groups, hydrophobicity/hydrophilicity, roughness, etc). Over the years, concerted efforts have been devoted to improving the long-term performance of FO and MD process for desalination process by reducing/minimizing fouling propensity via several major strategies that can be divided into three main categories in which the first strategy deals with the employment of adequate pretreatment process on the source water prior to membrane process [8]-[10]. The second category involves the development of advanced membrane surface properties that could exhibit high antifouling resistance [11], [12]. The third category which is critical during filtration process is to optimize the operational conditions to achieve minimum fouling degree [13], [14].

A number of reviews have been published over the last few years to cover the development of FO and MD process for desalination process [15]-[18]. However, from our review of the literature, we have not found any review article dedicated to the fouling mitigation of both FO and MD processes for desalination of brackish water and seawater. In view of the importance of emerging membrane technologies for desalination process, the main objective of this paper is to provide a comprehensive review on the fouling mitigation strategies in FO and MD technologies. The first section of this review is to provide a brief description on concept of $\mathrm{FO}$ and MD process that is driven based on osmotic pressure difference and temperature difference, respectively. It is followed by the discussion on the fouling mechanisms in the respective membrane process. Three main categories of the state-of-the-art strategies for mitigating membrane surface fouling, i.e., pretreatment process, development of advanced membranes with improved surface properties and optimization of operational parameters will be 
thoroughly reviewed in the subsequent sections. At last, the challenges faced by the emerging membrane processes as well as future outlook are highlighted.

\section{Basic Principle of FO and MD Process for Desalination}

The principle of FO and MD for desalination processes is different compared to the conventional RO technology. Unlike RO technology that requires extremely high external hydraulic pressure force during filtration process, both FO and MD processes only need minimum external mechanical pressure for liquid circulation in the system. As illustrated in Figure 2(a), the main driving force in a FO membrane process is the osmotic pressure difference $(\Delta \pi)$ between the two solutions across a semi-permeable membrane (typically polyamide (PA) thin film composite (TFC) membrane). In FO process, water molecules diffuse from feed solution of lower concentration (saline water) through membrane to draw solution of higher concentration. Higher membrane water flux is expected by increasing the concentration of draw solution owing to the increased effective osmotic pressure driving force, provided the characteristics of membranes and feed solution properties remain the same. However, it must be noted that when the orientation of TFC membrane in the FO process is reversed (i.e., polyamide layer facing draw solution), significantly higher water flux is able to achieve owing to the reduction in the effect of internal concentration polarization (ICP). This process, known as pressure retarded osmosis (PRO) is mainly used for sustainable energy production.

The main criterion of selecting a draw solution is that it must have a higher osmotic pressure than the feed solution. A sodium chloride $(\mathrm{NaCl})$ solution is very often used because it has high solubility and is relatively simple to reconcentrate to high concentration using RO process without risk of scaling [19]. In most of the lab-scale FO studies [20]-[23], draw solution composed of $2 \mathrm{M} \mathrm{NaCl}$ is used to ensure sufficient osmotic pressure difference between draw water and feed solution. Typically, the membrane used in FO process should exhibit low structural $(\mathrm{S})$ parameter $(\mathrm{S}$ parameter value $=$ thickness $\times$ tortuosity/porosity) in order to mitigate the internal concentration polarization (ICP) phenomenon that occurs within the membrane structure [24]. The S parameter value is a measure of the resistance of the substrate of the FO membrane towards solute diffusion. The smaller the S parameter value, the easier for the dissolved solutes to diffuse through the porous substrate and the greater the membrane water flux [25]. In addition, FO membrane should have at least $90 \%$ rejection against $\mathrm{NaCl}$ solution (tested in dead-end/cross-flow RO process) in order to ensure minimum reverse draw solute flux that will affect water flux stability in long run [26], [27]. On the other hand, the water molecules transport through microporous membrane (typically made of hydrophobic material) in MD process is governed by partial pressure difference across microporous membrane [28]. The partial pressure difference across the membrane can be achieved by creating temperature difference $(\Delta \mathrm{T})$ between two sides of membrane as shown in Figure 2(b). Generally, one side of the membrane is contacted with hot solution (saline water) and another side of it directly or indirectly comes in contact with cold solution (fresh water), depending on the configuration of MD process. The water vapor passing through the porous membrane structure from hot solution would condense on the cold side to produce high-quality distillate. 
There are four major types of MD processes, namely (a) direct contact membrane distillation (DCMD), (b) air gap membrane distillation (AGMD), (c) sweeping gas membrane distillation (SGMD), and (d) vacuum membrane distillation (VMD). The details about the differences between these MD processes can be found elsewhere [29], [30]. Of these MD processes, DCMD is the most widely employed configuration in desalination process owing to its simplicity in terms of design and setup [29], [31]. The temperature of the feed solution in the DCMD process should be below the boiling point of the solution. It can vary from few degrees higher than the ambient temperature to $90^{\circ} \mathrm{C}$. The temperature of the cold solution is normally set at $20^{\circ} \mathrm{C}$. Compared to other MD configurations, DCMD process suffers higher degree of heat loss via conduction. Nevertheless, it is worth noting that DCMD is a process mainly suited for applications in which water is the major component of the feed solution (e.g., brackish water and seawater). According to Khayet and Matsuura [5], the pore size of membranes used in MD process can range from several nanometers to few micrometers, but the pore size distribution should be as narrow as possible and the liquid entry pressure (LEP) should as high as possible to prevent feed liquid from penetrating into membrane pores. As tortuosity factor (measure of the deviation of the pore structure from straight cylindrical pores normal to the surface) and membrane thickness are inversely proportional to the membrane permeability, Khayet and Matsuura [5] emphasized that the values of both parameters should be kept small.

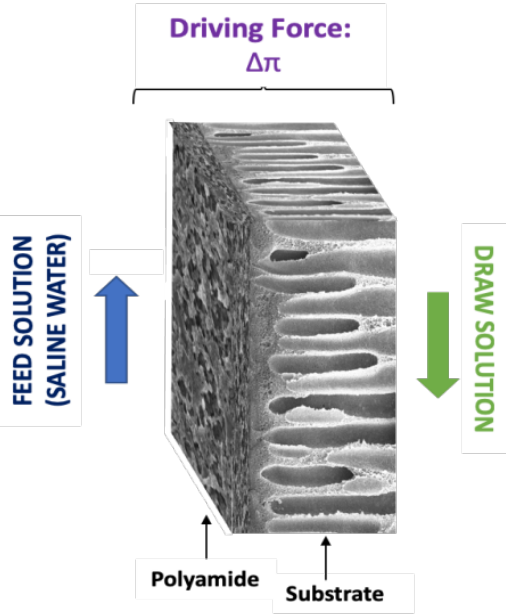

(a)

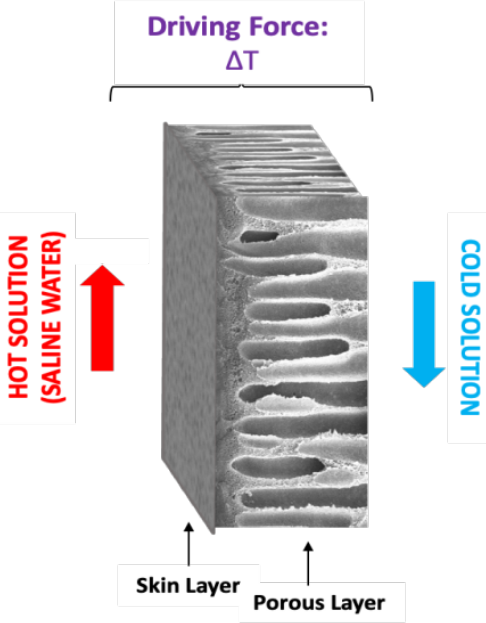

(b)

Figure 2. Schematic diagram of (a) osmotically-driven FO membrane process and (b) thermally-driven MD process for desalination

\section{Brief overview on fouling mechanisms in FO and MD}

Membrane fouling is always one of the main challenges in the development of membrane technologies, particularly the $\mathrm{RO}$ process [32]. In $\mathrm{RO}$, high hydraulic pressure is applied to overcome the high feed osmotic pressure. Moreover, the high pressure also plays a role in pushing the water molecules through the small RO membrane pores with pore radius of approximately $0.25 \mathrm{~nm}$ [33][34]. High pressure operation makes the RO membranes prone to membrane fouling. FO and MD are generally thought to be more resistant toward fouling compared to RO. Typically, the FO membranes exhibit similar pore size to those of RO membranes. However, less pressure is needed as the draw solution with high osmotic pressure tends to pull the water molecules through the membrane. Meanwhile, MD is a thermally driven process that utilizes the hydrophobic microporous membranes for separation and operates at 
lower pressure. Fouling could occur in any membrane surface when there is an interaction of force between foulants and surface of membrane, that described by DLVO theory. According to this theory, it introduces that about interaction between net particle-surface which is summation of the Van deer Waals and the electrical double layer forces. In other word, fouling occurred when the foulants have different charges [35]. This is according to different charges of foulants would led to an attraction towards membrane surface by forming a deposition. However, vice versa for foulants with similar charges. Similarly, this mechanism also happens on membrane in MD process. Moreover, fouling in MD gives additional thermal and hydraulic resistance [36]. Accordingly, fouling formation would reduce temperature difference across the membrane or increase in temperature polarization, resulting lesser driving force [37]. Whereas, the fouling resistance of FO membrane is primarily dictated by membrane selective layer, while the water flux is principally determined by the internal concentration polarization (ICP) that occurred within membrane substrate. Figure 3 shows the schematic diagram of fouling mechanism in (a) membrane distillation, and (b) forward osmosis.

(a)

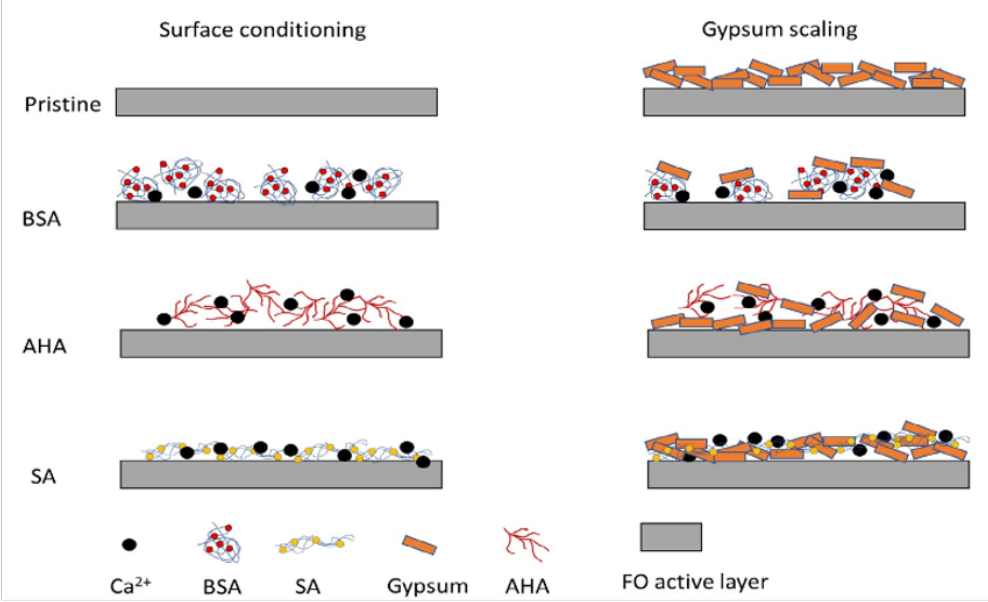

(b)

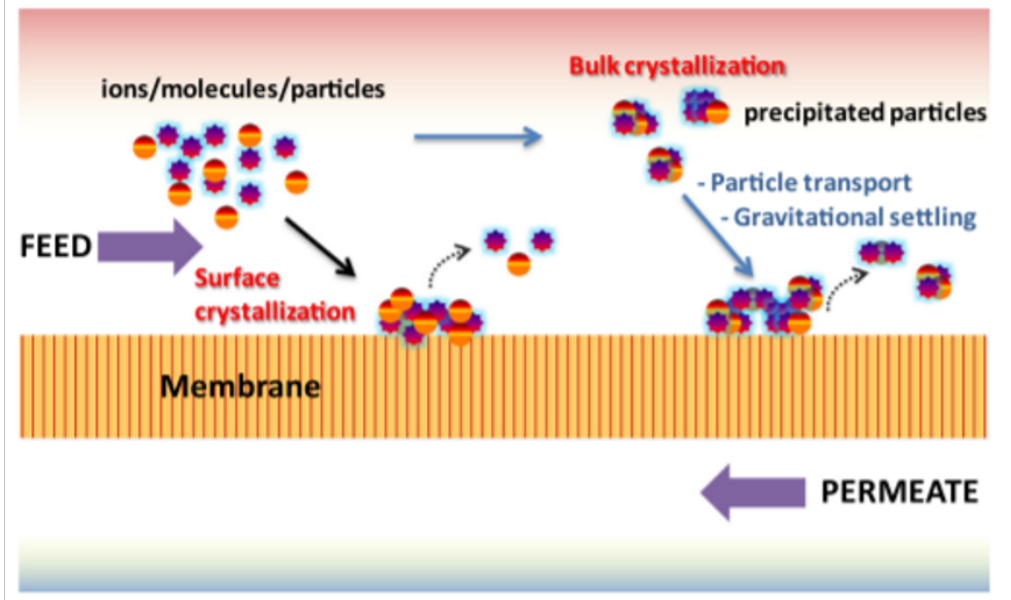

Figure 3. Schematic diagram of fouling mechanism in (a) membrane distillation [38], and (b) forward osmosis [39]

Several studies have compared the fouling behaviours of FO and RO and found that FO demonstrated slower flux decline and was easier to clean compared to RO [40][41]. On the other hand, no scientific evidence has been reported on the comparison of the fouling behaviours between MD and RO. The claims on the fouling resistance of MD are usually vague, and sometimes, not discussed at all [38][42]. The concern on the MD membrane fouling is 
always neglected due to the general perspectives that MD operates at conditions that do not promote fouling, such as low operating pressure, relatively large pore size and membrane hydrophobicity [43]. In this review, the membrane fouling and fouling mitigations of FO and MD will be highlighted.

In FO, fouling occurs when a cake/gel layer forms on the membrane surface or blocks the internal pores especially the porous support layer. There are two different FO membrane orientations, namely active layer-feed solution (AL-FS) and active layer-draw solution (ALDS) orientations. In AL-FS orientation, fouling occurs when the foulant in feed solution deposits on the surface of the membrane active layer, ensuing cake/gel layer formation (Figure 4). This is known as external fouling, which is similar to the fouling mechanism in RO [44][45][46]. The external fouling issues can be mitigated through the optimization of the hydrodynamic conditions of the feed water, such as enhancing the crossflow velocity with the use of feed spacer, incorporation of the pulsed flow, and applying the air scouring. Meanwhile, in AL-DS orientation, the fouling is built up via (a) the adsorption of foulant on the walls of the pores of the support layer, or (b) the deposition of foulant on the side of the dense active layer facing the support layer (Figure 4). The latter mechanism, which is also known as internal fouling, usually happens in AL-DS orientation and could lead to pore clogging when the foulant enters the porous support layer and adsorbs on the pore walls. In order to prevent the internal fouling, AL-FS orientation is recommended for the FO operation. Since the foulant layer does not experience significant hydraulic compaction, the fouling of FO can be easier to mitigate as compared to that of RO.

a

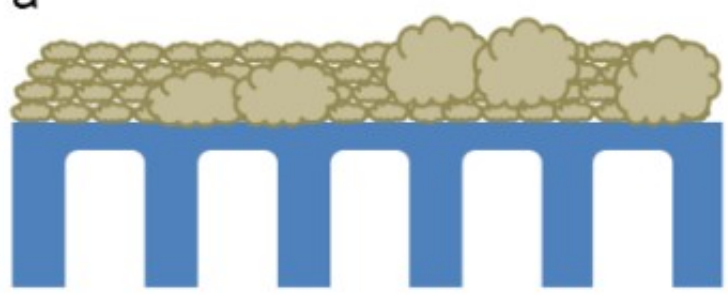

External Fouling in AL-FS Orientation b

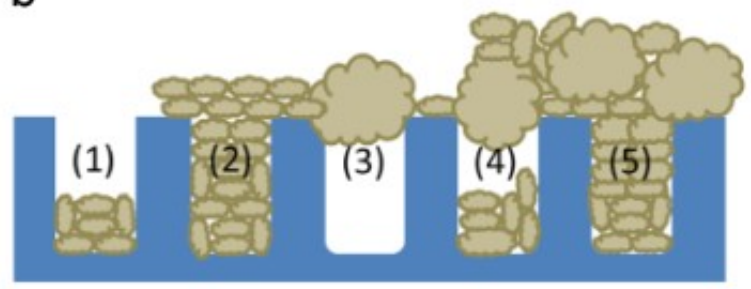

Internal Fouling and External Fouling in AL-DS Orientation

Figure 4. FO membrane fouling: (a) External fouling in AL-FS orientation, and (b) internal fouling and external fouling in AL-DS orientation [47].

Similarly, MD also faces the build-up of foulant on the external membrane surface and in the membrane pore (Figure 5). However, the fouling phenomenon of MD is different from that of FO as MD involves the heat exchange process, different transport phenomena and the use of the hydrophobic membrane. Usually, MD faces the issue of scale formation on the membrane surface when treating the concentrated salt solutions. Throughout the years, numerous investigations on the development of MD for new separation applications have revealed different types of fouling. For instance, the severity of fouling increases when treating the solutions composed of macromolecules, especially the protein typed macromolecules, as the macromolecules tend to adsorb onto the membrane surface. During the MD process, the molecules are adsorbed on the hydrophobic surface to form an initial layer of foulant. A thick cake layer is eventually formed under high convective flux when the molecules accumulate on the membrane surface. The increase in the net heat resistance and the mass transfer would cause a decrease in the cake layer formation. Therefore, the fouling layer thickness can be easily controlled by manipulating the heat and mass transfer in the MD process. 


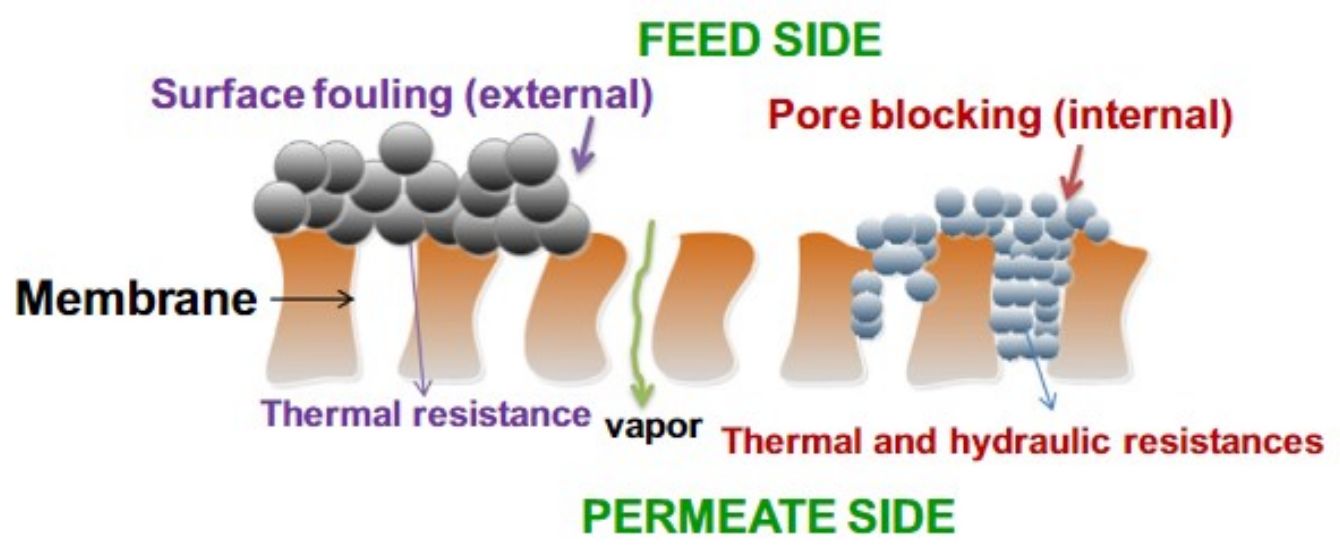

Figure 5. Membrane fouling can be categorized into surface fouling (external) and pore blocking (internal) [48]

MD fouling can be generally categorized into three groups, namely (a) inorganic fouling, (b) organic fouling, and (c) biological fouling. The fouling mechanisms and their combined effects on the MD process are schematically illustrated in Figure 6. The membrane will consequently experience partial or complete surface fouling and pore blocking as the process proceeds. Inorganic fouling or scaling is caused by the accumulation of hard salt precipitates such as calcium sulfate, calcium carbonate, silicate, calcium phosphate and sodium chloride. Inorganic fouling occurs when the feed nucleates and crystallizes on the membrane surface due to the changes in temperature and water evaporation. The organic fouling in the MD process is caused by colloidal organic matters such as humic substances, extracellular polymeric substances (EPS) and proteins. Meanwhile, biological fouling or biofouling is caused by the build-up of microorganisms on the membrane surface that causes a decrease in permeate flux. 


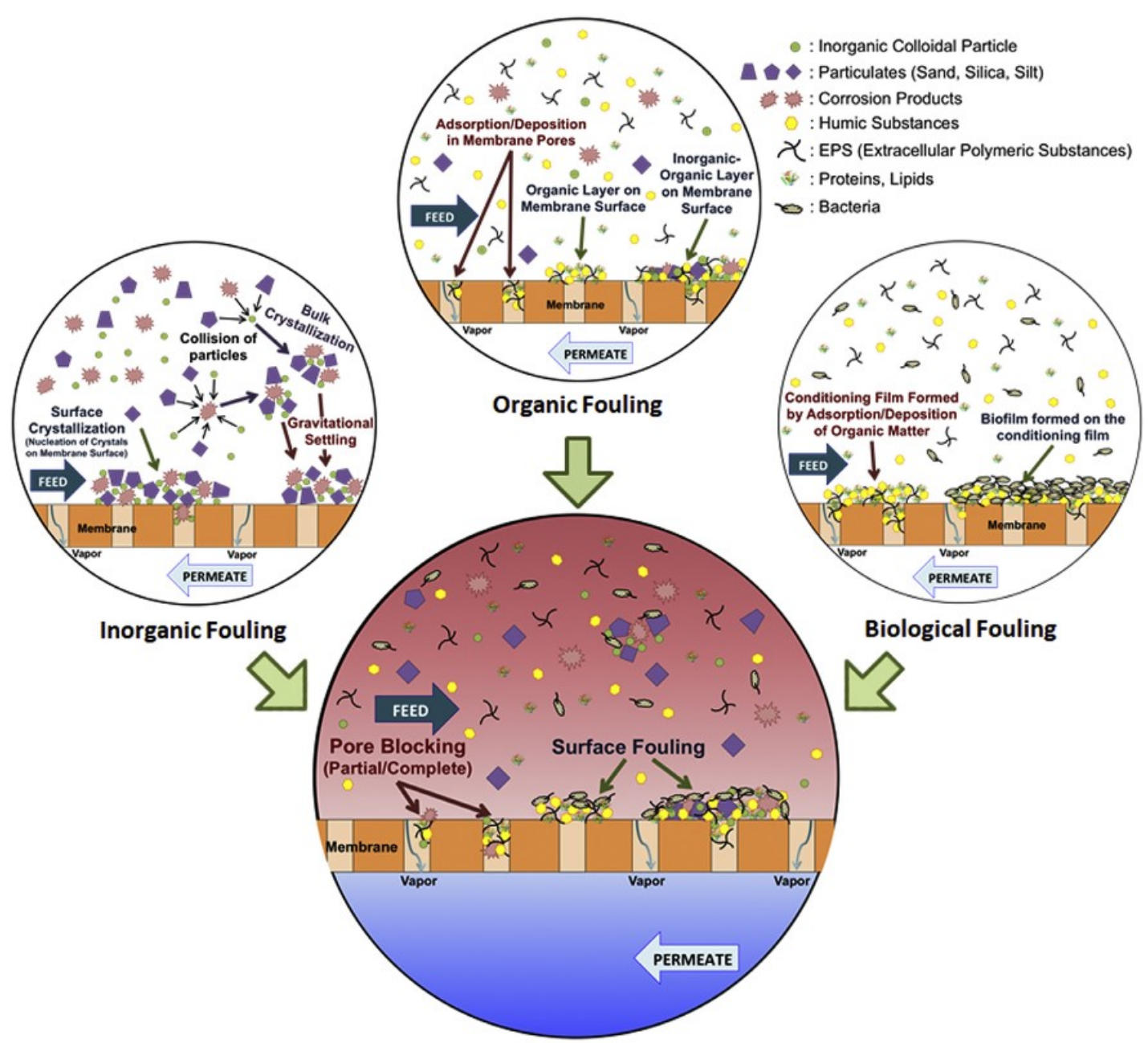

Figure 6. The build-up of inorganic, organic and biological fouling leads to partial or complete pore blocking (internal fouling) and surface fouling (external fouling) in MD membrane [38].

\section{4. $\quad$ Fouling Mitigation Strategies}

\subsection{Pretreatment}

The success of desalination process using membrane-based technology is highly dependent on design of feed pretreatment. Pretreatment must be effective in reducing membrane fouling potential in a reliable and consistent manner. In the development of an appropriate pretreatment process, the focus is on removing as many fouling constituents in the feed water as possible prior to the membrane process. In the following sub-sections, an overview on the recent development of conventional and membrane-based pretreatment process will be provided.

\subsubsection{Conventional Treatment Methods}


The conventional treatment methods that are widely employed for large-scale seawater reverse osmosis (SWRO) desalination plants worldwide are also suitable as pretreatment process for FO and MD process. The main roles of pretreatment methods are to significantly reduce level of total suspended solids (TSSs) and various forms of fouling and scaling rates, preserving performance and life span of membranes. A membrane-based process that is equipped with inadequate or less effective pretreatment measures may suffer from undesired low system performance. Typically, sedimentation is the primary unit of the conventional treatment processes. It is usually followed by other treatment methods that are designed based on the source water characteristics. Three general treatment approaches are (a) dissolved air floatation (DAF) followed by dual media filter (DMF) and cartridge filter, (b) DMF followed by cartridge filter and (c) DAF followed by sand filter and cartridge filter [49]. For all cases, coagulation process is taken place before the water entering the first unit of conventional treatment process and antiscalant is normally added to the water after completing conventional treatment process. Antiscalant is required to minimize deposition of scale forming ions on the membrane surface. Sodium bisulfite (or activated carbon) sometimes is used to reduce unreacted chlorine during chlorination step as the presence of chlorine even at extremely low concentration $(\mathrm{mg} / \mathrm{L})$ could deteriorate PA selective layer of TFC membrane. It must be noted that the dosage of anti-scalant and sodium bisulfite should be carefully controlled as overdosing might pose negative impacts not only on the membrane desalination process (increased biofouling potential) but also marine environment (from the concentrate stream discharged). In this section, a brief description on the important units of the conventional treatment methods will be provided. For more details, readers are referred to relevant reviews published recently [49], [50].

Sedimentation is a commonly used process in water purification process. For desalination process, it has the capability of handling source water with daily average turbidity of 30 Nephelometric Turbidity Unit (NTU) and even 50 NTU in the case of turbidity spikes for short period of operation [49]. In the event of algal bloom that could increase significantly the turbidity to exceed $100 \mathrm{NTU}$, standard design of sedimentation is inadequate to produce treated water with desired level of less than 2 NTU [51]. Compared to the sedimentation, DAF where pressurized air bubbles are introduced into the feed water air is more effective in handling high-turbid source water, greatly reducing low-density particulates such as algal cells and suspended particles. An optimized DAF was reported to be able to remove up to $99 \%$ of algae [52], [53]. In a full-scale DAF process operated in South Korea, it was reported that the plant was able to consistently produce treated water with low turbidity $(0.16-1.16 \mathrm{NTU})$ from the high-turbidity water (up to $430 \mathrm{NTU}$ ) throughout 4-year study period [54]. Nevertheless, it must be pointed out that integrating DAF with sedimentation is highly recommended to achieve desirable water quality, particularly during an unexpected increase in source water turbidity. Such integration is also important to ensure media filters are not easily clogged by the algae which could affect productivity of filter.

DMF that consists of $0.4-0.8 \mathrm{~m}$ of anthracite over $1-2 \mathrm{~m}$ of sand is often used in existing large-scale desalination process to remove fairly large number of remaining impurities (with few micrometers in size) through a bed of porous and granular material. With respect to separation efficiency, DMF is more effective than single media filter and is capable of producing water of higher quality. Additional layer of granular activated carbon is used when the source water contains relatively high level of organic compounds. With this additional layer, a portion of organic compounds could be removed by adsorption [55]. To further improve the quality of water, cartridge filter with particle size rating as small as $1 \mu \mathrm{m}$ is used as the last unit 
of conventional process for final removal of any suspended particulates that have passed through the DMF [56].

\subsubsection{Membrane-based Method}

When microporous membrane (typically ultrafiltration (UF) category) was used as pretreatment at its early stage of implementation in desalination plant, many people were skeptical about its performance and operation cost. Nevertheless, the successful implementation of several UF membranes process in the mid-2000s have led to many full-scale integrated UF-RO desalination plants built worldwide including Singapore, China, United Arab Emirates, Saudi Arabia and Spain, etc. [57], [58]. The key to the successful operation of UF membrane for desalination process is dependent on the membrane pore size. Of the wide pore size range of UF membranes and its different configuration (vacuum driven or pressuredriven) available in the current market, the vacuum-driven hollow fiber membranes with a nominal pore size of around $0.02 \mu \mathrm{m}$ is best known to be the most effective in removing potential foulants, e.g., algae, bacteria, silt, and organic matters responsible for membrane fouling. Typically, UF membrane is able to consistently produce water with turbidity less than 0.1 NTU and 15-min Silt Density Index (SDI15) less than 2.5 and is less influenced by the seasonal changes in the source water properties [57].

Compared to the pressure-driven membrane process, the vacuum-driven membrane process requires $10-20 \%$ less space and 10-30\% less energy, assuming similar operating conditions [51]. Owing to the lower trans-membrane pressure employed, the vacuum driven membrane usually experiences lower degree of fouling and has more stable performance during operation [49]. As energy consumption is one of the main concerns of microporous membrane implementation in desalination process, many research studies have been conducted in recent years to develop low-pressure or gravity-driven membrane (GDM) as efficient pretreatment process prior to desalination process [59]-[62]. In general, integration of membrane pretreatment may increase the capital costs of the desalination system, but the operational costs may decrease if membrane fouling can be effectively reduced by the integration [63]. Wu et al. [64] developed a low energy and chemical-free GDM process using hollow fiber membrane modules of different packing density for pretreating seawater. Figure 7 shows the experimental setup of the GDM process and membrane modules used for evaluation. The results showed that the submerged membrane reactor tested up to 250 days was able to achieve permeate flux stabilized at $18.6 \mathrm{~L} \mathrm{~m}^{-2} \mathrm{~h}^{-1}$ at hydrostatic pressure of $40 \mathrm{mbar}$. Hydrostatic pressure was created as the membrane module was placed $40 \mathrm{~cm}$ below the overflow water line in the reactor. As lower module packing density could offer more space for eukaryotes to move and predate bacteria attached onto membrane surface, higher water flux was experienced. More importantly, the GDM system was found to effectively reduce turbidity level and viable cells and showed reasonably high removal rates against transparent exopolymer particles, TEP (41-85\%). However, it was found that GDM system was not able to reduce dissolved organic carbon (DOC) in the permeate, possibly because some microbial species could convert $\mathrm{CO}_{2}$ into organic substances [62].

A recent study showed that the performance of GDM system could be further improved by integrating it with biofiltration (BF) column packed with anthracite media as shown in 
Figure 8 [65]. The presence of BF column as a pretreatment before the GDM was efficient in separating organic substances via biodegradation/biosorption behavior of the biofilm developed, resulting in production of superior permeate quality from the integrated BF-GDM process. Nevertheless, the integrated BF-GDM process suffered from poor performance in reducing dissolved and assimilable organic substances in seawater which was caused by the decomposition of suspended organic materials and carbon fixation by biofilm [66]. Although these two studies showed that the integrated BF-GDM process exhibited lower water flux than the GDM process (probably due to the limited predation and movement of eukaryotes in membrane biofilm), the benefits offered by the integrated process, i.e., reduced membrane fouling (for subsequent RO membrane process) and lower pretreatment cost could offset the lower water productivity.
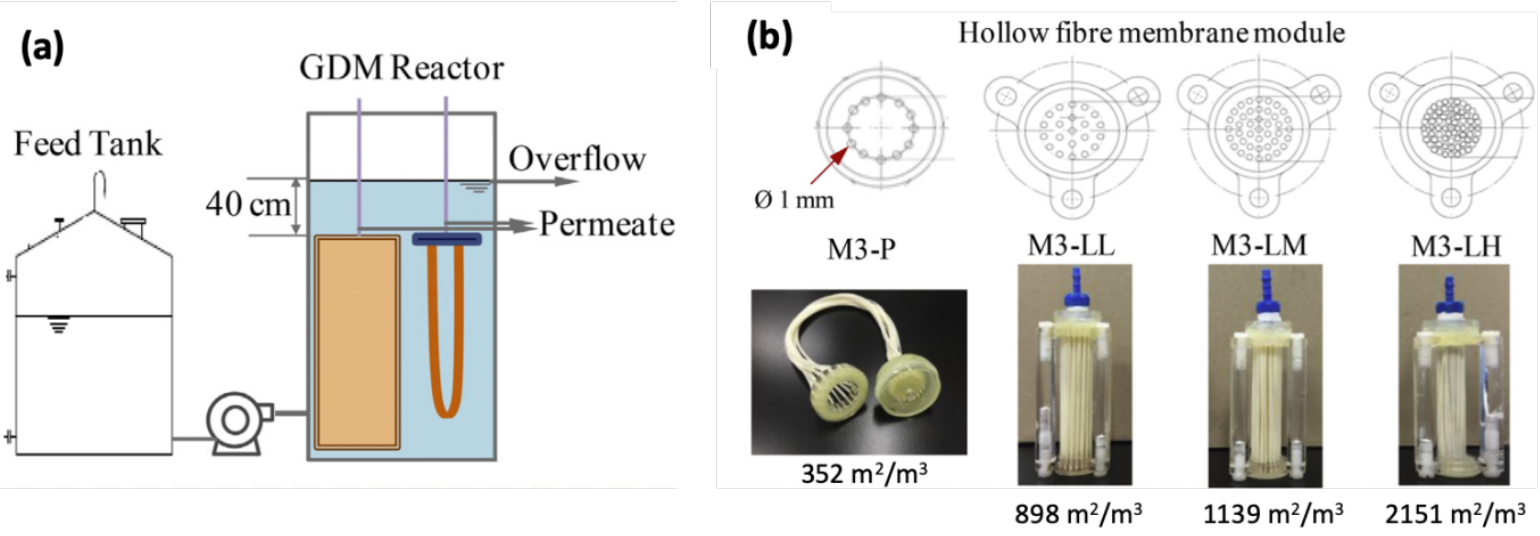

Figure 7. (a) Experimental setup of pilot (720 L) and lab-scale (8.4 L) GDM system and (b) Outside-in hollow fiber membrane module with different packing density (Membrane pore size: $0.1 \mu \mathrm{m})$ [64].

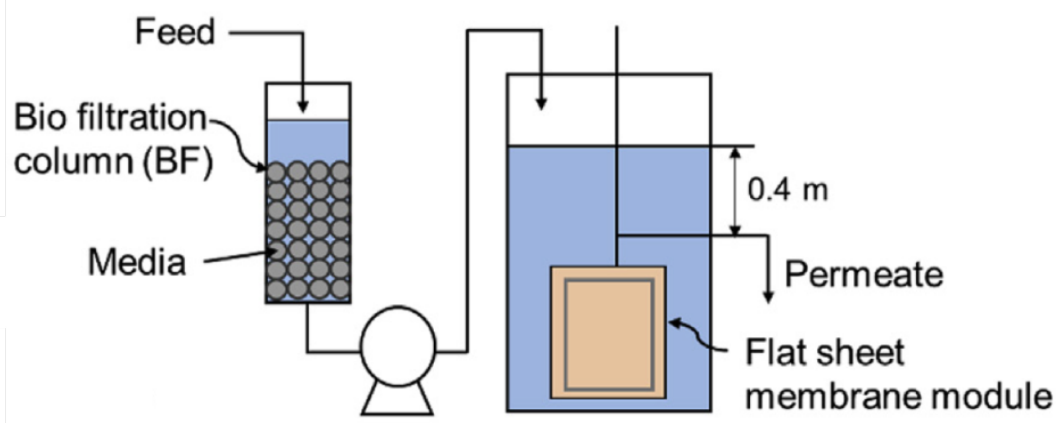

Figure 8. Schematic diagram of integrating membrane pretreatment process with BF column [65].

As microporous membrane showed relatively poor performance in reducing the level of DOC, Monnot et al. [67] coupled the UF process with granular activated carbon (GAC) for adsorptive removal of DOC from the source water. With the use of GAC, around 70\% of DOC and $90 \%$ of TEP could be removed from the source water prior to the UF membrane process, leading to reduced fouling potential on the UF membrane surface. Using the same combination of pretreatment processes, the authors investigated the influence of GAC on the performance of a community-scale of desalination plant (capacity of $5 \mathrm{~m}^{3}$ day $^{-1}$ ) and reported that the GAC was able to protect UF membrane from rapid fouling [68]. During 50 days of operation, GAC enabled to remove most of DOC while UF membrane was effective to reduce TEP, turbidity 
value and bacteria. The combined process resulted in higher water recovery rate and reduced energy consumption for subsequent RO membrane process.

To alleviate UF membrane fouling, Huang et al. [69] utilized combined ozone and powdered activated carbon (PAC) technologies prior to UF membrane (see Figure 9) to improve separation efficiencies of organic matters. According to Treguer et al. [70], small molecular organics are preferentially adsorbed by activated carbon while for aromatic compounds, oxidation is able to oxidize electron-rich areas in target molecules and reduces their aromaticity. The results found that combined ozone and PAC pretreatment could remarkably reduce trans-membrane pressure (TMP) increase whereby ozone played greater role in delaying TMP increase. Furthermore, this combined treatment could improve removal efficiencies of large and medium molecular compounds (e.g., biopolymer and humic-like substances) as well as microbial organics, leading to reduced fouling of UF membrane.

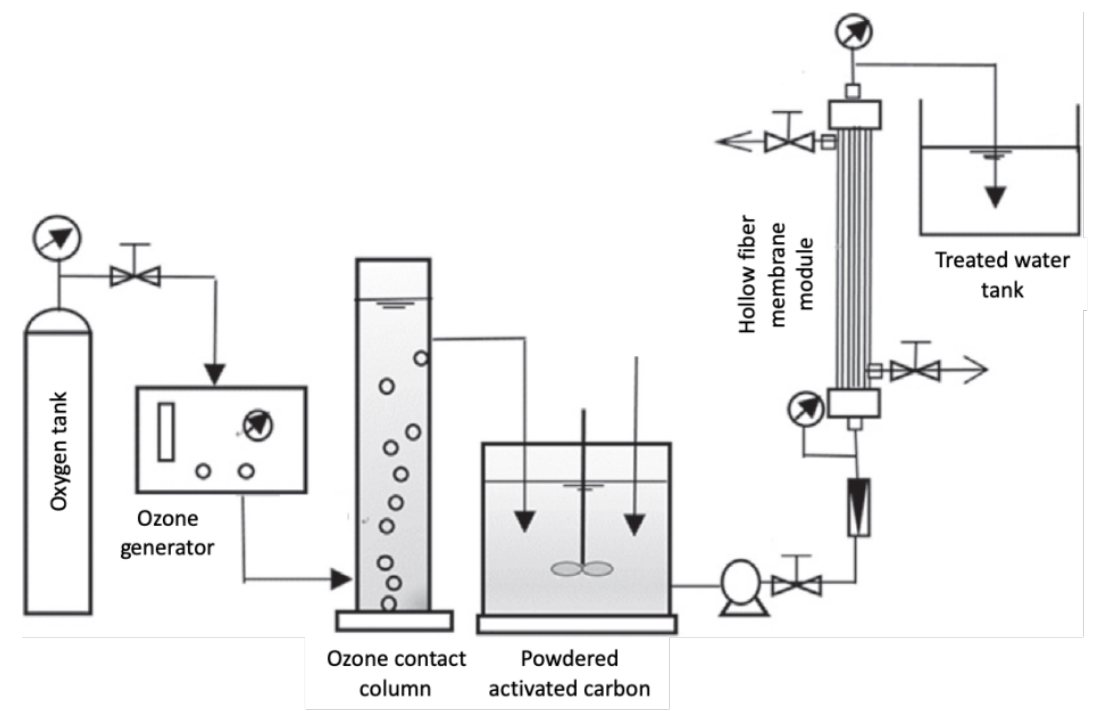

Figure 9. Schematic diagram of combined ozone and PAC treatment prior to UF membrane process [69].

\subsubsection{Curing Temperature}

The curing temperature of the membrane could affect its water flux and the reverse solute flux. A study from Suwaileh et. al. [71] on FO shows that when the curing temperature was increased from $50{ }^{\circ} \mathrm{C}$ to $60{ }^{\circ} \mathrm{C}$ over $4 \mathrm{~h}$, the water flux increased slightly from $24.1 \mathrm{~L} \mathrm{~m}^{-2}$ $\mathrm{hr}^{-1}$ to $24.7 \mathrm{~L} \mathrm{~m}^{-2} \mathrm{hr}^{-1}$ using $1 \mathrm{M} \mathrm{NaCl}$ as DS and DI water as FS, while the reverse solute flux declined slightly from $76.8 \mathrm{gMH}$ to $71.3 \mathrm{gMH}$. It means that the solubility, diffusivity and crosslinking degree of the coating solution could be increased when the curing temperature was increased to $60{ }^{\circ} \mathrm{C}$. This would result in the formation of a thinner and more continuous selective layer on the support layer. By increasing the curing temperature to $70{ }^{\circ} \mathrm{C}$, the water flux declined slightly and the reverse solute flux did not have any change. Thus, $60{ }^{\circ} \mathrm{C}$ was the optimum curing temperature for that study. Also, Ji and co-workers [72] did their study on the effect of curing temperature on membrane performance. The membrane performance varied when the curing temperature was increased from $30{ }^{\circ} \mathrm{C}$ to $60{ }^{\circ} \mathrm{C}$. The rejection of $\mathrm{K}_{2} \mathrm{SO}_{4}$ increased from $75.2 \%$ to $88.0 \%$ while the water flux decreased from $17.9 \mathrm{~L} \mathrm{~m}^{-2} \mathrm{hr}^{-1}$ to $6.7 \mathrm{~L}$ 
$\mathrm{m}^{-2} \mathrm{hr}^{-1}$. It means that higher curing temperature results in higher cross-linking degree and denser membrane surface. By taking into account both aspects of rejection and water flux, $50{ }^{\circ} \mathrm{C}$ curing temperature was optimum. Also, Devia and co-workers [73] also investigated the effect of curing temperature on the FO membrane performance. It was found out that the solutes rejection was insensitive to the temperature variation, instead, water flux was significantly affected by it. In the study, a curing temperature of $25^{\circ} \mathrm{C}$ was found to be optimum.

\subsection{Membrane Surface Modification}

\subsubsection{Forward Osmosis}

Fouling is an undesirable phenomenon for membrane application as it can adversely affect the membrane efficiency over time. Apart from that, it increases the costing as a fouled membrane has to be replaced periodically. There are several factors which affect the fouling propensity of a membrane. An efficient membrane with low fouling propensity must have low surface roughness and strong hydrophilicity. Besides, depending on the feed solution, filler types and surface charges also affect fouling propensity. Thus, novel modifications have been developed by researchers on membrane surface to improve the performance of desalination especially on fouling. There are several methods for membrane surface modification, such as active layer incorporation, layer-by-layer (LBL) assembly method, double-skinned coating, substrate coating/blending. Figure 10 illustrates the techniques used to modify TFC FO membrane. Meanwhile, Table 1 lists down some advantages and disadvantages of the membrane surface modification.

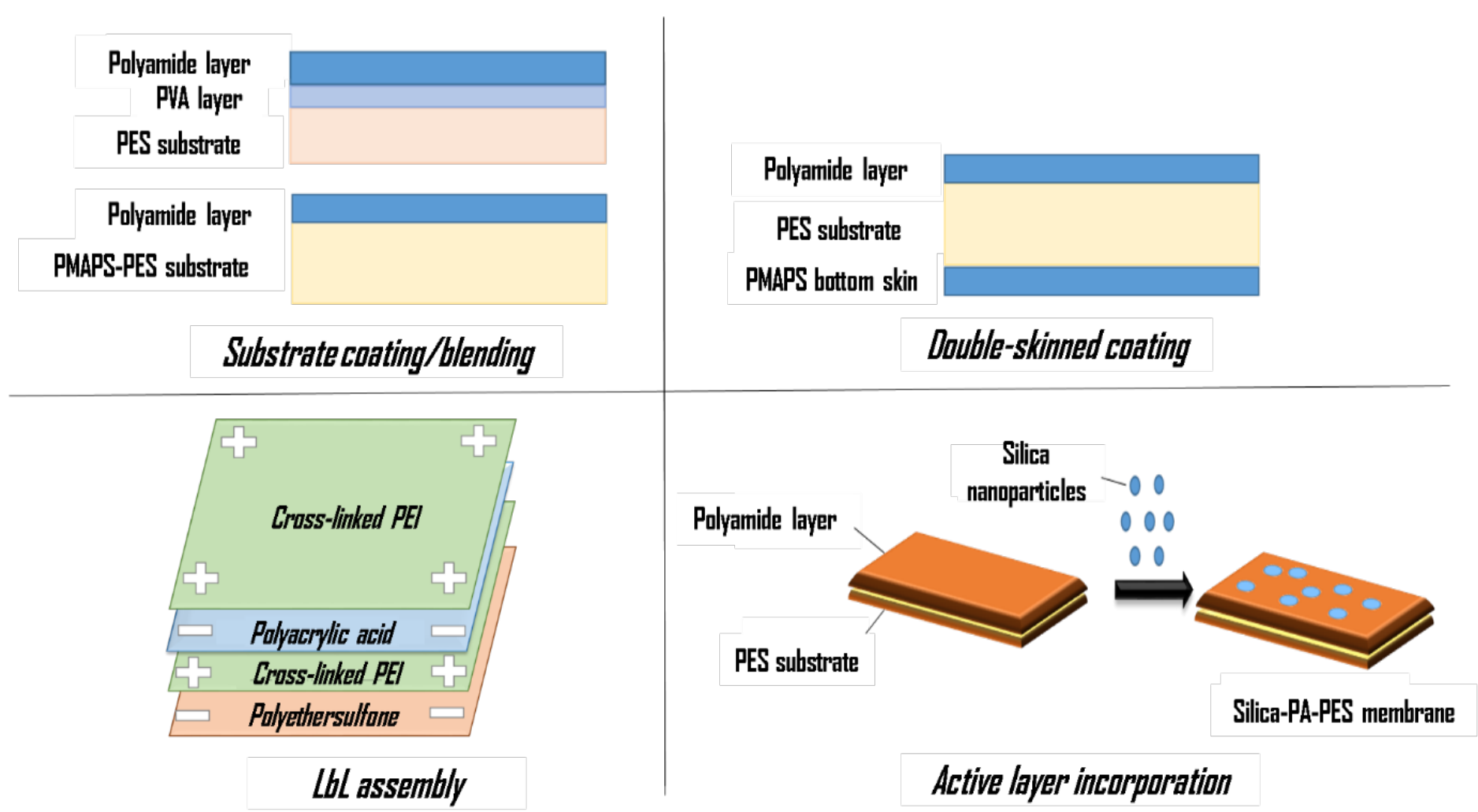

Figure 10. Techniques used to modify TFC FO membranes 
Table 1: Summary of membrane modification methods

\begin{tabular}{|c|c|c|}
\hline Membrane modification & Advantages & Disadvantages \\
\hline Modification of active layer & $\begin{array}{l}\text { - Improved membrane } \\
\text { selectivity and rejection. } \\
\text { - Improved surface } \\
\text { hydrophilicity. } \\
\text { - Reduced fouling } \\
\text { propensity. }\end{array}$ & $\begin{array}{l}\text { - Uncontrolled ICP } \\
\text { phenomenon. }\end{array}$ \\
\hline Substrate coating/blending & $\begin{array}{l}\text { - Reduced ICP phenomenon. } \\
\text { - Improved water } \\
\text { permeability. }\end{array}$ & $\begin{array}{l}\text { - Dispersion of filler in dope } \\
\text { solution is challenging. } \\
\text { - Cannot control membrane } \\
\text { selectivity and rejection. }\end{array}$ \\
\hline LbL assembly technique & $\begin{array}{l}\text { - Improved water } \\
\text { permeability (NF-like skin). } \\
\text { - Good rejection towards } \\
\text { divalent ions. }\end{array}$ & $\begin{array}{l}\text { - Low monovalent ions } \\
\text { rejection. } \\
\text { - Rejection layer may not } \\
\text { function well under high } \\
\text { ionic strength. } \\
\text { - Reduced water flux. }\end{array}$ \\
\hline Double-skinned coating & $\begin{array}{l}\text { - Reduced reverse solute } \\
\text { flux. } \\
\text { - Reduced internal fouling } \\
\text { problem. }\end{array}$ & - Reduced water flux. \\
\hline
\end{tabular}

\subsubsection{Modification of active layer}

Generally, active layer incorporation serves the purpose of improving the membrane surface hydrophilicity while reducing fouling. Meanwhile, it could also potentially affect the transport phenomena such as water transport and reverse solute diffusion. Hence, material selection becomes crucial as to alleviate fouling issue while maintaining a decent water flux and low reverse solute flux. Polydopamine (PDA) is a material good for surface modification as it has the ability to adhere to many types of substrates regardless of the surface energy. It has copious functional groups which could covalently immobilize biomolecules and metal ions. Thus, its application in surface modification is wide due to its versatility. In membrane separation process, PDA coating can greatly improve surface hydrophilicity and alleviate fouling [74]. It has been extensively used in antifouling coating for pressure-driven membrane process throughout the past few years [75]. Nonetheless, most of the modifications were substrate modification, while active layer modification using PDA is still uncommon. Guo and co-workers [76] investigated the effect of PDA active layer coating on FO performance. PDA was coated onto a Hydration Technology Innovations (HTI) commercial TFC FO membrane. The water contact angle also reduced significantly indicating increasing membrane surface hydrophilicity. Both of these improvements could render better antifouling behavior. The PDA layer could significantly impair the chemical interaction of carboxylic groups of $\mathrm{PA}$ and $\mathrm{Ca}^{2+}$ ions, hence restricting the formation of the fouling layer. In this study, the coating duration of 30 mins was adequate to ensure complete coating of PDA. A prolonged coating duration has undesirably created a thicker coating layer that reduced water permeability. The $\mathrm{NaCl}$ permeability decreased from $2.3 \mathrm{~L} \mathrm{~m}^{-2} \mathrm{hr}^{-1}$ to $1.6 \mathrm{~L} \mathrm{~m}^{-2} \mathrm{hr}^{-1}$ upon PDA coating accompanied with improved salt rejection. An interesting phenomenon was the modified membrane showed enhanced water flux compared to the neat membrane, which usually would not happen for RO 
process which is pressure driven due to the hydraulic resistance induced by the coating layer. This is because water flux in FO process is mainly affected by ICP effect. As the PDA coating lowered the reverse solute diffusion which in turn reducing ICP effect, the water flux increased. Figure 11 depicts the polymerization process and structure of PDA.

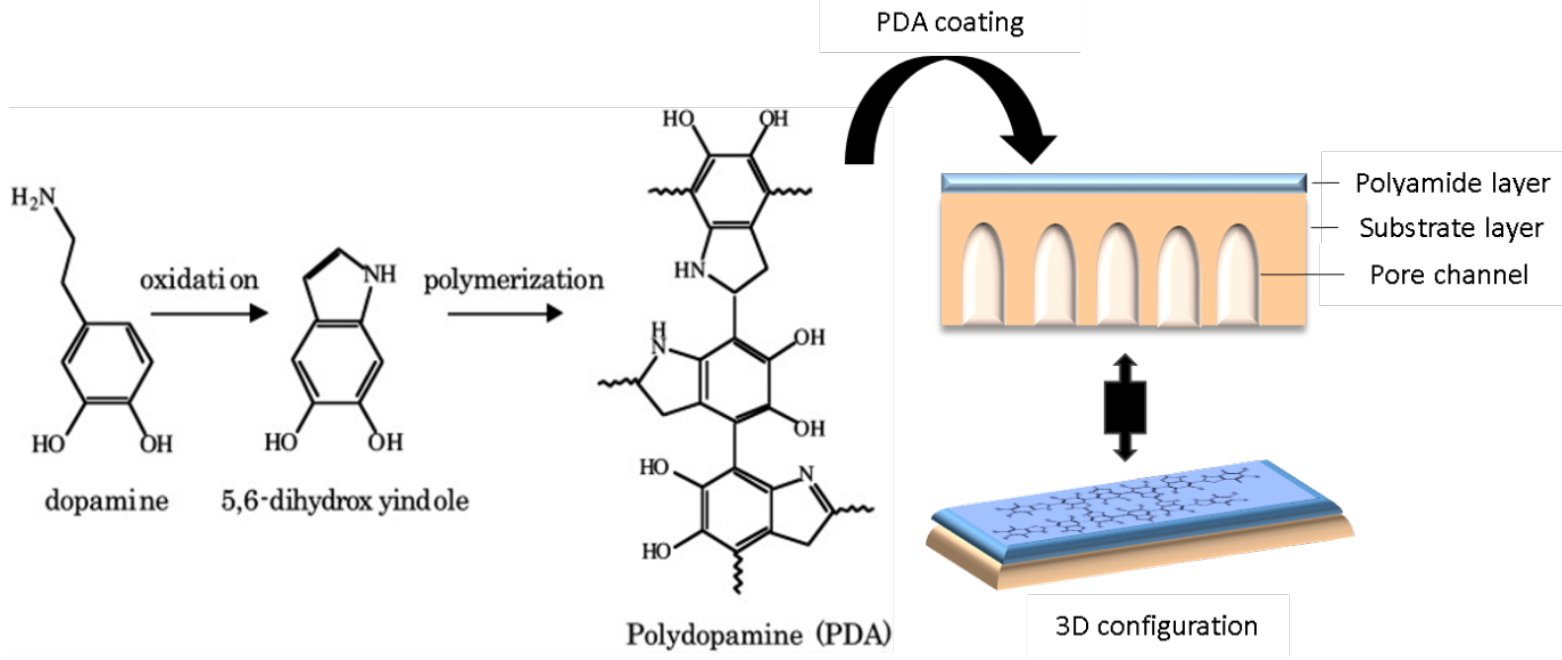

Figure 11. Structure and polymerization process of PDA followed by coating onto PA layer

Pao and co-workers [77] grafted polyamidoamine (PAMAM) dendrimer onto TFC-FO membrane via covalent bonds to treat domestic wastewater. The resultant PAMAM-TFC-FO membrane possessed robust fouling capacity and excellent ammonia selectivity. PAMAM dendrimer is rich in easily-protonated terminal amine groups. While PA active layer possesses a lot of negatively-charged carboxyl groups, upon grafting with PAMAM dendrimer, it counteracts the negative charges of the carboxyl groups and causes the PA layer surface to have remarkable zeta potential (isoelectric point), as well as superior surface hydrophilicity. Due to the electrostatic repulsion between the $\mathrm{NH}_{4}{ }^{+} \mathrm{N}$ and the protonated amine layer, the resultant PAMAM-TFC-FO membrane had an excellent $\mathrm{NH}_{4}{ }^{+} \mathrm{N}$ rejection of $98.23 \%$ and remarkable reverse solute flux reduction by employing $\mathrm{NH}_{4} \mathrm{Cl}$ solutions as FS. The protonated amine groups effectively repelled the multivalent metal ions of same charge $\left(\mathrm{Mg}^{2+}, \mathrm{Ca}^{2+}\right.$ and $\mathrm{Fe}^{3+}$, etc) and prevented severe fouling from occurring [78]. Chiao and co-workers [79] developed antifouling FO membrane using $\mathrm{N}$-aminoethyl piperazine propane sulfonate (AEPPS) zwitterions. Zwitterions are ions possessing both anionic and cationic moieties. Recent years, the use of zwitterion in membrane modification for surface hydrophilicity and antifouling characteristics improvement has been investigated thoroughly. The hydration layer formed between water molecules and zwitterions via electrostatic attraction becomes a physical wall for adsorption of protein molecules on the membrane surface which prevents the occurrence of fouling [80]. Moreover, the incorporation of zwitterion successfully reduced water contact angle for TFC membrane creating a more hydrophilic surface, hence improving the water permeability across the membrane. The presence of amine group in AEPPS reacts with TMC forming amide linkage which results in augmentation of zwitterion in PA layer.

Seyedpour and co-workers [81] incorporated graphene quantum dots (GDQs) in the PA active layer via IP in order to reduce biofouling phenomenon. The resultant thin film nanocomposite (TFN) successfully shown improved water permeability. Most importantly, GDQs with high ability to destroy the integrity of bacterial cell membrane shown great antibacterial properties, in which reduction in the generation of S.aureus and E. coli by about 95\% was achieved. Besides, Shakeri and co-workers [82] fabricated a novel polyoxometalate 
based open framework (POM-OFs) incorporated PA layer TFN membrane for water flux and antifouling behaviour improvement. Lately, metal organic frameworks (MOF) has been extensively used in membrane modification. However, the major shortcoming is the incompatibility between the hard organic nanomaterials and the soft polymer matrix can lead to severe membrane selectivity issue [83]. Thus, organic ligands were used to modify these nanomaterials to solve the incompatibility issue [84]. The modification also grants extra water permeability to the nanomaterials. POM-OFs is a novel hybrid material which comprises of polyoxometalate clusters as inorganic building blocks linked with organic cationic ligands. Similar to zeolites and MOFs, POM-OFs are very porous and have huge surface area, have strong hydrothermal stability and hydrophilic in nature. The existence of orderly tubular pores further enhance the water permeability of POM-OFs. The modified TFN membrane exhibited higher water flux compared to the neat TFC membrane, and also the slight reduction in salt rejection due to increase membrane surface roughness is negligible, again proving the feasibility of it. In term of fouling, the modified TFN membrane had lots of tiny, leaf-like structure while the neat membrane had ridge-valley structure which could trap foulant. In short, the modified TFN membrane exhibited a more stabilized water flux over time.

To alleviate fouling issue, Tiraferri and his co-workers [85] optimized the TFC membrane surface properties by coating TFC surface with tailored silica nanoparticles functionalized with super hydrophilic ligands containing quaternary amine or ammonium moieties. The modified membrane showed significantly lower fouling, with no reported water flux. Similar study was done by Niksefat et. al. [86] by incorporating silica nanoparticles onto PA layer. Nonetheless, the salt rejection reported was low. Apart from silica nanoparticles, Ma et. al. [87] in his study found out $\mathrm{NaY}$ zeolite nanoparticles as an approach to enhance water flux by incorporating them onto PA active layer due to their hydrophilic properties. The optimum zeolite loading $(0.1 \mathrm{wt} \%)$ was obtained as excessive zeolite loading can result in flux reduction. The $0.1 \mathrm{wt} \%$ zeolite incorporated TFN membrane outperformed all the membranes with a water permeability of around $80 \%$ increment to the neat membrane. Meanwhile, the FO water flux had similar trend with the water permeability test. It indicates that the flux was significantly improved with the incorporation of low loading zeolite [87]. Besides, Amini and co-workers [88] in the study incorporated amine-functionalized multi-walled carbon nanotubes (MWCNTs) onto PA active layer of his TFC membrane. The resultant membrane exhibited significantly enhanced water flux and salt rejection. The best TFN membrane $(0.1 \mathrm{wt} \%$ MWCNTs) exhibited water flux of $95.7 \mathrm{~L} \mathrm{~m}^{-2} \mathrm{hr}^{-1}$, nearly $160 \%$ higher than the neat membrane. Nonetheless, the addition of MWCNTs faces limitation as high loading of MWCNTs in the MPD solution can potentially affect the IP process results in membrane selectivity being affected [88].

\subsubsection{Substrate Blending/Coating}

Generally, the ICP phenomenon is governed by the porous substrate while the salt rejection and flux permeation is controlled by active layer. Generally, RO membranes exhibits poor performance in FO application due to the adverse ICP effects. Hence to alleviate the ICP effects of FO desalination, the support layer fabricated must be hydrophilic, highly porous, having low tortuosity and structural parameter (S) value. Nonetheless, most of the substrates are fabricated using polysulfone (PSf) which is hydrophobic and inhibit wetting. Thus, some 
modifications were done to membrane substrate that focus on improving water flux and mitigating ICP phenomenon. While the ICP phenomenon is lessened, the membrane fouling issue can be alleviated. Imparting hydrophilicity to the membrane is a good way to enhance water flux.

As mentioned in the previous sub-section, PDA-substrate modification is a popular method to impart hydrophilicity and adsorption properties to the membrane. Kwon and co-workers [89] fabricated a high performance and superb durability TFC FO membrane on a polyethylene (PE) support modified by PDA via an unconventional aromatic solvent-based (toluene) IP process. The hydrophobic pristine PE support was hydrophilized uniformly by the PDA coating and become suitable for long-term operation. Also, toluene-based IP process created a highly permselective PA active layer on the hydrophilic PDA-modified PE support (DPE), whereby permeability-selectivity trade-off has always been a limitation for performance enhancement with the aliphatic solvent-based IP process [90]. The resultant DPE-TFC membrane successfully exhibited a FO water flux 4.5 times higher and reverse solute flux $63 \%$ lower than the commercial HTI-CTA membrane. Also, the DPE-TFC membrane had an excellent mechanical and chemical robustness, which could be potentially durable in mechanically and chemically harsh environments. Saraf and co-workers [21] modified the membranes by coating poly(vinyl) alcohol (PVA) onto the PSf substrate. Maleic acid and glutaraldehyde were used as the cross-linking agent. When being tested with seawater, maleic acid cross-linked PVA membrane had significantly better performance compared to glutaraldehyde cross-linked PVA membrane. However, both membranes showed no distinct difference when being tested with brackish water. Arena et. al. [22] in his study also did coating onto the membrane substrate to impart hydrophilicity. PDA was coated onto PSf support layer casted onto a non-woven polyester (PET). The modified membranes successfully improved the water flux by around $60 \%$ for FO tests. Cho et. al. [23] modified the hydrophobic PSf substrate by incorporating hydrophilic carboxylic acid groups onto it which granted higher water flux $\left(18 \mathrm{~L} \mathrm{~m}^{-2} \mathrm{hr}^{-1}\right)$ compared to neat PSf substrate using $1 \mathrm{M} \mathrm{MgCl}_{2}$ as DS. Nevertheless, the drawback of the modified membrane is that higher concentration of DS is necessary for the membrane to be mechanically stable.

Zhou and co-workers [24] fabricated TFC FO membrane with PSf-mixed-sulfonated poly(phenylene oxide) (SPPO) as the substrate to enhance internal osmotic pressure (IOP). They proposed a theory that the presence of IOP could compensate the effect of dilutive ICP in FO which subsequently grants higher water flux. IOP is generated by the immobilized sodium ions in SPPO which eases water transport in the AL-FS mode. The enhanced water flux when tested under AL-DS mode can be up to $25 \mathrm{~L} \mathrm{~m}^{-2} \mathrm{hr}^{-1}$. The fouling phenomenon also reduced significantly. In order to render ICP effects, Emadzadeh et. al. [25] incorporated $\mathrm{TiO}_{2}$ onto PSf support layer. The incorporation of $\mathrm{TiO}_{2}$ increased the membrane porosity and develops finger-like structure, which results in improved water permeability. Yet, it was reported that the amount of $\mathrm{TiO}_{2}$ employed has to be appropriate as excessive loadings of $\mathrm{TiO}_{2}$ cause high reverse salt flux, which is owing to the development of a less dense cross-linked active layer. The optimum $\mathrm{TiO}_{2}$ concentration which exhibited both excellent water flux and low reverse salt flux was $0.5 \mathrm{wt} \%$. The incorporation of fillers in the support layer could negatively affect the formation and integrity of top active layer during IP process.

To develop a perfect surface for PA layer deposition, Liu and co-workers [26] employed double blade casting technique to incorporate nano-sized silica into PSf support layer. Using this technique, the fabricated substrate has a silica-impregnated porous bottom layer. The top layer is free from silica which makes it an ideal surface for active layer deposition. The incorporation 
of silica nanoparticles is able to reduce the ICP effects while the defect-free active layer is able to increase the salt retention. Goh et. al. [27] designed a functionalized MWCNTs immobilized polyethylenimine mixed polyamide-imide (PEI-PAI) hollow fiber FO membrane. PAI substrate was fabricated via phase inversion, followed by MWCNT immobilization via vacuum filtration and lastly PEI chemical post-treatment to obtain a positively-charged selective layer. Compared to the PEI-PAI membrane of Setiawan et. al. [28] without MWCNT, the membrane showed significant improvement in the water permeability $\left(4.48 \mathrm{~L} \mathrm{~m}^{-2} \mathrm{hr}^{-1} \mathrm{bar}^{-1}\right)$ at $1 \mathrm{bar}$, which was around $49.9 \%$ increment. The $\mathrm{MgCl}_{2}$ retention was able to maintain at $87.8 \%$. The increased water permeability and flux is due to the presence of nanocorridors between the MWCNT and PEI polymer matrix which have low water resistance and facilitate water movement along the gaps across the membrane. To reduce the ICP effects and enhance the water flux, Puguan et. al. [29] fabricated a highly hydrophilic cross-linked electrospun PVA nanofiber substrate, followed by IP of PA layer atop it. The PVA was cross-linked using acid catalyzed glutaraldehyde in acetone solution. Compared to the commercial HTI membrane, the resultant water flux exhibited by the membrane was 7-8 times higher because the structural parameter has become significantly lower. Nevertheless, more research needs to be carried out for the membrane to be mechanically robust.

\subsubsection{LBL Assembly Technique}

LBL approach is a promising method to prepare a NF-like membrane with ultrathin selective layer. LBL membrane has good rejection towards divalent ions as well as strong thermal stability that has been successfully employed for NF operations throughout years [91]. LBL method basically requires the deposition of several polyelectrolytes with opposite charges onto porous substrate surface in alternate sequence. The first polyelectrolyte layer on the porous support layer is usually linked by electrostatic attraction or hydrophobic attraction. LBL technique can be easily employed to produce composite polyelectrolyte multilayer membranes to obtain improved water flux and rejection for FO. Despite able to exhibit decent water flux and acceptable rejection for divalent ions such as $\mathrm{Mg}^{2+}$ and $\mathrm{SO}_{4}{ }^{2-}$, nonetheless, due to the relatively loose selective layer, the retention of monovalent ions such as $\mathrm{Na}^{+}$is remarkably low. Surface charge of the selective layer is also important. A membrane with the same surface charge to the solutes could reduce membrane surface scaling by electrostatic repulsion [92]. The same charge induces repulsion to minimize the adherence of solutes onto the membrane surface, hence fouling can be reduced.

Suwaileh et. al. [93] prepared a positively-charged membrane by utilizing LBL adsorption of PEI and polyacrylic acid (PAA). Figure 12 illustrates the synthesis process of support layer followed by LbL deposition of PAA and PEI layers. Simple vacuum assisted filtration method was performed to adsorb the PEI film onto the polyethersulfone (PES) substrate. Next, PAA was dispersed in DI water and poured to the PEI film. It was then left for an hour to allow adsorption to occur. The water contact angle decrease could be possibly due to the large amount of amine functional groups in the 4.5 bi-layers substrate. However, internal fouling phenomenon occurred whereby the water flux declined slowly after the deposition of 
the second PEI layer. This is possibly due to the overlapping of PEI molecules on the substrate causing reformation of the pore channel alignment which resulted in entrapment of solutes. Also, as the deposited bilayers increase, the membrane become thicker and more compact which resulted in decrease water flux. The same group of researchers combined the homogeneous polyelectrolyte complex membranes (HPECMs) method and LBL method to create membrane with homogeneous continuous selective layer and controlled cross-linking degree of the polyelectrolytes for brackish water desalination [71]. After optimization, the resulted membrane with 2.5 bi-layers was found out to have the best water permeability and reverse salt flux. The polyelectrolytes used were PDADMAC as cationic layer and $\mathrm{CMCNa}$ as anionic layer. The strong positive charges of PDADMAC was to maintain the substrate at $\mathrm{pH}$ value $<6$ so that the polyelectrolyte would be less protonated. A polyelectrolytes ratio of $0.1 \mathrm{M}$ PDADMAC: $0.001 \mathrm{M}$ MCMCNa successfully produced membrane with the best performance. From the SEM surface characterization, it was noticed that the selective layer formed was smooth and homogeneous. Also, from the zeta potential measurements, it could be known that the positive charges on the support layer can be increased by increasing the number of bilayers. The membrane internal pore fouling problem could be potentially reduced as high positive charges could reduce the reverse solute flux of positively-charged ions.

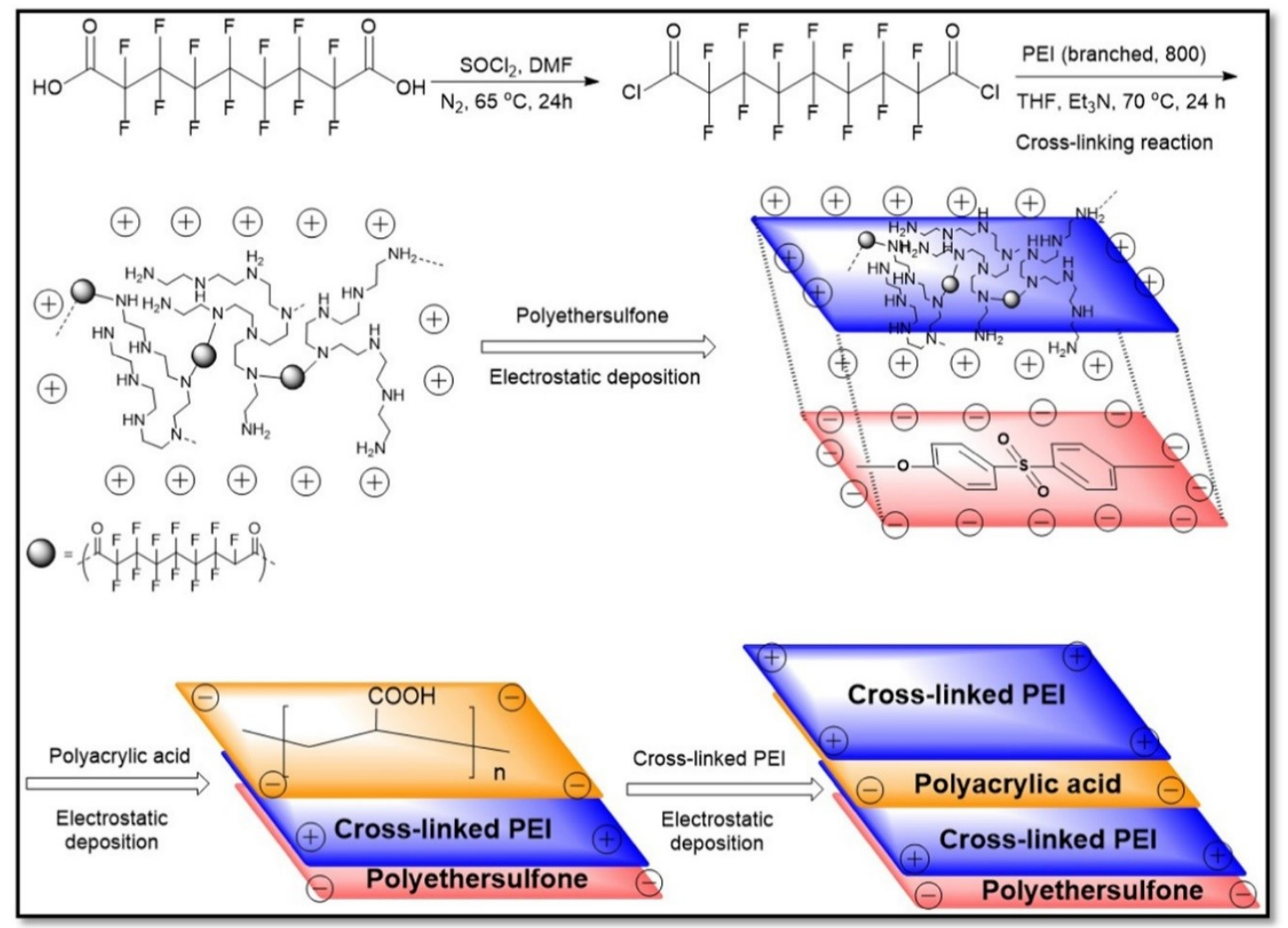

Figure 12: Schematic diagram of the synthesis process of PEI layer and LbL assembly of PEI and PAA layers on PES substrate [93]

To investigate the fouling phenomenon for TFC-FO membrane when using sodium alginate as foulant, Salehi and co-workers [94] used LbL assembly method to coat cationic chitosan nanosheets and anionic graphene oxide nanosheets in the PA layer. Graphene oxide has superior hydrophilicity and good antifouling properties but poor adherence, while chitosan with good film-forming ability is complementary to graphene oxide. Chitosan also possesses 
good antifouling properties. The resultant TFC membrane formed from chitosan and graphene oxide via LbL method exhibited excellent antifouling properties, which was possibly credited to the surface charges, roughness and hydrophilicity. Nonetheless, with $10 \mathrm{LbL}$ bilayers coated, the modified membrane had a relatively low water permeation and reverse salt flux using $1 \mathrm{M}$ sucrose or $1 \mathrm{M} \mathrm{Na}_{2} \mathrm{SO}_{4}$ as DS and DI water as FS. This could be potentially a trade-off between the reverse salt flux and the water flux. Similarly, Kang and co-workers [95] also prepared a graphene oxide FO membrane via LbL assembly for desalination in their study. It is notably that the ordered structure of LbL FO membrane would diminish after long running in sodium ions because the limiting effect of sodium ions would expand the spacing between graphene oxide layers. Therefore, oxidized carbon nanotubes (OCNTs) was inserted into the graphene oxide interlayer as the tubular structure of OCNTs would prevent the expansion of graphene oxide. Interestingly, due to the weak interaction between graphene oxide and OCNTs, the membrane bilayers structure formed would become loose and allow ions to pass through easily ended up with ICP effect. Hence, poly dimethyl diallyl ammonium chloride (PDDA) was employed as the linking agent because the membrane formed would become much denser and restrict the movement of ions across the membrane. The resultant GO-OCNTs-PES membrane with 5 bilayers showed the best performance. Using $\mathrm{NaCl}, \mathrm{MgCl}_{2}, \mathrm{Na}_{2} \mathrm{SO}_{4}$ as DS and DI water as FS, the membrane modified with OCNTs exhibited significant improvement in water flux while the reverse solute flux of $\mathrm{NaCl}$ decreased by $70.2 \%$. Thus, regarding the salt rejection and water flux, the GO-OCNTs-PES membrane had outperformed the control membrane.

The alleviation of ICP also indirectly reduces the fouling propensity of the membrane. Often, the lacking of efficient drawing agent has restricted the potential of FO application. Without a suitable drawing agent, water flux is greatly limited. To address this issue, Zeng and co-workers [96] designed a multiple-layers temperature responsive hydrogel based on poly(Nisopropylacrylamide-co-sodium acrylate) (P(NIPAAm-co-SA). The multiple layers consist of drawing layer with high SA concentration responsible for attracting water molecules and releasing layer without SA to preserve the lower critical solution temperature (LCST) of P(NIPAAm) for swift water release. In short, the absorb-and-release mechanism of the membrane accelerated the water movement across the membrane by altering the temperature which resulted in very high water flux. The water flux increased proportionally with SA concentration. However, the water release mechanism was adversely affected as well as the concentration of SA in the P(NIPAAm-co-SA) samples went higher because it would lose the LCST phase transition. Reducing the SA concentration only slightly increased the water release ratio.

By aiming at mitigating ICP and membrane fouling phenomenon for desalination, $\mathrm{Li}$ and co-workers [97] modified TFC FO membrane by coating with laminar molybdenum disulfide $\left(\mathrm{MoS}_{2}\right)$ via LbL assembly method. PAA and PEI were chosen as the negative and positive electrolytes respectively. The LBL deposition was done by dipping the membrane first in PEI solution, followed by $\mathrm{MoS}_{2}$ and finally PEI forming a PAA-MoS $-\mathrm{PEI}$ trilayer. Despite the popularity of graphene in membrane coating, the application of graphene is however further limited due to its instability in aqueous solution [98]. Compared to graphene, $\mathrm{MoS}_{2}$ with high stability in aqueous solution became a promising alternative for membrane modification and also due to its separation capability, multifunctional and antifouling properties. Due to the excellent surface hydrophilicity, the coating of $\mathrm{MoS}_{2}$ granted the resultant membrane better hydrophilicity with higher water flux and lower reverse solute flux. $\mathrm{MoS}_{2}$ with fouling-release properties also endowed good antifouling performance to the resultant FO membrane. With just simple hydraulic washing, the modified membrane flux could recover close to initial flux after each cycle of experiments. In order to develop a positively-charged membrane, Wu et. al. 
[99] used PEI in aqueous phase and TMC in organic phase to form thin film layer atop PES substrate via IP. The resultant selective layer was rough, compact and non-uniform. Contradictorily, the membrane exhibited excellent water flux and high salt rejections $(>80 \%)$ for all $\mathrm{NaCl}, \mathrm{MgCl}_{2}, \mathrm{MgSO}_{4}$, and $\mathrm{Na}_{2} \mathrm{SO}_{4}$. Following this, to fabricate TFC membrane with uniform selective layer, Akbari and co-workers [100] coated PEI on a porous PSf support layer, then cross-link them using p-xylene dichloride (XDC) and lastly quaternization using methyl iodide (MI). The resultant selective layer was uniform and thin $(<3-4 \mu \mathrm{m})$. Most importantly, it gave decent water flux and high salt rejections for $\mathrm{NaCl}, \mathrm{CaCl}_{2}, \mathrm{MgSO}_{4}$, and $\mathrm{Na}_{2} \mathrm{SO}_{4}$. As the resultant selective layer was uniform, less severe fouling issue and flux decline was observed.

\subsubsection{Double-skinned Coating}

Similar to LBL assembly method, double-skinned coating method also involves the coating of extra layer, but at the bottom part of the porous support layer instead of overlapping each other atop active layer. The double-skinned coating method aims to reduce the ICP effects and internal fouling problem. Most of the time, to obtain high water flux, AL-DS configuration whereby the support layer is facing the feed solution is favorable compared to AL-FS configuration. However, it also indicates that the solutes can easily accumulate in the substrate pore which results in concentrative ICP and also reduced water flux. Thus, this fouling phenomenon can be solved by coating another rejection skin as a barrier at the bottom of support layer to prevent clogging of foulants in the membrane pores.

Song and co-workers [101] fabricated a double-skinned TFC FO membrane with same top and bottom layers which were CNTs incorporated PA layers. The incorporation of CNTs gave the membrane extra water channels and improved antifouling capability which resulted in permeability improvement. CNTs is able to damage the cell membranes of microorganisms and disrupt the metabolic pathways accompanied by the oxidation stress, which causes death/inactivation of microorganisms. The control TFC membrane experienced a severe flux decline during antifouling test. Nonetheless, the double-skinned TFN membrane had only a slight decrease in normalized flux during antifouling test. Moreover, the double-skinned membrane also had a higher flux recovery rate. It showed that the bottom-skinned dense layer was successful in preventing the foulants from entering in and clogging the substrate pores. Also, the double-skinned TFN membrane exhibited higher water flux compared to the control membrane, indicating hydrophilicity improvement. Table 2 summarizes the membrane developments in these few years.

\subsubsection{Membrane Distillation}

Polymeric membranes are commonly employed as a barrier between the two phases in the MD operation. These porous MD membranes can be synthesized via different methods depending on the nature of the polymeric materials. For instance, the chemically stable PP and PTFE membranes are fabricated through melt extrusion and subsequent stretching for pore 
formation. Thermal induced phase separation (TIPS) or non-solvent induced phase separation (NIPS) techniques are usually employed for the preparation of PVDF hollow fiber membranes [102]. Table 3 shows a comparison of the NIPS and TIPS techniques for the PVDF membrane preparation. Despite having the contact angles of $\geq 90^{\circ}$, the hydrophobic MD membranes still face the organic fouling issues [103]. These issues can be minimized through the modification of the membrane surface by grafting with special anti-wetting agents. Attempts have been made to produce superhydrophobic [104][105], underwater superoleophobic [106][107] and omniphobic [108] membrane surfaces in order to improve the anti-wetting and anti-fouling properties of the MD membranes. Superhydrophobic membranes have limited anti-wetting and anti-fouling properties for the separation of wastewater comprising of low surface tension impurities, such as oil, surfactants and amphiphilic organic contaminants. The underwater superoleophobic membrane surfaces deliver a restrained kinetic barricade towards the low surface tension substances that are miscible with or soluble in water, such as surfactants and alcohols. On the other hand, omniphobic membranes show the potential for the mitigation of any type of foulant due to their remarkable ability to repel water and other low surface tension contaminants.

Table 3. Comparison of the NIPS and TIPS techniques for the PVDF membrane preparation

\begin{tabular}{|c|c|c|}
\hline 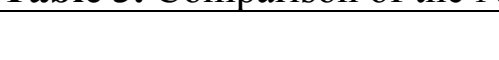 & NIPS technique & TIPS technique \\
\hline Solvents or diluents used & $\begin{array}{l}\begin{array}{l}\text { DMAc, DMF, NMP, } \\
\text { tetrahydrofuran } \\
\text { dimethylsulfoxide (DMSO). }\end{array} \\
\end{array}$ & $\begin{array}{l}\text { Triacetin, sulfolane, } \\
\text { dimethyl phthalate (DMP), } \\
\text { dibutyl phthalate (DBP). }\end{array}$ \\
\hline $\begin{array}{l}\text { Influencing parameters for } \\
\text { the membrane fabrication }\end{array}$ & More & Less \\
\hline Processing temperature & Lower & Higher \\
\hline $\begin{array}{l}\text { Minimum membrane pore } \\
\text { size }\end{array}$ & Smaller & Larger \\
\hline $\begin{array}{lll}\text { Membrane } \\
\text { distribution }\end{array}$ pore size & Wider & Narrower \\
\hline \multicolumn{3}{|l|}{$\begin{array}{l}\text { Typical PVDF membrane } \\
\text { microstructure }\end{array}$} \\
\hline $\begin{array}{l}\text { Mechanical strength of the } \\
\text { membrane }\end{array}$ & Weaker & Stronger \\
\hline Antifouling property & Better & Lower \\
\hline Major disadvantage & Difficult recovery of solvent & High energy consumption \\
\hline
\end{tabular}

\subsubsection{Superhydrophobic Coating}

The anti-wetting and anti-fouling properties of MD membranes can also be improved by roughening the membrane surface using nanoparticles, followed by decreasing the surface energy through fluorosilanization. For instance, Urmenyi et al. [109] coated the macroporous PES membrane with silica through the alkaline hydrolysis of tetraethoxysilane (TEOS), followed by the functionalization with silylating agents. The fluorination of the silica-PES membrane resulted in an increase of contact angle from 62 to $142^{\circ}$ with a high LEP of 3 bar. Sun et al. [110] fabricated a superhydrophobic PES membrane by treating the membrane 
surface with silica sol, followed by silanization with fluoroalkylsilane. The contact angle of the membrane was significantly improved from 75 to $154^{\circ}$ after the treatment. In 2012, Razmjou et al. [111] developed a superhydrophobic PVDF membrane by depositing the $\mathrm{TiO}_{2}$ nanoparticles on the membrane surface through the hydrothermal process. The deposition of $\mathrm{TiO}_{2}$ nanoparticles led to the formation of hierarchical membrane surface structure with enhanced surface roughness. This significantly improved the contact angle and LEP of the membrane to $166^{\circ}$ and $195 \mathrm{kPa}$, respectively. The fouling test results showed that both pristine and modified membranes exhibited similar fouling behaviour. However, the modified membrane demonstrated a higher flux recovery, signifying the enhanced anti-fouling property.

\subsubsection{Omniphobic Coating}

Recently, omniphobic membranes have received tremendous attention for the treatment of saline water involving low surface tension pollutants by MD [112]. Omniphobic membranes can be developed via the coating of the membrane surface with a functional layer that exhibits re-entrant structure and low surface energy [113]. The re-entrant structure with low surface energy bestows the membrane surface with excellent repellence towards liquid through the entrapment of the air underneath the liquid. Such membrane surface is advantageous for improving the anti-wetting and anti-fouling properties of the MD membrane. For instance, Wang and Lin [114] compared three types of membranes with different wetting characteristics, which included a hydrophobic membrane, an omniphobic membrane and a composite membrane with a hydrophobic substrate and a superhydrophilic skin layer. It was found that severe fouling occurred on both hydrophobic and omniphobic membranes. This was due to the very low membrane surface energy that led to the attractive hydrophobic-hydrophobic interaction. Interestingly, the oil droplets did not penetrate through the pores of the omniphobic membrane, whereas penetration of oil droplets occurred for the hydrophobic membrane. Hence, it can be concluded that the omniphobic membrane is more suitable for the treatment of oily seawater. Accordingly, the recent work also demonstrated the excellent performance of the omniphobic membrane for the treatment of oily seawater [115]. The omniphobic membrane was fabricated by electrospraying the fluorinated zinc oxide $(\mathrm{ZnO})$ nanoparticles mixed with polyvinylidene fluoride-co-hexafluoropropylene (PVDF-HFP) on the surface of an organosilane functionalized PVDF membrane.

Electrospinning is an arising technique for the fabrication of the omniphobic membrane for MD applications. Electrospinning can produce one-dimensional porous nanofibrous mat with the preferable properties for the MD process [116]. Through this technique, the topology of the membrane can be easily manipulated by controlling the properties of dope and electrospinning parameters. Remarkably, the electrospun membranes possess high porosity, interconnected open pore structure and high surface area to volume ratio. In addition, the electrospun membrane can also be easily immobilized on different types of substrate surface. Hou et al. [108] developed a novel omniphobic MD membrane with excellent anti-wetting properties via electrospinning. The omniphobic membrane was synthesized from a hydrophilic polymer-nanoparticle composite consisting of cellulose acetate and silica nanoparticles with fluorinated fibrous network on the membrane surface. The authors found that the omniphobic membrane demonstrated better anti-wetting performance towards the water and other low surface tension liquids when comparing to commercial PVDF and PTFE membranes. Table 4 summarize the modification approaches in developing omniphobic surfaces. 
Table 4. Summary of the modification approaches in the development of omniphobic membranes

\begin{tabular}{|c|c|c|}
\hline Modification approach & $\begin{array}{c}\text { Water contact } \\
\text { angle }\left(^{\circ}\right)\end{array}$ & Ref \\
\hline Electrospinning using fluoroPOSS-PMMA polymer blends & 165 & {$[117]$} \\
\hline $\begin{array}{c}\mathrm{SiO}_{2} \text { deposition, followed by reactive ion etching of } \mathrm{SiO}_{2} \text { and } \\
\text { subsequent isotropic etching of Si via } \mathrm{XeF}_{2}\end{array}$ & 165 & {$[118]$} \\
\hline $\begin{array}{c}\text { Controlled growth of } \mathrm{NH}_{2} \text {-MIL-53 (Al) MOF structure assisted } \\
\text { by post-synthetic modification with PFO-Cl }\end{array}$ & 151 & {$[119]$} \\
\hline Nanoimprint lithography followed by Teflon AF coating & 150 & {$[120]$} \\
\hline $\begin{array}{c}\text { Electrospinning of poly(vinylidenefluoride) (PVDF) nanofibers, } \\
\text { followed by solution immersion treatment }\end{array}$ & 150 & {$[121]$} \\
\hline
\end{tabular}

In 1982, Cheng and Wiersma pioneering the development of Janus membrane into MD by preparing dual-layer structure of opposing properties on membrane surface [122]. The duallayer commonly induce superhydrophobic substrate and superhydrophilic coating layer. With this special properties, this type of membrane could sustain stable MD performance by solving two major problems in MD which are; wetting and fouling. Wang and Lin prepared Janus membrane by developing a hydrophobic membrane from PVDF as substrate and coated it with perfluorooctanoate/chitosan/silica nano-particle (PFO/CTS/SiNP) nanoparticle-polymer composite via spray coating [114]. In addition, another two types of membranes (hydrophobic and omniphobic) were prepared to compare its wettability and fouling with Janus membrane. Accordingly, it was observed that the hydrophobic and omniphobic membrane were completely wetted. In addition, the hydrophobic membrane induced was fouled first before wetting occurred but omniphobic membrane was able to resist fouling the re-entrant surface structure. Meanwhile, Janus membrane was able to resist both wetting and fouling phenomenon, leading to stable flux and near-zero salt rejection. Nowadays, several approaches have been implemented in preparing Janus membrane in MD to be a viable technology for desalinating hypersaline wastewater. For example, Huang et al. used two different substrates which are hydrophobic and and omniphobic [123]. For hydrophobic substrate, the membrane was prepared using CTAB/PVDF-HFP, dip coated with fluorinated SiNPs followed by fluorination via chemical vapour deposition. Whereas, similar preparation for omniphobic but another coating layer of SiNPs, chitosan and perfluorooctanoate were added through spray coating. In addition, another two membranes were also prepared to compare which are hydrophobic and omniphobic. Result found that fouling does not occur for both Janus membrane and can retain its flux up to 10 hours.

\subsubsection{Ceramic Membrane Surface Modification}

Ceramic membranes exhibit several superior features over their polymeric counterparts in terms of thermal, structural and chemical stabilities. However, ceramic membranes are not preferable for the MD applications as the membrane surfaces contain abundant hydroxyl groups, which make the membranes hydrophilic in nature [124]. Recent studies have focused on the surface modification of ceramic membranes for hydrophobic properties in order to better exploit the advantageous properties of ceramic membranes for the MD applications. Chemical modification has been widely employed to enhance the hydrophobicity of ceramic membranes. Generally, there are three silane agent grafting approaches being commonly applied for the surface modification of ceramic membranes, such as immersion, chemical vapor deposition (CVD) and immersion methods. 
Among these three methods, immersion is the most widely employed method for the surface modification of ceramic membranes due to its simplicity and rapid operation [125]. For instance, Ko et al. [126] developed a hydrophobic alumina membrane by modifying the membrane surface with $1 \mathrm{H}, 1 \mathrm{H}, 2 \mathrm{H}, 2 \mathrm{H}$, perfluorooctyltriethoxysilane via immersion method. The membrane demonstrated an improvement in contact angle from 30 to $138^{\circ}$ and was later used for MD desalination. In general, prior to immersion grafting, the silane agent is initially activated in solvents, such as water, hexane and alcohol. The reactive halogen and alcohoxy groups are transformed into - $\mathrm{OH}$ group. After the activation of the silane agent, the ceramic membrane is immersed into the silane agent solution where chemisorption of the reactive silane molecules occurs on the surface of the ceramic membrane. CVD method is usually employed for the thin film coatings on the ceramic membrane surface [127][128]. Different from the immersion technique, CVD requires heat to vaporize the silane agent and involves a small amount of solvent. The reaction between the silane agent vapor and - $\mathrm{OH}$ group on the ceramic membrane surface is similar to that of the immersion method. Meanwhile, TEOS and methyltriethoxysilane (MTES) are the common precursors for the sol-gel method. This method starts with the reaction between TEOS, ethanol and water at room temperature to form colloidal silica. The process continues with the addition of MTES, which reacts with ethanol under continuous stirring at the temperature of $60^{\circ} \mathrm{C}$. The solution should be aged for at least 3 days before it can be used for the grafting of the ceramic membrane. Figure 13 shows the schematic diagrams of different ceramic membrane modification methods.
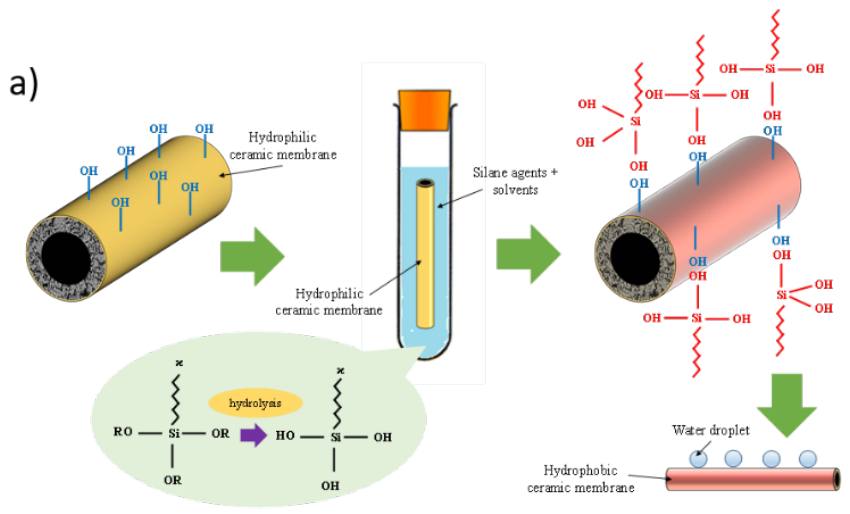

b)
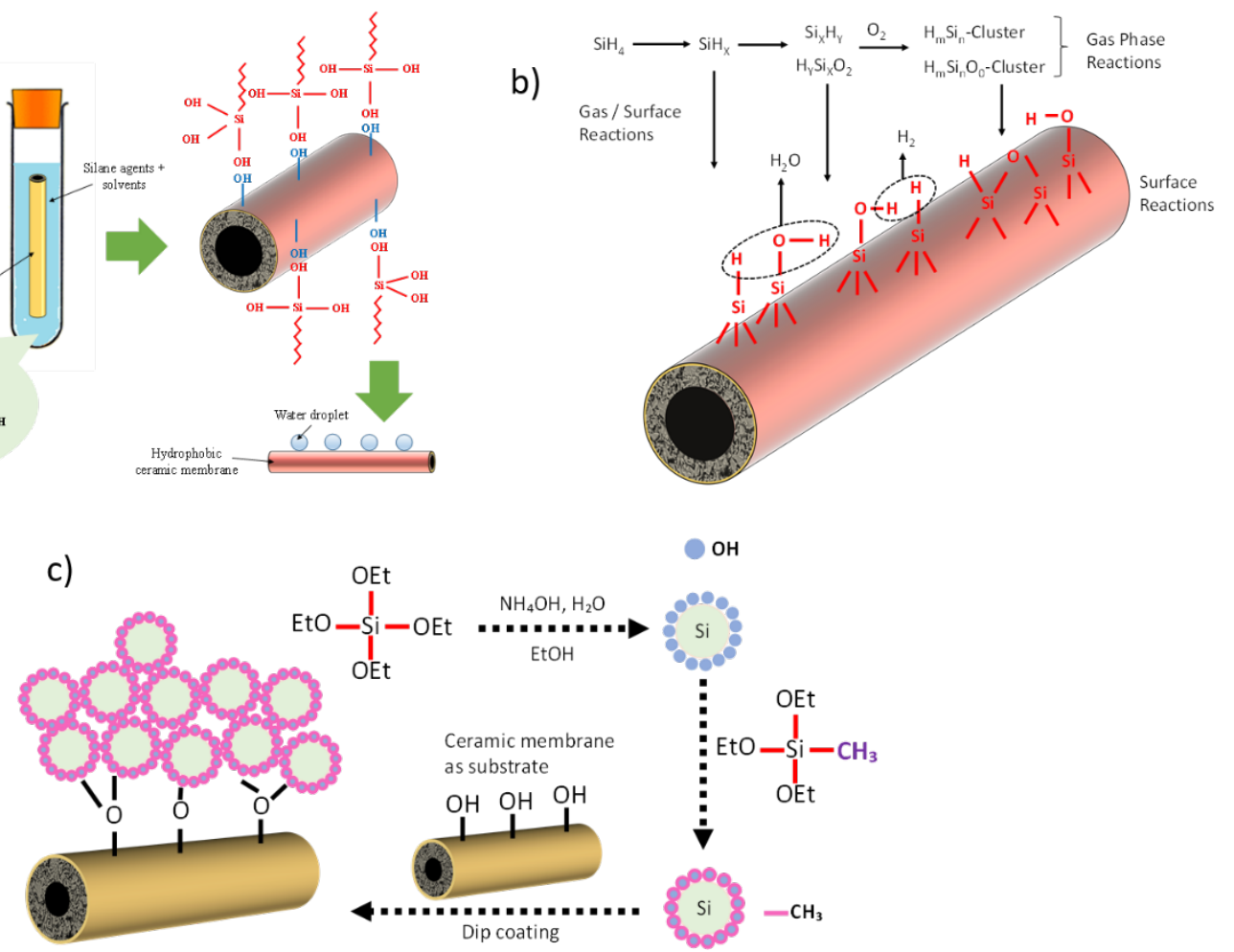

Figure 13. Schematic diagrams of ceramic membrane modification methods for MD applications; a) immersion, b) CVD and c) sol-gel [125] 


\subsection{Operating Condition}

\subsubsection{Forward Osmosis}

The performance of FO process is significantly influenced by its operating conditions. The operating parameters could have either desirable or adverse effects on FO performance. Thus, process optimization is needed to make the whole process more efficient and economically feasible. For instance, DS and FS flowrates, DS concentration, membrane operating configuration and curing temperature are mainly the operating condition which could tweak the performance. During FO process, the FS and DS are circulated at cross-flow direction in direct contact with the active layer and support layer sides of the membrane at certain flowrates. Peristaltic pump and pressure transmitter are used to circulate and control the flowrates of the solutions. Meanwhile, the temperature of FS and DS is also constantly monitored and controlled by temperature transmitter or temperature-controllable stirrer with thermometer. Figure 14 shows the common operating conditions for a FO system.

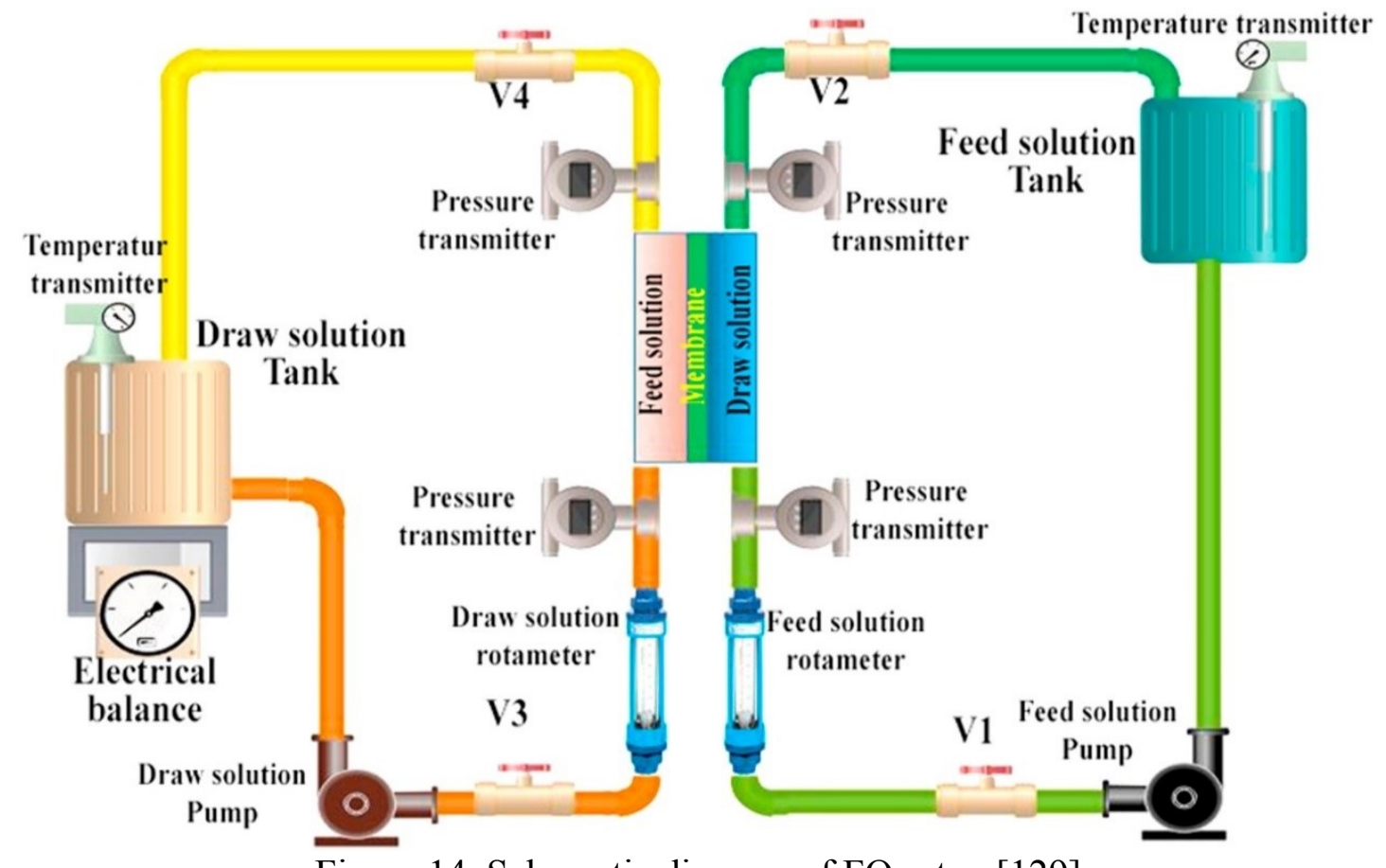

Figure 14. Schematic diagram of FO setup [129]

\subsubsection{Draw Solution and Feed Solution Flow Rates}

The DS and FS flowrates are important in deciding the recovery rate and the final DS concentration. Here, the recovery rate is defined as the percentage ratio of water flux to the inlet FS flowrate. Generally, a FO system is deemed efficient when it is able to exhibit low final DS concentration along with high recovery rate. By increasing the DS flowrate, a higher recovery rate can be achieved. However, increasing the DS flowrate also results in higher DS concentration, hence optimum DS flowrate has to be obtained. The variation in flowrates causes change in mass transfer coefficient which results in external concentration polarization affecting the solution-membrane interface concentration. This can lead to fouling. Therefore, 
Ali and co-workers [13] did a FO analysis to obtain optimum DS flowrate using MATLAB software. Although the optimum operating condition is usually determined by either maximum recovery rate or minimum final DS concentration, nevertheless since previous studies show that higher recovery rate granted by higher DS flowrate comes along with a higher final DS concentration, the operating conditions which give maximum recovery rate or minimum final DS concentration are not always the optimum conditions [130]. Thus, a new performance parameter, overall performance rating (OPR) was proposed in the study, combining the recovery rate and final DS concentration with the amount of membrane elements. Basically, the operating conditions which give the highest OPR is the optimum conditions. The invention of OPR is useful as different FO systems and membranes have their very own optimum operating conditions. Thus, OPR is generally applicable in all cases regardless of membrane types, configuration, system setup etc. Besides, Seo and co-workers [131] also did a modelling study on the optimizing strategy for a FO-RO hybrid system for seawater desalination and wastewater reuse. From the analysis, the RO operating pressure and the FO DS flowrate are the major factors affecting the system performance. It is recommended to have a low DS flowrate and a high FS flowrate for the FO operation. To minimize the DS flowrate, the FO system installed in front of the RO system should be in parallel configuration. Also, to maximize the FS flowrate (wastewater), the wastewater intake can be increased. It is also important to have a thorough cost analysis for the pre-treatment cost and energy consumption of wastewater in order to maintain a sufficient FS flowrate. Although low DS flowrate is favorable, a low DS flowrate however could cause membrane fouling and thus should be taken into consideration. This is the reason why high FS flowrate is required as it accelerates the dilution process of DS and can reduce the concentration polarization effect, hence less fouling. Apart from that, Devia et. al. [73] studied the effect of operating conditions on FO for nutrient rejection using $\mathrm{MgCl}_{2}$ as DS. It showed that higher cross flowrates could produce higher water fluxes. However, only moderate cross flowrates could achieve high nutrient rejection. At this case, the optimum flowrates for high nutrient rejection was $0.25 \mathrm{~ms}^{-1}$. Figure 15 depicts that cross flowrates can affect water fluxes significantly but have almost no impact on the nutrient rejections.
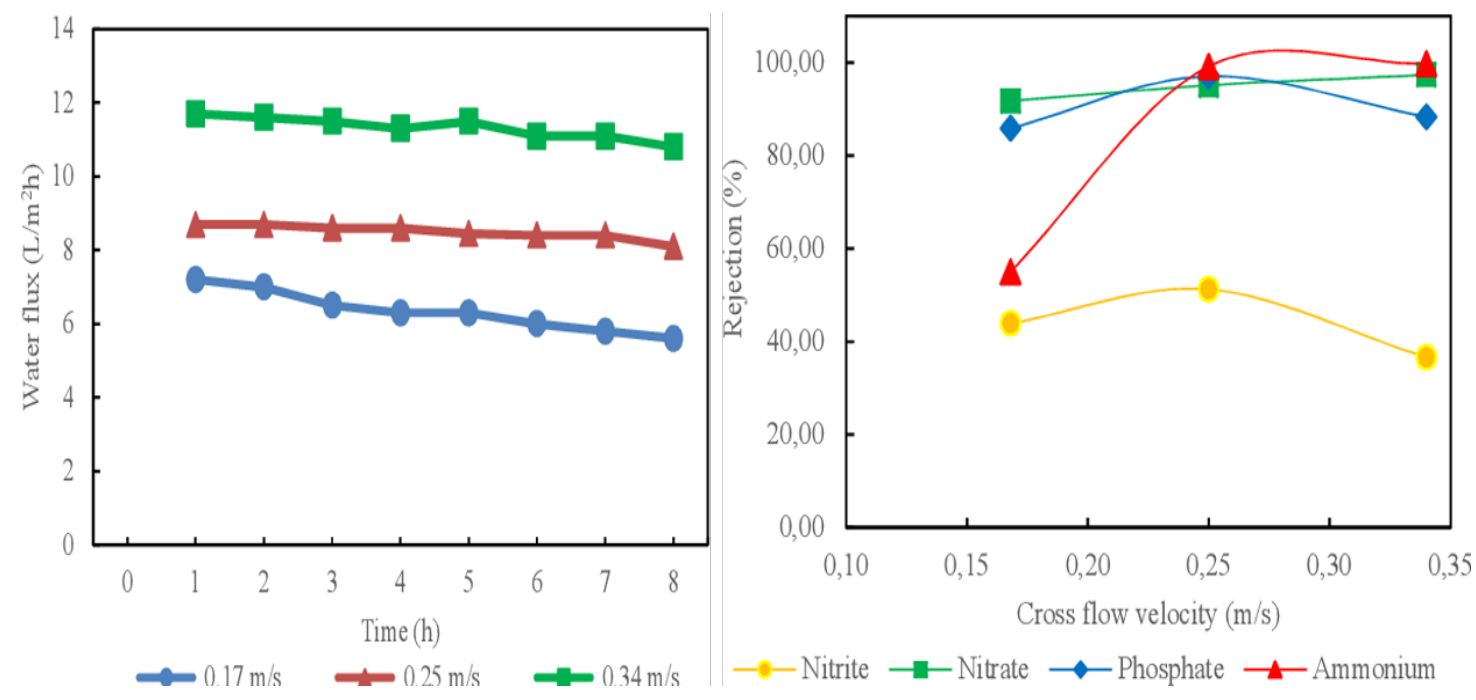

Figure 15 Water fluxes and nutrient rejections with the CTA-NW membrane for a $1 \mathrm{M} \mathrm{MgCl}_{2}$ DS at different cross flowrates [73] 


\subsubsection{Draw Solution Concentration}

The DS concentration mainly affects the water permeation and reverse solutes permeation. As the DS concentration increases, water permeation would usually increase because of the higher osmotic pressure induced by higher concentration DS. However, it is also coupled with an increase in reverse solute flux. The reverse solute flux over time could cause clogging of solutes in the membrane pores resulting in severe ICP and fouling. As a result, although the initial water flux is higher, but it would reduce more drastically over time compared to a lower DS concentration due to fouling. Also, a higher concentration of DS also undergoes more rapid dilution, which results in more severe flux decline. There is also a permeability-selectivity trade-off mechanism. Despite endowing higher water flux, high concentration DS also usually gave lower rejection. Thus, it is important to find the optimum DS concentration which could give high water permeation and high rejection but low ICP effect. Suwaileh et. al. [71] in his study noticed that as the $\mathrm{NaCl}$ DS concentration was increased from $0.5 \mathrm{M}$ to $2.0 \mathrm{M}$, the water flux experienced a gradual increase and peaked at $1.5 \mathrm{M}$, followed by a more drastic decrease. Guo et. al. [76] also used $0.5 \mathrm{M}$ to $2.0 \mathrm{M}$ of $\mathrm{NaCl}$ as the DS for FO application in his study. The water flux increased as the DS concentration increased. Notably, the $2 \mathrm{M} \mathrm{NaCl} \mathrm{DS}$ had the lowest reverse solute flux compared to the other DS concentration, which made it the most feasible DS in his study. Also, Song et. al. [101] in his study employed $1 \mathrm{M}-2.5 \mathrm{M}$ of $\mathrm{MgCl}_{2}$ as draw solution. It was also observed that the water flux increased with DS concentration. However, it could be noticed that the enhancement effect was more noticeable at lower DS concentration due to the relatively milder ICP effect. In short, regardless of the type of DS, most of the studies have employed $1 \mathrm{M}-2 \mathrm{M}$ concentration of DS in the FO operation, proving that such DS concentration could work the best over long-term FO operation. Nonetheless, different membrane modification methods could provide slightly different results.

\subsubsection{Membrane distillation}

Operating conditions such as temperature, $\mathrm{pH}$ and flow rate of feed and permeate streams are very important for the DCMD process. In DCMD, the hot feed and cold permeate solutions are in direct contact with the hydrophobic membrane, and the solutions are circulated tangentially to the membrane surface at low flow rates [132][31]. The hydrophobic membrane acts as a barrier to separate the hot feed and cold permeate. A liquid-vapor interface is formed at the entrance of the membrane pore. The transmembrane temperature difference creates a vapor pressure difference between both sides of the membrane, which induces the transport of vapor from one side of the membrane to the other. Figure 16 illustrates the typical setup for the DCMD system consisting all important components of MD, for example flow rate that measured by flowmeter. The temperatures and pressures of the feed and permeate solutions are usually measured at both inlets and outlets of the membrane module. The pressures of the feed and permeate streams should always be maintained near to the atmospheric pressure in order to avoid membrane pore wetting. 


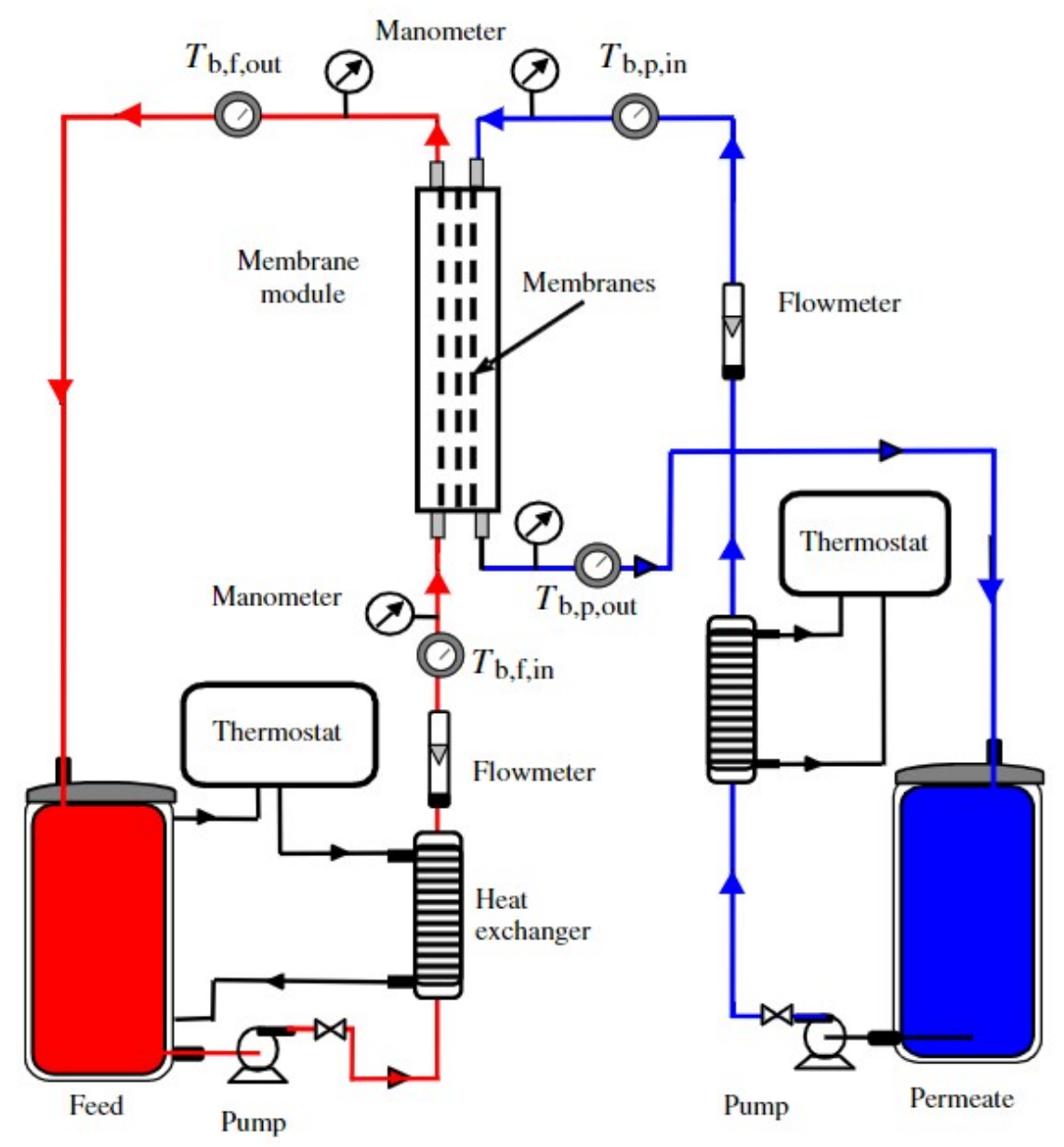

Figure 16. Schematic diagram of the DCMD setup [133]

\subsubsection{Feed Temperature}

Temperature is one of the most significant parameters affecting the scaling and fouling phenomena in the MD process. For instance, a study reported an increase in the permeate flux for about 87 and $92 \%$ when the feed temperature was increased from 40 to $70^{\circ} \mathrm{C}$ (Figure 17) [134]. The vapor pressure increases exponentially along with the increase in temperature, resulting in an increase in driving force. Manna et al. [135] justified the exponential dependence of vapor pressure towards the temperature through the Antoine equation:

$P^{o}=\exp \left(23.238-\frac{3841}{T-45}\right)$

where $\mathrm{P}^{\mathrm{o}}$ and $\mathrm{T}$ are the vapor pressure $(\mathrm{Pa})$ and temperature $(\mathrm{K})$ of water, respectively. 


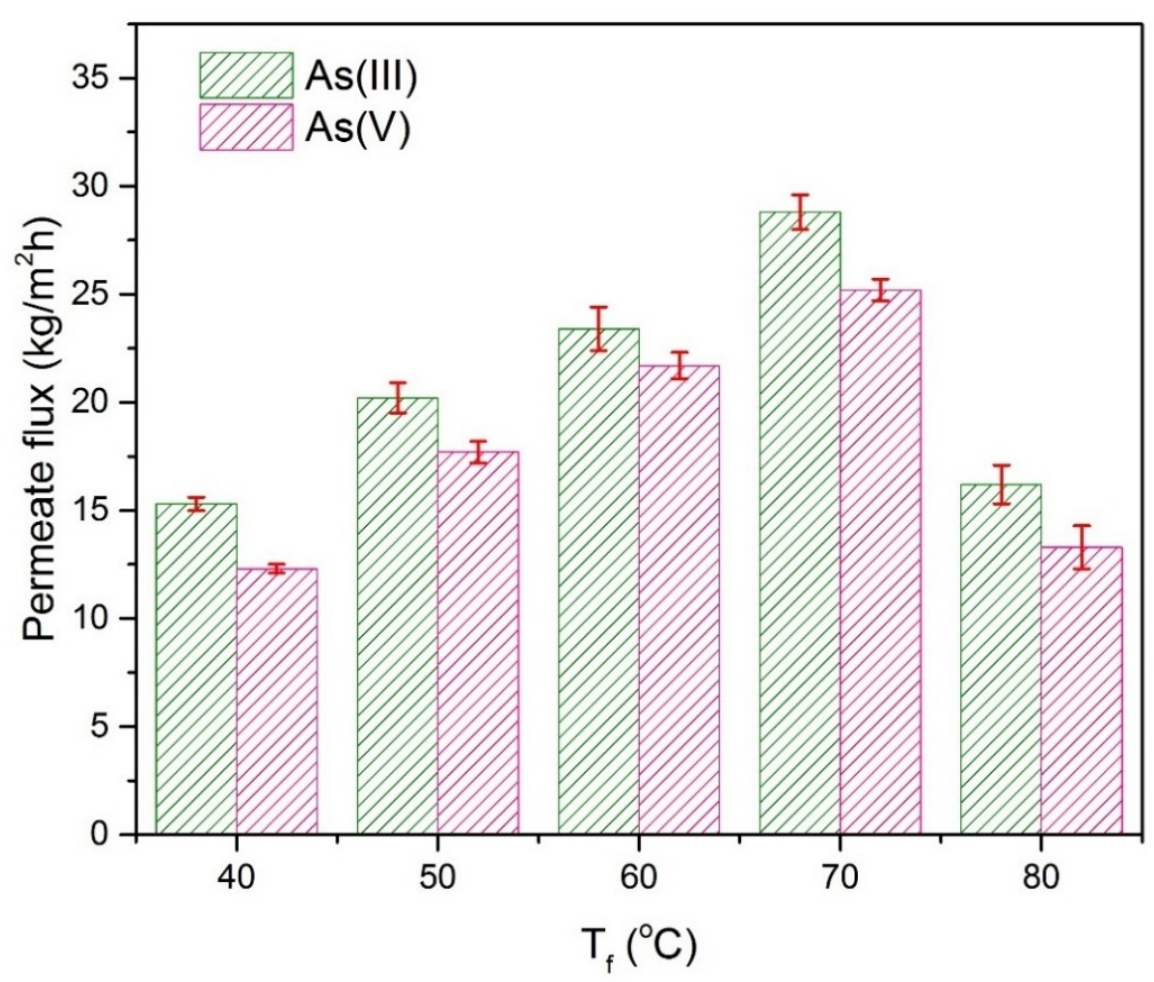

Figure 17. Effect of feed temperature on the permeate flux of the hydrophobic kaolin hollow fibre membrane during the DCMD process (hot stream: $1 \mathrm{ppm}$ of $\mathrm{As}(\mathrm{V})$ solution with $\mathrm{pH}$ 7.48 at a flow rate of $0.7 \mathrm{LPM}$; cold stream: temperature of $15^{\circ} \mathrm{C}$ and a flow rate of 0.5

$$
\text { LPM) [37] }
$$

Gryta [136] suggested that the residues formed on the membrane surface would cause the adjacent pores being filled with feed solution (partial membrane wetting). Besides, the foulant layer deposited on the membrane surface also creates additional resistance towards the heat transfer, consequently affecting the overall heat transfer coefficient. The increase in the temperature enhances the driving force of the mass transfer, which results in a decrease in fouling on the membrane. Khayet and Matsuura [5] suggested that it is better to work the MD system under high feed temperatures although the temperature polarization effect increases with the feed temperatures. Warsinger et al. [18] mentioned that the high feed temperature brings substantial influence towards the formation of biofouling due to the low tolerance of microorganisms towards high temperature. Krivorot et al. [124] reported that the hollow fibre membranes did not experience any biofouling problem when the operating feed temperature was above $60^{\circ} \mathrm{C}$. This was because most of the microorganisms failed to function at such high temperatures. Currently, there has no study been reported on the effect of permeate temperature towards the fouling problem in MD. Table 5 lists the previous studies on the effect of feed temperature towards the permeate flux of the DCMD process.

Table 5. Effect of feed temperature towards the permeate flux of the DCMD process.

\begin{tabular}{|c|c|c|c|c|c|}
\hline $\begin{array}{c}\text { Membrane } \\
\text { type }\end{array}$ & $\begin{array}{c}\text { Feed } \\
\text { solution }\end{array}$ & $\begin{array}{c}\text { Feed } \\
\text { temperature }\end{array}$ & $\begin{array}{c}\text { Permeate } \\
\text { Flux } \\
\left(\mathrm{Kg} / \mathrm{m}^{2} \mathrm{~h}\right)\end{array}$ & Trend & References \\
\hline PTFE & $\mathrm{NaCl}$ & $17.5-31$ & $2.88-25.2$ & Increase & {$[137]$} \\
\hline PVDF & $\mathrm{NaCl}$ & $43-68$ & $6.1-28.8$ & Increase & {$[138]$} \\
\hline
\end{tabular}




\begin{tabular}{|c|c|c|c|c|c|}
\hline PTFE & $\mathrm{NaCl}$ & $5-45$ & $1.0-42.0$ & Increase & {$[139]$} \\
\hline Alumina & $\mathrm{NaCl}$ & $62-70$ & $0.39-0.55$ & Increase & {$[126]$} \\
\hline
\end{tabular}

\subsubsection{Feed pH}

Feed $\mathrm{pH}$ of MD could affect the increment of MD flux due to the different of foulant type that can be found in the feed tank. As described, MD fouling can be classified into organic, inorganic and biological fouling. For inorganic, the fouling can be happening through the deposition of hard deposition consisting of several types of hard salts such as calcium sulfate, calcium carbonate, silicon, etc. Meanwhile, organic fouling consists of organic matter such as proteins and humic acid, thereby biofouling consists of microorganisms. Accordingly, different conditions of MD fouling could be observed. For example, reaction of water with salts produced $\mathrm{H}_{3} \mathrm{O}^{+}$or $\mathrm{OH}^{-}$, thus turning the water into base or acid that induced different level of water $\mathrm{pH}$. A study by Karakulski and Grtya observed that heating process in MD could cause inorganic salt deposition on membrane surface and induce fouling [136]. Thereby, this problem could be solving by acidification of feed to $\mathrm{pH} 4 \mathrm{using} \mathrm{HCl}$. Another study by Srisurichan et al. shows that no significant pattern can be observed although at different $\mathrm{pH}$ level when the feed is organic humic acid [140]. However, the study found that when calcium carbonate salt was added into the feed could cause humic acid deposition on the membrane surface. Thereby, a thick humic acid layer was formed and induced fouling. This problem could be solving easily by reduce the feed $\mathrm{pH}$ into $\mathrm{pH} 3$.

\subsubsection{Feed Flow Rate}

Feed flow rate could also mitigate the MD fouling by achieving minimization of boundary layer resistance. This could be done by increasing the flow rate as it could reduce the thickness of thermal boundary layer as well as temperature polarization effect. As a result, a high MD flux could be obtained. A study by Jacob et al. shows that the mitigation of MD could be done by increasing the feed flow rate from $0.005 \mathrm{~m} / \mathrm{s}$ to $0.014 \mathrm{~m} / \mathrm{s}$ to achieve elevated MD flux with value of $9.22 \mathrm{~kg} / \mathrm{m}^{2} / \mathrm{h}$ [141]. This is due to the decrement of boundary layer resistance to $1.74 \times 10^{6} \mathrm{~m}^{2} \mathrm{~s} \mathrm{~Pa} / \mathrm{kg}$. In addition, increasing the feed flow rate could also mitigate the fouling in $\mathrm{MD}$ as it could prevent the pore blocking by the molecules during the process ad temperature reduction as well and concentration, resulting from heat and mass transfer enhancement. Banat et al. investigate five types of feed flow rate during the treatment of methylene blue and found that the flux could be increased by increasing the flow rate from 14 to $57 \mathrm{~mL} / \mathrm{s}$ [142]. The study found that at lower flow rate, the dye molecules blocked certain pore and induce low flux, for example, flux of $4.7 \mathrm{~kg} / \mathrm{m}^{2}$.h at flow rate of. Meanwhile, the flux increased to $8.1 \mathrm{~kg} / \mathrm{m}^{2} . \mathrm{h}$ when the flow rate increased to $57 \mathrm{~mL} / \mathrm{s}$.

\subsection{Membrane Cleaning 4.4.1 Forward Osmosis}

Since fouling issue could cause severe flux decline, the after-test cleaning methods serve an important role in recovering the water flux. Membrane cleaning could be physical or chemical process, or combining both physical and chemical processes. For FO, most of the membrane cleaning are physical process. On-line washing with cleaning agent recycling at both FS and DS sides of the membrane is deemed the most common techniques used for membrane cleaning. Apart from that, depending on the characteristics and nature of the solutes (charge, hydrophilicity, etc.), the cleaning agent used is also important. Yu et. al. [143] did 
membrane cleaning by recycling a more concentrated FS and a less concentrated DS to induce water flow direction from DS to FS. It is commonly known as the osmotic backwashing in FO, in order to flush the entrapped solutes out of membrane pores. The same study also compared between osmotic backwashing and cleaning by changing cross-flow velocity and air-scouring to identify the most effective cleaning method for FO. After a prolonged period of fouling with activated sludge, the flux was completely recovered with osmotic backwashing using DI water within a short period, and proved to be more efficient than the latter. Lotfi et. al. [144] used synthetic wastewater comprising of more than 10 types of organic compounds as FS in his FO study. The membrane cleaning was done by cross-flow velocity of $800 \mathrm{~mL} \mathrm{~min}^{-1}$ with DI water on both FS and DS sides for 15 min followed by osmotic backwashing using $0.6 \mathrm{M} \mathrm{NaCl}$ at FS and DI water at DS for $20 \mathrm{~min}$ for post-cleaning. Complete flux recovery was able to achieve despite the complex composition of synthetic wastewater feed. Liu and co-workers [145] cleaned FO membrane fouled with simulated radioactive wastewater using on-lined cleaning with DI water recycling at both FS and DS sides at the flow velocities of $11 \mathrm{~cm} \mathrm{~s}^{-1}$. After that, the membrane was further cleaned externally by ultrasonic and immersing in $\mathrm{HCl}$ solution, both for $2 \mathrm{~h}$. It was found that $\mathrm{HCl}$ cleaning was more effective than ultrasonic, whereby the flux was able to fully recover. Apart from these more complicated methods, FO post-cleaning can also be done in an easier approach. For instance, Lee and co-workers [146] used DI water to circulate on both FS and DS sides to clean fouled membrane in an FO oily wastewater treatment application. Nearly full flux recovery was able to retain.

\subsubsection{Membrane Distillation}

Unlike FO, hydrophobic membranes such as PTFE and PVDF were used in MD system in which deemed to be chemically stable and induce less fouling due to its hydrophobicity and system configuration itself. However, Koschikowski et al. observed reduction in flux and distillate quality for the pilot-plant MD system, resulting from membrane fouling issue. In particular, fouling in MD not only reduce water flux, but it can cause membrane wetting that disturb the quality of distillate, can exacerbate temperature and concentration, and concentration polarization at membrane surface [147][148]. Membrane lifetime in MD depends on how it can recover from fouling. Due to the hydrophobicity properties of its surface, especially for PTFE membrane that had high hydrophobicity compared to PVDF, membrane cleaning can sometimes be done by flushing the used PTFE membrane with deionized water (DI) at very low pressure [149]. Accordingly, for $\mathrm{MD}$, membrane cleaning are conducted through cleaning process at three different approaches: (1) warm caustic clean using $\mathrm{NaOH},(2)$ ambient chlorine cleaning $(\mathrm{NaOCl})$, and (3) deionized water. Among these three approaches, caustic cleaning was found to be the most successful in recovering membrane flux and mass transfer coefficient. For example, Dow et al. applied this warm caustic cleaning using $1.5 \mathrm{wt} . \% \mathrm{NaOH}$ at $55^{\circ} \mathrm{C}$ for 45 minutes immersion towards membrane after MD process at 65 days [150]. Prior to the cleaning process, the membrane flux was observed to decrease from $5 \mathrm{~L} / \mathrm{m}^{2} \mathrm{~h}$ to $2 \mathrm{~L} / \mathrm{m}^{2} \mathrm{~h}$. Interestingly, flux could be recovered to $4 \mathrm{~L} / \mathrm{m}^{2} \mathrm{~h}$ after first caustic cleaning, as well as membrane mass coefficient that induced $61 \%$ recovery. In addition, it should be mentioned too that the solution chosen for chemical cleaning process for MD are based on several criteria, such as type of foulant, type of cleaning used in previous studies for MD and special solution obtained for certain condition from literatures. For type of foulant, acid cleaners are required for fouling that caused by soluble salts like calcium carbonate and iron oxide, thereby, organic fouling needed alkaline cleaners. Naidu et al. performed chemical cleaning process with acid towards PTFE membrane after treatment of wastewater from RO concentrated that contained elevated ions $\left(\mathrm{ca}^{2+}, \mathrm{Mg}^{2+}, \mathrm{Na}^{+}\right.$, etc.) and salts concentrated using $0.1 \%$ citric acid [151]. After 
cleaning, drying process is compulsory to enable complete membrane hydrophobicity recovery [152].

\section{Future Outlook and Conclusions}

In addition to the energy required by the membranes for desalination process, other stages of desalination process, e.g., water intake, pretreatment, post-treatment and brine discharge also consume energy. Of these stages, pretreatment of the raw saline water before it is delivered to the membrane process accounts for most of this energy use [3], [153]. Technically speaking, the existing pretreatment methods do not encounter major problems in the desalination process and have been gradually evolved since the early implementation stage of SWRO membrane desalination process in the 1960s. Nevertheless, a good understanding on the feed water quality and fouling propensity particularly on the FO and MD membrane processes should be continuously developed in order to provide appropriate guidance for the design of efficient pretreatment process. Furthermore, reducing the cost of pretreatment and improving its removal efficiency are always the main priority of the industry and we have seen increasing number of relevant publications in recent years. Some of the innovative approaches are employment of GDM as energy-efficient membrane pretreatment process and design of hybrid pretreatment process (microporous membrane with activated carbon) for effective removals of molecular compounds and microbial organics. More research however is still needed to validate the cost of saving for large-scale desalination process.

FO and MD are less susceptible to fouling problem as they used low pressure compared to RO. This is according to high pressure process offered by RO that push foulant into the pores, thus induce pore clogging resulting fouling. In both FO and MD, fouling are divided into two which are external and internal fouling. External fouling occurred when there is existence of cake or gel layer on the membrane surface. Meanwhile, internal fouling occurred when the foulant enter the membrane's pores, adsorb on the pores walls and clogged the pores. Accordingly, mitigation strategies such as surface modification and operating condition are recognised as techniques to reduce the fouling problem. It is interesting to note that there are various approaches on surface modification for MD towards desalination. These includes modification of membrane into superhydrophobic, underwater superoleophobic membranes and omniphobic. Among all techniques, omniphobic received recent attention as it promoted anti-wetting as well as anti-fouling due to the re-entrant structure produced. Interestingly, development of hydrophobic ceramic membrane for MD also received attention. To resolve the hydrophilic nature of ceramic membrane, modification on the surface of ceramic membrane have been proposed which are immersion, CVD and sol-gel method. Meanwhile, feed temperature as operating condition plays crucial factor to solve fouling problem. This is according to that high feed temperature will maintain high vapour pressure gradient and therefore, high mass flux across the membrane.

FO and MD are less susceptible to fouling problems as they operate at lower pressure compared to RO. The high-pressure RO feed pushes the foulant into the pores, which eventually leads to fouling and pore clogging. In FO and RO, fouling can be categorized as external and internal fouling. External fouling occurs when the cake/gel layer forms on the membrane surface. On the other hand, internal fouling occurs when the foulant enters the membrane pores and adsorbs on the pore walls, which eventually will clog the pores. The fouling issues can be mitigated through several strategies such as surface modification of 
membranes and optimization of operating conditions. There are various approaches on the surface modification of MD membranes for fouling mitigation, such as the development of membranes with superhydrophobic, omniphobic and Janus properties. Omniphobic membranes with the re-entrant structures have received the widest attention due to their excellent anti-wetting and anti-fouling properties. However, wetting and fouling phenomenon were still occurred on this membrane kind when hypersaline wastewater with complex compositions was treated. Accordingly, dual-layer membrane with opposing properties on both surface, known as Janus membrane was introduced. The first Janus membrane was introduced in 1982 with superhydrophobic membrane as substrate and modified with hydrophilic surface through spray coating. Nowadays, more approaches have been developed to improve the performance of Janus membrane by using omniphobic membrane as substrate. As a result, excellent membrane performance was obtained with efficient anti-fouling and anti-wetting properties. In addition, attention has also been given to the development of the hydrophobic ceramic membrane for MD desalination. Different ceramic membrane surface modification techniques, including immersion, CVD and sol-gel methods, have been developed to resolve the hydrophilic nature of the ceramic membranes. In addition, the MD fouling problems can also be reduced by manipulating the feed temperature, $\mathrm{pH}$ and flow rate. High feed temperature maintains the high vapor pressure gradient, which leads to high vapor flux across the membrane, resulting in lower fouling propensity. Meanwhile, different conditions were observed when different $\mathrm{pH}$ was studied. It was found that inorganic contaminants in feed water could increase and decrease the $\mathrm{pH}$ level of water, thus affecting the MD fouling. However, this problem could be easily solved by feed acidification method. Thereby, flow rate gave the most effect on fouling mitigation as optimum flow rate could reached turbulence, producing stable flux during MD process.

There are several challenges that need to be considered when modifying the membrane surface, including the leaching problem during the membrane fabrication process, difficulty in controlling the membrane thickness and instability of nanoparticles embedded in the membrane matrix. In fact, the membrane properties limit the flux performance of MD. Optimum pore size and porosity are the essential membrane properties for MD applications. It should be noted that (1) the membrane pores should not be too large as this increases the membrane wetting tendency, leading to the passage of salt into the pores, and (2) the membrane pores should not be too small as this is detrimental to the heat and mass transfers across the membrane, affecting the membrane flux performance. Recently, the development of multilayer membranes (dual and triple layered membranes) for MD applications have been gaining increasing interest. Most of these multilayer membranes are prepared via electrospinning, coating and grafting techniques, which are costly and time consuming. On the other hand, the phase inversion technique is more cost and energy efficient for the fabrication of multilayer membranes as the membranes can be developed in a single step. The multilayer membranes fabricated via the phase inversion technique have shown better performance than that of single layer membrane in various applications such as photocatalytic separation and solid oxide fuel cell. In addition, the problems of the agglomeration of nanoparticles embedded in the membrane matrix can also be overcome through this technique. However, to date, the development of the multilayer membrane consisting of hydrophobic and superhydrophobic layers for MD applications is still limited. The introduction of the dual-layer hydrophobic membrane could be interesting for future studies for better performance of MD.

In a nutshell, some recent studies have proven that the energy consumption of FO desalination is higher than RO desalination[24][25]. One of the main reason is that with the readily available technological developments, FO technology is not economically feasible as 
the technology itself cannot be a standalone process for desalination, which means usually a secondary treatment/process is required. Literally, the biggest challenge for FO commercialization comes from the economic feasibility. Precise economic assessment has to be by taking some major factors into consideration, which are concentration polarization, reverse solute flux, membrane fouling, lack of proper choice for membrane selection, and unavailability of ideal draw solution. All the challenges are related to each other in a certain way. A FO membrane production should have high repeatability to promote commercialization. A good FO membrane must exhibit high water flux, hence the structural parameter value (S) must be low. Also, low reverse solute flux can be achieved with a highly selective active membrane layer which in turn alleviates membrane fouling. To reduce the detrimental effects of ICP, the membrane substrate has to be highly porous. Nonetheless, conflicts arise while choosing the ideal draw solution. This is because the ideal draw solutes should be small enough to facilitate water transport, yet small size draw solutes also indicate an increase in reverse solute flux and membrane fouling. Thus, all the aforementioned factors must be considered while planning research on FO desalination.

Besides, it is noticed that novel modification methods are yet to be developed and more researches need to be done in order to produce high performance FO membranes. This is because the current methods employed for FO membranes fabrication are generally the same as conventional methods used for RO membranes fabrication. Most of the time, the researchers focus on just the water permeability constant $(A)$ and solute permeability constant $(B)$. However, it is also very important to determine the solute resistivity $(K)$ and structural parameter $(S)$ of the newly developed membrane as these parameters are directly reflecting the severity of ICP effects. Rather than just pure water flux, the FO performance must also be determined by reverse solute flux because of the existence of the strong trade-off between salt retention and water flux. Last but not least, membrane reusability has to be further considered too in the future studies to make it more practically commercialized.

\section{Acknowledgement}

The authors would like to acknowledge the financial support provided by Ministry of Education Malaysia under Malaysia Research University Network 4L873.

\section{References}

[1] S. Miller, H. Shemer, and R. Semiat, "Energy and environmental issues in desalination," Desalination, vol. 366, pp. 2-8, 2014.

[2] G. M. Geise, "Desalination : Water for an Increasingly Thirsty World in EuropeNow," EuropeNow, 2018.

[3] M. Elimelech and A. P. William, "The Future of Seawater and the Environment," Science (80-. )., vol. 333, pp. 712-717, 2011.

[4] A. M. Awad, R. Jalab, J. Minier-Matar, S. Adham, M. S. Nasser, and S. J. Judd, "The status of forward osmosis technology implementation," Desalination, vol. 461, pp. 10- 
21, 2019.

[5] M. Khayet and T. Matsuura, Membrane Distillation Principles and Applications. Elsevier B.V, 2011.

[6] A. Bennett, "Desalination and water reuse: What's the future for forward osmosis?," Filtration+Separation, vol. 50, no. 5, pp. 28-34, 2013.

[7] E. Mendez, "Sustainable desalination: Membrane distillation delivers greener clean water," Filtr. Sep., vol. 49, no. 5, pp. 26-28, 2012.

[8] K. Sardari, P. Fyfe, and S. R. Wickramasinghe, "Integrated electrocoagulation Forward osmosis - Membrane distillation for sustainable water recovery from hydraulic fracturing produced water," J. Memb. Sci., vol. 574, no. October 2018, pp. 325-337, 2019.

[9] K. Sardari, P. Fyfe, D. Lincicome, and S. R. Wickramasinghe, "Aluminum electrocoagulation followed by forward osmosis for treating hydraulic fracturing produced waters G RA P H I C A L AB S T R A C T," Desalination, vol. 428, no. November 2017, pp. 172-181, 2018.

[10] J. Wang, D. Qu, M. Tie, H. Ren, X. Peng, and Z. Luan, "Effect of coagulation pretreatment on membrane distillation process for desalination of recirculating cooling water," Sep. Purif. Technol., vol. 64, pp. 108-115, 2008.

[11] W. Sun, F. Shen, Z. Wang, Y. Zhang, and Y. Wan, "An ultrathin, porous and in-air hydrophilic / underwater oleophobic coating simultaneously increasing the fl ux and antifouling property of membrane for membrane distillation," Desalination, vol. 445, no. August, pp. 40-50, 2018.

[12] M. Ghanbari, D. Emadzadeh, W. J. Lau, S. O. Lai, T. Matsuura, and A. F. Ismail, "Synthesis and characterization of novel thin film nanocomposite (TFN) membranes embedded with halloysite nanotubes (HNTs) for water desalination," Desalination, vol. 358, pp. 33-41, 2015.

[13] S. M. Ali, J. E. Kim, S. Phuntsho, A. Jang, J. Y. Choi, and H. K. Shon, "Forward osmosis system analysis for optimum design and operating conditions," Water Res., vol. 145, pp. 429-441, 2018.

[14] M. Rezaei, D. M. Warsinger, J. H. Lienhard V, M. C. Duke, T. Matsuura, and W. M. Samhaber, "Wetting phenomena in membrane distillation: Mechanisms, reversal, and prevention," Water Res., vol. 139, pp. 329-352, 2018.

[15] L. Eykens, K. De Sitter, C. Dotremont, L. Pinoy, and B. Van Der Bruggen, "Membrane synthesis for membrane distillation : A review," Sep. Purif. Technol., vol. 182, pp. 36-51, 2017.

[16] W. Lun, A. Wahab, D. Johnson, and N. Hilal, "Forward osmosis research trends in desalination and wastewater treatment: A review of research trends over the past decade," J. Water Process Eng., vol. 31, no. July, p. 100886, 2019.

[17] M. Qasim, N. A. Darwish, S. Sarp, and N. Hilal, "Water desalination by forward (direct) osmosis phenomenon : A comprehensive review," Desalination, vol. 374, pp. 47-69, 2015.

[18] D. M. Warsinger, J. Swaminathan, E. Guillen-Burrieza, H. A. Arafat, and J. H. Lienhard V, "Scaling and fouling in membrane distillation for desalination applications: A review,” Desalination, vol. 356, pp. 294-313, Jan. 2015.

[19] T. Y. Cath, A. E. Childress, and M. Elimelech, "Forward osmosis: Principles, applications, and recent developments," J. Memb. Sci., vol. 281, pp. 70-87, 2006.

[20] T. M. Salehi, M. Peyravi, M. Jahanshahi, W.-J. Lau, and A. S. Rad, "Impacts of zeolite nanoparticles on substrate properties of thin film nanocomposite membranes for engineered osmosis," J. Nanoparticle Res., vol. 20, no. 113, p. 15 pages, 2018.

[21] D. Emadzadeh, W. J. Lau, T. Matsuura, N. Hilal, and A. F. Ismail, "The potential of 
thin film nanocomposite membrane in reducing organic fouling in forward osmosis process," Desalination, vol. 348, pp. 82-88, 2014.

[22] D. Emadzadeh et al., "Synthesis, modification and optimization of titanate nanotubespolyamide thin film nanocomposite (TFN) membrane for forward osmosis (FO) application," Chem. Eng. J., vol. 281, pp. 243-251, 2015.

[23] M. Ghanbari, D. Emadzadeh, W. J. Lau, H. Riazi, D. Almasi, and A. F. Ismail, "Minimizing structural parameter of thin film composite forward osmosis membranes using polysulfone/halloysite nanotubes as membrane substrates," Desalination, vol. 377, pp. 152-162, 2016.

[24] W. J. Lau et al., "Development of microporous substrates of polyamide thin film composite membranes for pressure-driven and osmotically-driven membrane processes: A review," J. Ind. Eng. Chem., vol. 77, pp. 25-59, 2019.

[25] T. Sirinupong, W. Youravong, D. Tirawat, W. J. Lau, G. S. Lai, and A. F. Ismail, "Synthesis and characterization of thin film composite membranes made of PSF-TiO 2 / GO nanocomposite substrate for forward osmosis applications," Arab. J. Chem., vol. 11, no. 7, pp. 1144-1153, 2018.

[26] D. Emadzadeh et al., "Solvothermal synthesis of nanoporous TiO2: The impact on thin-film composite membranes for engineered osmosis application," Nanotechnology, vol. 27, no. 345702, p. 11 pages, 2016.

[27] M. Rezaei-DashtArzhandi, M. H. Sarrafzadeh, P. S. Goh, W. J. Lau, A. F. Ismail, and M. A. Mohamed, "Development of novel thin film nanocomposite forward osmosis membranes containing halloysite/graphitic carbon nitride nanoparticles towards enhanced desalination performance," Desalination, vol. 447, pp. 18-28, 2018.

[28] N. M. Mokhtar, W. J. Lau, A. F. Ismail, S. Kartohardjono, S. O. Lai, and H. C. Teoh, "The potential of direct contact membrane distillation for industrial textile wastewater treatment using PVDF-Cloisite 15A nanocomposite membrane," Chem. Eng. Res. Des., vol. 111, pp. 284-293, 2016.

[29] A. Alkhudhiri, N. Darwish, and N. Hilal, "Membrane distillation: A comprehensive review," Desalination, vol. 287, pp. 2-18, 2012.

[30] E. Curcio and E. Drioli, "Membrane distillation and related operations - A review," Sep. Purif. Rev., vol. 34, pp. 35-86, 2005.

[31] N. M. Mokhtar, W. J. Lau, A. F. Ismail, and B. C. Ng, "Physicochemical study of polyvinylidene fluoride-Cloisite $15 \mathrm{~A} \AA$ composite membranes for membrane distillation application," RSC Adv., vol. 4, no. 108, pp. 63367-63379, 2014.

[32] E. W. Tow et al., "Comparison of fouling propensity between reverse osmosis, forward osmosis, and membrane distillation," J. Memb. Sci., vol. 556, pp. 352-364, Jun. 2018.

[33] H. M. Park, J. Yoo, and Y. T. Lee, "Improved fouling resistance for RO membranes by a surface modification method," J. Ind. Eng. Chem., vol. 76, pp. 344-354, Aug. 2019.

[34] L. Zheng et al., "Characteristics and formation mechanism of membrane fouling in a full-scale RO wastewater reclamation process: Membrane autopsy and fouling characterization," J. Memb. Sci., vol. 563, pp. 843-856, Oct. 2018.

[35] S. K. Hubadillah, M. H. D. Othman, M. A. Rahman, A. F. Ismail, and J. Jaafar, "Preparation and characterization of inexpensive kaolin hollow fibre membrane (KHFM) prepared using phase inversion/sintering technique for the efficient separation of real oily wastewater," Arab. J. Chem., 2018.

[36] Z. Harun, S. Hubadillah, S. Hasan, and M. Z. Yunos, "Effect of Thermodynamic Properties on Porosity of Ceramic Membrane Prepared by Phase Inversion," Appl. Mech. Mater., vol. 575, pp. 31-35, 2014.

[37] S. K. Hubadillah, M. H. D. Othman, A. F. Ismail, M. A. Rahman, and J. Jaafar, "A low 
cost hydrophobic kaolin hollow fiber membrane (h-KHFM) for arsenic removal from aqueous solution via direct contact membrane distillation," Sep. Purif. Technol., 2018.

[38] M. R. Choudhury, N. Anwar, D. Jassby, and M. S. Rahaman, "Fouling and wetting in the membrane distillation driven wastewater reclamation process - A review," $A d v$. Colloid Interface Sci., vol. 269, pp. 370-399, Jul. 2019.

[39] Q. V. Ly, Y. Hu, J. Li, J. Cho, and J. Hur, "Characteristics and influencing factors of organic fouling in forward osmosis operation for wastewater applications: A comprehensive review," Environ. Int., vol. 129, pp. 164-184, 2019.

[40] D. B. Gingerich and M. S. Mauter, "Quantity, Quality, and Availability of Waste Heat from United States Thermal Power Generation," Environ. Sci. Technol., vol. 49, no. 14, pp. 8297-8306, Jul. 2015.

[41] J. Blanco Gálvez, L. García-Rodríguez, and I. Martín-Mateos, "Seawater desalination by an innovative solar-powered membrane distillation system: the MEDESOL project," Desalination, vol. 246, no. 1-3, pp. 567-576, Sep. 2009.

[42] B. G. Choi, D. I. Kim, and S. Hong, "Fouling evaluation and mechanisms in a FO-RO hybrid process for direct potable reuse," J. Memb. Sci., vol. 520, pp. 89-98, Dec. 2016.

[43] Y. Chun et al., "Fouling characteristics and their implications on cleaning of a FO-RO pilot process for treating brackish surface water," Desalination, vol. 394, pp. 91-100, Sep. 2016.

[44] C. Boo, M. Elimelech, and S. Hong, "Fouling control in a forward osmosis process integrating seawater desalination and wastewater reclamation," J. Memb. Sci., vol. 444, pp. 148-156, Oct. 2013.

[45] Z.-Y. Li, V. Yangali-Quintanilla, R. Valladares-Linares, Q. Li, T. Zhan, and G. Amy, "Flux patterns and membrane fouling propensity during desalination of seawater by forward osmosis," Water Res., vol. 46, no. 1, pp. 195-204, Jan. 2012.

[46] B. Mi and M. Elimelech, "Organic fouling of forward osmosis membranes: Fouling reversibility and cleaning without chemical reagents," J. Memb. Sci., vol. 348, no. 1-2, pp. 337-345, 2010.

[47] Q. She, R. Wang, A. G. Fane, and C. Y. Tang, "Membrane fouling in osmotically driven membrane processes: A review," J. Memb. Sci., vol. 499, pp. 201-233, Feb. 2016.

[48] L. D. Tijing, Y. C. Woo, J.-S. Choi, S. Lee, S.-H. Kim, and H. K. Shon, "Fouling and its control in membrane distillation-A review," J. Memb. Sci., vol. 475, pp. 215-244, Feb. 2015.

[49] M. Badruzzaman, N. Voutchkov, L. Weinrich, and J. G. Jacangelo, "Selection of pretreatment technologies for seawater reverse osmosis plants: A review," Desalination, vol. 449, pp. 78-91, 2019.

[50] S. F. Anis, R. Hashaikeh, and N. Hilal, "Reverse osmosis pretreatment technologies and future trends: A comprehensive review," Desalination, vol. 452, pp. 159-195, 2019.

[51] N. Voutchkov, Seawater Pretreatment.pdf. Water Treatment Academy, 2010.

[52] R. Henderson, S. A. Parsons, and B. Jefferson, "The impact of algal properties and pre-oxidation on solid-liquid separation of algae," Water Res., vol. 42, pp. 1827-1845, 2008.

[53] J.M. Rovel, "Why a SWRO in Taweelah — Pilot plant results demonstrating feasibility and performance of SWRO on gulf water," in IDA Congress. Desalination: The Source of Sustainable Water Supplies, 2003.

[54] B. Y. Sohn, T. J. Park, B. S. Oh, S. B. Kwon, and J. W. Kang, "A case study of the DAF-based drinking water treatment plant in Korea," Sep. Sci. Technol., vol. 15, pp. 3873-3890, 2008. 
[55] N. Voutchkov, "Considerations for selection of seawater filtration pretreatment system," Desalination, vol. 261, pp. 354-364, 2010.

[56] K. T. Chua, M. N. A. Hawlader, and A. Malek, "Pretreatment of seawater: Results of pilot trials in Singapore," Desalination, vol. 159, pp. 225-243, 2003.

[57] W. J. Lau, P. S. Goh, A. F. Ismail, and S. O. Lai, "Ultrafiltration as a pretreatment for seawater desalination: A review," Membr. Water Treat., vol. 5, no. 1, pp. 15-29, 2014.

[58] J. Suarez, B. Salgado, A. Casanas, J. C. Gonzalez, and J. Pordomingo, “One-year operational experience with ultrafiltration as pretreatment of seawater reverse osmosis desalination system (Maspalomas-I Plant)," Desalin. Water Treat., vol. 55, no. 10, pp. 2813-2821, 2015.

[59] E. Akhondi et al., "The Performance and Fouling Control of Submerged Hollow Fiber (HF) Systems: A Review," Appl. Sci., vol. 7, no. 8, p. 765, 2017.

[60] H. Chang et al., "Evaluating the performance of gravity-driven membrane filtration as desalination pretreatment of shale gas flowback and produced water," J. Memb. Sci., vol. 587, p. 117187, 2019.

[61] G. Di Profio, X. Ji, E. Curcio, and E. Drioli, "Submerged hollow fiber ultrafiltration as seawater pretreatment in the logic of integrated membrane desalination systems," Desalination, vol. 269, no. 1-3, pp. 128-135, 2011.

[62] E. Akhondi et al., "Gravity-driven membrane filtration as pretreatment for seawater reverse osmosis: Linking biofouling layer morphology with flux stabilization," Water Res., vol. 70, pp. 158-173, 2015.

[63] H. Huang, K. Schwab, and J. G. Jacangelo, "Pretreatment for low pressure membranes in water treatment: A review," Environ. Sci. Technol., vol. 43, no. 9, pp. 3011-3019, 2009.

[64] B. Wu et al., "Improved performance of gravity-driven membrane filtration for seawater pretreatment: Implications of membrane module configuration," Water Res., vol. 114, pp. 59-68, 2017.

[65] S. Lee, S. R. Suwarno, B. W. H. Quek, L. Kim, B. Wu, and T. H. Chong, “A comparison of gravity-driven membrane (GDM) reactor and biofiltration + GDM reactor for seawater reverse osmosis desalination pretreatment," Water Res., vol. 154, pp. 72-83, 2019.

[66] B. Wu et al., "Optimization of gravity-driven membrane (GDM) filtration process for seawater pretreatment," Water Res., vol. 93, pp. 133-140, 2016.

[67] M. Monnot, S. Laborie, and C. Cabassud, "Granular activated carbon filtration plus ultrafiltration as a pretreatment to seawater desalination lines: Impact on water quality and UF fouling," Desalination, vol. 383, pp. 1-11, 2016.

[68] M. Monnot, H. T. K. Nguyên, S. Laborie, and C. Cabassud, "Seawater reverse osmosis desalination plant at community-scale: Role of an innovative pretreatment on process performances and intensification," Chem. Eng. Process. - Process Intensif., vol. 113, pp. 42-55, 2017.

[69] W. Huang et al., "Effects of combined ozone and PAC pretreatment on ultrafiltration membrane fouling control and mechanisms," J. Memb. Sci., vol. 533, no. March, pp. 378-389, 2017.

[70] R. Treguer, R. Tatin, A. Couvert, D. Wolbert, and A. Tazi-Pain, “Ozonation effect on natural organic matter adsorption and biodegradation - Application to a membrane bioreactor containing activated carbon for drinking water production," Water Res., vol. 44, pp. 781-788, 2010.

[71] W. Suwaileh, D. Johnson, S. Khodabakhshi, and N. Hilal, "Development of forward osmosis membranes modified by cross-linked layer by layer assembly for brackish 
water desalination," J. Memb. Sci., vol. 583, pp. 267-277, 2019.

[72] Y. Ji, Q. An, Q. Zhao, H. Chen, J. Qian, and C. Gao, "Fabrication and performance of a new type of charged nanofiltration membrane based on polyelectrolyte complex," $J$. Memb. Sci., vol. 357, no. 1, pp. 80-89, 2010.

[73] Y. P. Devia, T. Imai, T. Higuchi, A. Kanno, K. Yamamoto, and M. Sekine, "Effect of Operating Conditions on Forward Osmosis for Nutrient Rejection Using Magnesium Chloride as a Draw Solution," Jun. 2015.

[74] X. Li, H. Shan, M. Cao, and B. Li, "Mussel-inspired modification of PTFE membranes in a miscible THF-Tris buffer mixture for oil-in-water emulsions separation," $J$. Memb. Sci., vol. 555, pp. 237-249, 2018.

[75] H.-C. Yang, J. Luo, Y. Lv, P. Shen, and Z.-K. Xu, "Surface engineering of polymer membranes via mussel-inspired chemistry," J. Memb. Sci., vol. 483, pp. 42-59, 2015.

[76] H. Guo, Z. Yao, J. Wang, Z. Yang, X. Ma, and C. Y. Tang, "Polydopamine coating on a thin film composite forward osmosis membrane for enhanced mass transport and antifouling performance," J. Memb. Sci., vol. 551, pp. 234-242, 2018.

[77] X. Bao et al., "Polyamidoamine dendrimer grafted forward osmosis membrane with superior ammonia selectivity and robust antifouling capacity for domestic wastewater concentration," Water Res., vol. 153, pp. 1-10, 2019.

[78] B. Mi and M. Elimelech, "Chemical and physical aspects of organic fouling of forward osmosis membranes," J. Memb. Sci., vol. 320, no. 1, pp. 292-302, 2008.

[79] Y.-H. Chiao et al., "Zwitterion augmented polyamide membrane for improved forward osmosis performance with significant antifouling characteristics," Sep. Purif. Technol., vol. 212, pp. 316-325, 2019.

[80] W.-W. Yue, H.-J. Li, T. Xiang, H. Qin, S.-D. Sun, and C.-S. Zhao, "Grafting of zwitterion from polysulfone membrane via surface-initiated ATRP with enhanced antifouling property and biocompatibility," J. Memb. Sci., vol. 446, pp. 79-91, 2013.

[81] S. F. Seyedpour, A. Rahimpour, A. A. Shamsabadi, and M. Soroush, "Improved performance and antifouling properties of thin-film composite polyamide membranes modified with nano-sized bactericidal graphene quantum dots for forward osmosis," Chem. Eng. Res. Des., vol. 139, pp. 321-334, 2018.

[82] A. Shakeri, H. Mighani, N. Salari, and H. Salehi, "Surface modification of forward osmosis membrane using polyoxometalate based open frameworks for hydrophilicity and water flux improvement," J. Water Process Eng., vol. 29, p. 100762, 2019.

[83] J. Zhu et al., "Elevated Performance of Thin Film Nanocomposite Membranes Enabled by Modified Hydrophilic MOFs for Nanofiltration," ACS Appl. Mater. Interfaces, vol. 9, no. 2, pp. 1975-1986, Jan. 2017.

[84] D. Ma, S. B. Peh, G. Han, and S. B. Chen, "Thin-Film Nanocomposite (TFN) Membranes Incorporated with Super-Hydrophilic Metal-Organic Framework (MOF) UiO-66: Toward Enhancement of Water Flux and Salt Rejection," ACS Appl. Mater. Interfaces, vol. 9, no. 8, pp. 7523-7534, Mar. 2017.

[85] A. Tiraferri, Y. Kang, E. P. Giannelis, and M. Elimelech, "Highly Hydrophilic ThinFilm Composite Forward Osmosis Membranes Functionalized with Surface-Tailored Nanoparticles," ACS Appl. Mater. \&amp; Interfaces, vol. 4, no. 9, pp. 5044-5053, Sep. 2012.

[86] N. Niksefat, M. Jahanshahi, and A. Rahimpour, "The effect of $\mathrm{SiO} 2$ nanoparticles on morphology and performance of thin film composite membranes for forward osmosis application," Desalination, vol. 343, pp. 140-146, Jun. 2014.

[87] N. Ma, J. Wei, R. Liao, and C. Y. Tang, "Zeolite-polyamide thin film nanocomposite membranes: Towards enhanced performance for forward osmosis," J. Memb. Sci., vol. 405-406, pp. 149-157, Jul. 2012. 
[88] M. Amini, M. Jahanshahi, and A. Rahimpour, "Synthesis of novel thin film nanocomposite (TFN) forward osmosis membranes using functionalized multi-walled carbon nanotubes," J. Memb. Sci., vol. 435, pp. 233-241, May 2013.

[89] S. J. Kwon et al., "Fabrication of high performance and durable forward osmosis membranes using mussel-inspired polydopamine-modified polyethylene supports," $J$. Memb. Sci., vol. 584, pp. 89-99, 2019.

[90] T. Kamada, T. Ohara, T. Shintani, and T. Tsuru, "Optimizing the preparation of multilayered polyamide membrane via the addition of a co-solvent," J. Memb. Sci., vol. 453, pp. 489-497, 2014.

[91] G. Zhang, H. Yan, S. Ji, and Z. Liu, "Self-assembly of polyelectrolyte multilayer pervaporation membranes by a dynamic layer-by-layer technique on a hydrolyzed polyacrylonitrile ultrafiltration membrane," J. Memb. Sci., vol. 292, no. 1-2, pp. 1-8, Apr. 2007.

[92] W. Cheng et al., "Selective removal of divalent cations by polyelectrolyte multilayer nanofiltration membrane: Role of polyelectrolyte charge, ion size, and ionic strength," J. Memb. Sci., vol. 559, pp. 98-106, Aug. 2018.

[93] W. Suwaileh, D. Johnson, S. Khodabakhshi, and N. Hilal, "Superior cross-linking assisted layer by layer modification of forward osmosis membranes for brackish water desalination," Desalination, vol. 463, pp. 1-12, Aug. 2019.

[94] H. Salehi, M. Rastgar, and A. Shakeri, "Anti-fouling and high water permeable forward osmosis membrane fabricated via layer by layer assembly of chitosan/graphene oxide," Appl. Surf. Sci., vol. 413, pp. 99-108, 2017.

[95] H. Kang et al., "Interlamination restrictive effect of carbon nanotubes for graphene oxide forward osmosis membrane via layer by layer assembly," Appl. Surf. Sci., vol. 465, pp. 1103-1106, 2019.

[96] J. Zeng, S. Cui, Q. Wang, and R. Chen, "Multi-layer temperature-responsive hydrogel for forward-osmosis desalination with high permeable flux and fast water release," Desalination, vol. 459, pp. 105-113, 2019.

[97] M.-N. Li et al., "Forward osmosis membranes modified with laminar MoS2 nanosheet to improve desalination performance and antifouling properties," Desalination, vol. 436, pp. 107-113, 2018.

[98] C.-N. Yeh, K. Raidongia, J. Shao, Q.-H. Yang, and J. Huang, "On the origin of the stability of graphene oxide membranes in water," Nat. Chem., vol. 7, p. 166, Jan. 2015.

[99] D. Wu, Y. Huang, S. Yu, D. Lawless, and X. Feng, "Thin film composite nanofiltration membranes assembled layer-by-layer via interfacial polymerization from polyethylenimine and trimesoyl chloride," J. Memb. Sci., vol. 472, pp. 141-153, Dec. 2014.

[100] A. Akbari, H. Solymani, and S. M. M. Rostami, "Preparation and characterization of a novel positively charged nanofiltration membrane based on polysulfone," J. Appl. Polym. Sci., vol. 132, no. 22, Jun. 2015.

[101] X. Song, L. Wang, C. Y. Tang, Z. Wang, and C. Gao, "Fabrication of carbon nanotubes incorporated double-skinned thin film nanocomposite membranes for enhanced separation performance and antifouling capability in forward osmosis process," Desalination, vol. 369, pp. 1-9, 2015.

[102] J. T. Jung, J. F. Kim, H. H. Wang, E. di Nicolo, E. Drioli, and Y. M. Lee, "Understanding the non-solvent induced phase separation (NIPS) effect during the fabrication of microporous PVDF membranes via thermally induced phase separation (TIPS)," J. Memb. Sci., vol. 514, pp. 250-263, Sep. 2016.

[103] A. M. Karam and T. M. Laleg-Kirati, "Membrane fouling modeling and detection in direct contact membrane distillation," J. Process Control, vol. 81, pp. 190-196, Sep. 
2019.

[104] Y. Yang et al., "Superhydrophobic modification of ceramic membranes for vacuum membrane distillation," Chinese J. Chem. Eng., vol. 25, no. 10, pp. 1395-1401, Oct. 2017.

[105] J. Guo, B. J. Deka, K.-J. Kim, and A. K. An, "Regeneration of superhydrophobic TiO2 electrospun membranes in seawater desalination by water flushing in membrane distillation," Desalination, vol. 468, p. 114054, Oct. 2019.

[106] M. Tang, D. Hou, C. Ding, K. Wang, D. Wang, and J. Wang, “Anti-oil-fouling hydrophobic-superoleophobic composite membranes for robust membrane distillation performance,” Sci. Total Environ., vol. 696, p. 133883, Dec. 2019.

[107] D. Hou, C. Ding, K. Li, D. Lin, D. Wang, and J. Wang, "A novel dual-layer composite membrane with underwater-superoleophobic/hydrophobic asymmetric wettability for robust oil-fouling resistance in membrane distillation desalination," Desalination, vol. 428, pp. 240-249, Feb. 2018.

[108] D. Hou, C. Ding, C. Fu, D. Wang, C. Zhao, and J. Wang, "Electrospun nanofibrous omniphobic membrane for anti-surfactant-wetting membrane distillation desalination," Desalination, vol. 468, p. 114068, Oct. 2019.

[109] A. M. Urmenyi, A. P. Philipse, R. G. H. Lammertink, and M. Wessling, "Polymer-ina-Silica-Crust Membranes: Macroporous Materials with Tunable Surface Functionality," Langmuir, vol. 22, no. 12, pp. 5459-5468, Jun. 2006.

[110] X. D. Sun, G. F. Li, Y. Z. Zhang, Y. X. Li, and H. Li, "Preparation of SuperHydrophobic Polyethersulphone Membrane by Sol-Gel Method," Adv. Mater. Res., vol. 79-82, pp. 839-842, 2009.

[111] A. Razmjou, E. Arifin, G. Dong, J. Mansouri, and V. Chen, "Superhydrophobic modification of $\mathrm{TiO} 2$ nanocomposite PVDF membranes for applications in membrane distillation," J. Memb. Sci., vol. 415-416, pp. 850-863, Oct. 2012.

[112] K. J. Lu, Y. Chen, and T.-S. Chung, "Design of omniphobic interfaces for membrane distillation - A review," Water Res., vol. 162, pp. 64-77, Oct. 2019.

[113] C. Lu et al., "F-POSS based Omniphobic Membrane for Robust Membrane Distillation," Mater. Lett., vol. 228, pp. 85-88, Oct. 2018.

[114] Z. Wang and S. Lin, "Membrane fouling and wetting in membrane distillation and their mitigation by novel membranes with special wettability," Water Res., vol. 112, pp. 38-47, Apr. 2017.

[115] B. J. Deka, J. Guo, N. K. Khanzada, and A. K. An, "Omniphobic re-entrant PVDF membrane with $\mathrm{ZnO}$ nanoparticles composite for desalination of low surface tension oily seawater," Water Res., vol. 165, p. 114982, Nov. 2019.

[116] N. Dizge, E. Shaulsky, and V. Karanikola, "Electrospun cellulose nanofibers for superhydrophobic and oleophobic membranes," J. Memb. Sci., vol. 590, p. 117271, Nov. 2019.

[117] A. Tuteja, W. Choi, J. M. Mabry, G. H. McKinley, and R. E. Cohen, "Robust omniphobic surfaces," Proc. Natl. Acad. Sci., vol. 105, no. 47, pp. 18200 LP - 18205, Nov. 2008.

[118] A. Tuteja et al., "Designing Superoleophobic Surfaces," Science (80-. )., vol. 318, no. 5856, pp. 1618 LP - 1622, Dec. 2007.

[119] T. T. Y. Tan et al., "Tuning Omniphobicity via Morphological Control of MetalOrganic Framework Functionalized Surfaces," J. Am. Chem. Soc., vol. 135, no. 44, pp. 16272-16275, Nov. 2013.

[120] R. Hensel, R. Helbig, S. Aland, A. Voigt, C. Neinhuis, and C. Werner, "Tunable nanoreplication to explore the omniphobic characteristics of springtail skin," NPG Asia Mater., vol. 5, no. 2, pp. e37-e37, 2013. 
[121] L. Deng et al., "Self-roughened omniphobic coatings on nanofibrous membrane for membrane distillation," Sep. Purif. Technol., vol. 206, pp. 14-25, Nov. 2018.

[122] D. Y. Cheng and S. J. Wiersma, "Composite membrane for a membrane distillation system," US4419242A, 1982.

[123] Y.-X. Huang, Z. Wang, J. Jin, and S. Lin, "Novel Janus Membrane for Membrane Distillation with Simultaneous Fouling and Wetting Resistance," Environ. Sci. Technol., vol. 51, no. 22, pp. 13304-13310, Nov. 2017.

[124] M. Krivorot, A. Kushmaro, Y. Oren, and J. Gilron, "Factors affecting biofilm formation and biofouling in membrane distillation of seawater," J. Memb. Sci., vol. 376, no. 1, pp. 15-24, 2011.

[125] S. K. Hubadillah et al., "Hydrophobic ceramic membrane for membrane distillation: A mini review on preparation, characterization, and applications," Sep. Purif. Technol., vol. 217, pp. 71-84, Jun. 2019.

[126] "Performance of ceramic membrane in vacuum membrane distillation and in vacuum membrane crystallization," Desalination, vol. 440, pp. 48-58, Aug. 2018.

[127] H. Sugimura, A. Hozumi, T. Kameyama, and O. Takai, "Organosilane self-assembled monolayers formed at the vapour/solid interface," Surf. Interface Anal., vol. 34, no. 1, pp. 550-554, Aug. 2002.

[128] I. Vlassiouk et al., "Large scale atmospheric pressure chemical vapor deposition of graphene," Carbon N. Y., vol. 54, pp. 58-67, Apr. 2013.

[129] S. Sahebi, H. K. Shon, S. Phuntsho, and B. Ramavandi, "Fabricating robust thin film composite membranes reinforced on woven mesh backing fabric support for pressure assisted and forward osmosis: A dataset," Data Br., vol. 21, pp. 364-370, 2018.

[130] S. Mondal, R. W. Field, and J. J. Wu, "Novel approach for sizing forward osmosis membrane systems," J. Memb. Sci., vol. 541, pp. 321-328, 2017.

[131] J. Seo, Y. M. Kim, S. H. Chae, S. J. Lim, H. Park, and J. H. Kim, “An optimization strategy for a forward osmosis-reverse osmosis hybrid process for wastewater reuse and seawater desalination: A modeling study," Desalination, vol. 463, pp. 40-49, 2019.

[132] C.-Y. Kuo, H.-N. Lin, and H.-A. Tsai, "Fabrication of a high hydrophobic PVDF membrane via nonsolvent induced phase separation," Desalination, vol. 233, no. 1-3, pp. 40-47, Dec. 2008.

[133] N. Dow et al., "Pilot trial of membrane distillation driven by low grade waste heat: Membrane fouling and energy assessment," Desalination, vol. 391, pp. 30-42, Aug. 2016.

[134] S. K. Hubadillah et al., "Green silica-based ceramic hollow fiber membrane for seawater desalination via direct contact membrane distillation," Sep. Purif. Technol., vol. 205, 2018.

[135] P. Pal and A. K. Manna, "Removal of arsenic from contaminated groundwater by solar-driven membrane distillation using three different commercial membranes," Water Res., vol. 44, no. 19, pp. 5750-5760, Nov. 2010.

[136] K. Karakulski and M. Gryta, "Water demineralisation by NF/MD integrated processes," Desalination, vol. 177, no. 1-3, pp. 109-119, Jun. 2005.

[137] C. Su et al., "Novel PTFE hollow fiber membrane fabricated by emulsion electrospinning and sintering for membrane distillation," J. Memb. Sci., vol. 583, pp. 200-208, 2019.

[138] Q. Huang, S. Gao, Y. Huang, M. Zhang, and C. Xiao, "Study on photothermal PVDF/ATO nanofiber membrane and its membrane distillation performance," $J$. Memb. Sci., vol. 582, pp. 203-210, 2019.

[139] Y. Chen et al., "Laminated PTFE membranes to enhance the performance in direct 
contact membrane distillation for high salinity solution," Desalination, vol. 424, pp. 140-148, 2017.

[140] S. Srisurichan, R. Jiraratananon, and A. G. Fane, "Humic acid fouling in the membrane distillation process," Desalination, vol. 174, no. 1, pp. 63-72, 2005.

[141] P. Jacob, P. Phungsai, K. Fukushi, and C. Visvanathan, "Direct contact membrane distillation for anaerobic effluent treatment," J. Memb. Sci., vol. 475, pp. 330-339, 2015.

[142] F. Banat, S. Al-Asheh, and M. Qtaishat, "Treatment of waters colored with methylene blue dye by vacuum membrane distillation," Desalination, vol. 174, no. 1, pp. 87-96, 2005.

[143] Y. Yu, S. Lee, and S. K. Maeng, "Forward osmosis membrane fouling and cleaning for wastewater reuse," J. Water Reuse Desalin., vol. 7, no. 2, pp. 111-120, May 2016.

[144] F. Lotfi, B. Samali, and D. Hagare, "Cleaning efficiency of the fouled forward osmosis membranes under different experimental conditions," J. Environ. Chem. Eng., vol. 6, no. 4, pp. 4555-4563, 2018.

[145] X. Liu, J. Wu, L. Hou, and J. Wang, "Fouling and cleaning protocols for forward osmosis membrane used for radioactive wastewater treatment," Nucl. Eng. Technol., 2019.

[146] W. J. Lee, P. S. Goh, W. J. Lau, C. S. Ong, and A. F. Ismail, “Antifouling zwitterion embedded forward osmosis thin film composite membrane for highly concentrated oily wastewater treatment," Sep. Purif. Technol., vol. 214, pp. 40-50, 2019.

[147] J. Koschikowski, M. Wieghaus, and M. Rommel, "Solar thermal-driven desalination plants based on membrane distillation," Desalination, vol. 156, no. 1, pp. 295-304, 2003.

[148] J. Koschikowski, M. Wieghaus, M. Rommel, V. S. Ortin, B. P. Suarez, and J. R. Betancort Rodríguez, "Experimental investigations on solar driven stand-alone membrane distillation systems for remote areas," Desalination, vol. 248, no. 1, pp. $125-131,2009$.

[149] A. K. An, J. Guo, S. Jeong, E.-J. Lee, S. A. A. Tabatabai, and T. Leiknes, "High flux and antifouling properties of negatively charged membrane for dyeing wastewater treatment by membrane distillation," Water Res., vol. 103, pp. 362-371, 2016.

[150] N. Dow et al., "Demonstration of membrane distillation on textile waste water: assessment of long term performance, membrane cleaning and waste heat integration," Environ. Sci. Water Res. Technol., vol. 3, no. 3, pp. 433-449, 2017.

[151] G. Naidu, S. Jeong, Y. Choi, and S. Vigneswaran, "Membrane distillation for wastewater reverse osmosis concentrate treatment with water reuse potential," $J$. Memb. Sci., vol. 524, pp. 565-575, 2017.

[152] E. Guillen-Burrieza, A. Ruiz-Aguirre, G. Zaragoza, and H. A. Arafat, "Membrane fouling and cleaning in long term plant-scale membrane distillation operations," $J$. Memb. Sci., vol. 468, pp. 360-372, 2014.

[153] C. Fritzmann, J. Löwenberg, T. Wintgens, and T. Melin, "State-of-the-art of reverse osmosis desalination," Desalination, vol. 216, pp. 1-76, 2007.

[154] R. K. McGovern and J. H. Lienhard V, "On the potential of forward osmosis to energetically outperform reverse osmosis desalination," J. Memb. Sci., vol. 469, pp. 245-250, 2014.

[155] Y. Kim, J. H. Lee, Y. C. Kim, K. H. Lee, I. S. Park, and S.-J. Park, “Operation and simulation of pilot-scale forward osmosis desalination with ammonium bicarbonate," Chem. Eng. Res. Des., vol. 94, pp. 390-395, 2015.

[156] Y. H. Cho, J. Han, S. Han, M. D. Guiver, and H. B. Park, "Polyamide thin-film composite membranes based on carboxylated polysulfone microporous support 
membranes for forward osmosis," J. Memb. Sci., vol. 445, pp. 220-227, Oct. 2013.

[157] Z. Zhou, J. Y. Lee, and T.-S. Chung, "Thin film composite forward-osmosis membranes with enhanced internal osmotic pressure for internal concentration polarization reduction," Chem. Eng. J., vol. 249, pp. 236-245, Aug. 2014.

[158] D. Emadzadeh, W. J. Lau, T. Matsuura, M. Rahbari-Sisakht, and A. F. Ismail, "A novel thin film composite forward osmosis membrane prepared from PSf-TiO2 nanocomposite substrate for water desalination," Chem. Eng. J., vol. 237, pp. 70-80, Feb. 2014.

[159] X. Liu and H. Y. Ng, "Fabrication of layered silica-polysulfone mixed matrix substrate membrane for enhancing performance of thin-film composite forward osmosis membrane," J. Memb. Sci., vol. 481, pp. 148-163, May 2015.

[160] K. Goh, L. Setiawan, L. Wei, W. Jiang, R. Wang, and Y. Chen, "Fabrication of novel functionalized multi-walled carbon nanotube immobilized hollow fiber membranes for enhanced performance in forward osmosis process," J. Memb. Sci., vol. 446, pp. 244 254, Nov. 2013.

[161] J. M. C. Puguan, H.-S. Kim, K.-J. Lee, and H. Kim, "Low internal concentration polarization in forward osmosis membranes with hydrophilic crosslinked PVA nanofibers as porous support layer," Desalination, vol. 336, pp. 24-31, Mar. 2014.

[162] C. Qiu, S. Qi, and C. Y. Tang, "Synthesis of high flux forward osmosis membranes by chemically crosslinked layer-by-layer polyelectrolytes," J. Memb. Sci., vol. 381, no. 12, pp. 74-80, Sep. 2011.

[163] S. Qi, C. Q. Qiu, Y. Zhao, and C. Y. Tang, "Double-skinned forward osmosis membranes based on layer-by-layer assembly-FO performance and fouling behavior," J. Memb. Sci., vol. 405-406, pp. 20-29, 2012.

[164] S. You et al., "Forward Osmosis with a Novel Thin-Film Inorganic Membrane," Environ. Sci. \&amp; Technol., vol. 47, no. 15, pp. 8733-8742, Jul. 2013.

[165] L. Setiawan, R. Wang, K. Li, and A. G. Fane, "Fabrication of novel poly(amideimide) forward osmosis hollow fiber membranes with a positively charged nanofiltration-like selective layer," J. Memb. Sci., vol. 369, no. 1-2, pp. 196-205, Mar. 2011.

[166] C. S. Ong et al., "Anti-Fouling Double-Skinned Forward Osmosis Membrane with Zwitterionic Brush for Oily Wastewater Treatment," Sci. Rep., vol. 7, no. 1, p. 6904, 2017.

[167] P. H. H. Duong, T. S. Chung, S. Wei, and L. Irish, "Highly permeable double-skinned forward osmosis membranes for anti-fouling in the emulsified oil-water separation process," Environ. Sci. Technol., vol. 48, no. 8, pp. 4537-4545, 2014.

[168] H. Li, W. Shi, X. Zeng, S. Huang, H. Zhang, and X. Qin, "Improved desalination properties of hydrophobic GO-incorporated PVDF electrospun nanofibrous composites for vacuum membrane distillation," Sep. Purif. Technol., vol. 230, p. 115889, Jan. 2020.

[169] X. Chen et al., "Tubular hydrophobic ceramic membrane with asymmetric structure for water desalination via vacuum membrane distillation process," Desalination, vol. 443, pp. 212-220, Oct. 2018.

[170] L. García-Fernández, B. Wang, M. C. García-Payo, K. Li, and M. Khayet, "Morphological design of alumina hollow fiber membranes for desalination by air gap membrane distillation," Desalination, vol. 420, pp. 226-240, Oct. 2017.

[171] D. Zhao, J. Zuo, K.-J. Lu, and T.-S. Chung, "Fluorographite modified PVDF membranes for seawater desalination via direct contact membrane distillation," Desalination, vol. 413, pp. 119-126, Jul. 2017.

[172] J. Zahirifar, J. Karimi-Sabet, S. M. A. Moosavian, A. Hadi, and P. Khadiv-Parsi, 
"Fabrication of a novel octadecylamine functionalized graphene oxide/PVDF duallayer flat sheet membrane for desalination via air gap membrane distillation," Desalination, vol. 428, pp. 227-239, Feb. 2018.

[173] K. Li, D. Hou, C. Fu, K. Wang, and J. Wang, "Fabrication of PVDF nanofibrous hydrophobic composite membranes reinforced with fabric substrates via electrospinning for membrane distillation desalination," J. Environ. Sci., vol. 75, pp. 277-288, Jan. 2019.

[174] L. N. Nthunya et al., "Fouling-resistant PVDF nanofibre membranes for the desalination of brackish water in membrane distillation," Sep. Purif. Technol., vol. 228, p. 115793, Dec. 2019.

[175] J. A. Prince, G. Singh, D. Rana, T. Matsuura, V. Anbharasi, and T. S. Shanmugasundaram, "Preparation and characterization of highly hydrophobic poly(vinylidene fluoride) - Clay nanocomposite nanofiber membranes (PVDF-clay NNMs) for desalination using direct contact membrane distillation," J. Memb. Sci., vol. 397-398, pp. 80-86, Apr. 2012.

[176] M. R. S. Kebria, A. Rahimpour, G. Bakeri, and R. Abedini, "Experimental and theoretical investigation of thin ZIF-8/chitosan coated layer on air gap membrane distillation performance of PVDF membrane," Desalination, vol. 450, pp. 21-32, Jan. 2019.

[177] D. Cheng et al., "Aluminum fumarate MOF/PVDF hollow fiber membrane for enhancement of water flux and thermal efficiency in direct contact membrane distillation," J. Memb. Sci., vol. 588, p. 117204, Oct. 2019.

[178] R. Zhou, D. Rana, T. Matsuura, and C. Q. Lan, "Effects of multi-walled carbon nanotubes (MWCNTs) and integrated MWCNTs/SiO2 nano-additives on PVDF polymeric membranes for vacuum membrane distillation," Sep. Purif. Technol., vol. 217, pp. 154-163, Jun. 2019. 
Table 2: Summary of the modification of FO membranes for desalination

\begin{tabular}{|c|c|c|c|c|c|c|}
\hline Membranes & Materials & Modification & $\begin{array}{l}\text { Feed Solution } \\
\text { (Draw } \\
\text { Solution) }\end{array}$ & $\begin{array}{l}\text { Water Flux } \\
\left(\mathbf{L} \mathbf{~ m}^{-2} \mathbf{h r}^{-1}\right)\end{array}$ & $\begin{array}{l}\text { Salt } \\
\text { Rejection } \\
(\%)\end{array}$ & Reference \\
\hline TFN & HTI TFC membrane & $\begin{array}{l}\text { PDA coating onto PA } \\
\text { layer }\end{array}$ & $\begin{array}{l}10 \mathrm{mM} \mathrm{NaCl} \\
(0.5-2 \mathrm{M} \mathrm{NaCl})\end{array}$ & $\begin{array}{lr}9.9 & \text { (TFC- } \\
\text { C0.5, } & \text { AL-FS }) \\
16.9 & \text { (TFC- } \\
\text { C0.5, } & \text { AL- } \\
\text { DS }) & \end{array}$ & $\sim 87.5(\mathrm{NaCl})$ & [76] \\
\hline TFN & $\begin{array}{l}\text { SPES substrate, PA active } \\
\text { layer }\end{array}$ & $\begin{array}{l}\text { Grafting of PAMAM } \\
\text { dendrimer nanoparticles } \\
\text { onto PA layer }\end{array}$ & $\begin{array}{l}\text { DI water/ } / \mathrm{NH}_{4} \mathrm{Cl} \\
(1 \mathrm{M} \mathrm{NaCl})\end{array}$ & $\sim 33(\mathrm{AL}-\mathrm{FS})$ & $93\left(\mathrm{NH}_{4}{ }^{+}-\mathrm{N}\right)$ & [77] \\
\hline $\begin{array}{l}\text { Zwitterionic } \\
\text { TFC }\end{array}$ & $\begin{array}{l}\text { PSf substrate, PA active } \\
\text { layer }\end{array}$ & $\begin{array}{l}\text { Augmentation of AEPPS } \\
\text { onto PA layer }\end{array}$ & $\begin{array}{l}\text { Sodium alginate } \\
\text { solution } \\
(2 \mathrm{M} \mathrm{NaCl})\end{array}$ & $\begin{array}{l}\sim 15 \text { (TFC-50, } \\
\text { AL-FS) } \\
\sim 30 \text { (TFC-50, } \\
\text { AL-DS) }\end{array}$ & $95.7(\mathrm{NaCl})$ & [79] \\
\hline TFN & $\begin{array}{l}\text { PES substrate, PA active } \\
\text { layer }\end{array}$ & $\begin{array}{l}\text { Incorporation of GQDs } \\
\text { onto PA layer }\end{array}$ & $\begin{array}{l}\text { Sodium alginate } \\
\text { solution } \\
(1 \mathrm{M} \mathrm{NaCl})\end{array}$ & $\begin{array}{l}\sim 30 \quad \text { (TFN- } \\
0.1, \text { AL-FS) }\end{array}$ & - & [81] \\
\hline TFN & $\begin{array}{l}\text { PES substrate, PA active } \\
\text { layer }\end{array}$ & $\begin{array}{l}\text { Incorporation of POM- } \\
\text { OFs onto PA layer }\end{array}$ & $\begin{array}{l}\text { DI water } \\
(1 \mathrm{M} \mathrm{NaCl})\end{array}$ & $\begin{array}{l}24.2 \\
\text { TFN }_{\mathrm{TW} .2}, \\
\text { AL-FS) } \\
35.5 \\
\text { (TFN }_{\mathrm{TW} .2} \text {, } \\
\text { AL-DS) }\end{array}$ & $92.43(\mathrm{NaCl})$ & [82] \\
\hline TFN & $\begin{array}{l}\text { PSf substrate, PA active } \\
\text { layer }\end{array}$ & $\begin{array}{l}\text { Incorporation of silica } \\
\text { nanoparticles onto PA } \\
\text { layer }\end{array}$ & $\begin{array}{l}10 \mathrm{mM} \mathrm{NaCl} \\
(2 \mathrm{M} \mathrm{NaCl})\end{array}$ & $\begin{array}{l}36 \pm 2 \quad(0.1 \\
\text { wt } \% \text { silica })\end{array}$ & $90 \pm 3(\mathrm{NaCl})$ & [86] \\
\hline TFN & $\begin{array}{l}\text { PSf substrate, PA active } \\
\text { layer }\end{array}$ & $\begin{array}{l}\text { Incorporation of } \mathrm{NaY} \\
\text { zeolite nanoparticles onto } \\
\text { PA layer }\end{array}$ & $\begin{array}{l}10 \mathrm{mM} \mathrm{NaCl} \text { or } \\
\text { DI water }\end{array}$ & $\begin{array}{l}30.7 \quad \text { (TFN } \\
0.1, \text { AL-DS) }\end{array}$ & $75.1(\mathrm{NaCl})$ & [87] \\
\hline
\end{tabular}




\begin{tabular}{|c|c|c|c|c|c|c|}
\hline & & & $\begin{array}{l}(0.5,1.0 \text { or } 2.0 \mathrm{M} \\
\mathrm{NaCl})\end{array}$ & $\begin{array}{l}14.6 \quad(\mathrm{TFN} \\
0.1, \mathrm{AL}-\mathrm{FS})\end{array}$ & & \\
\hline TFN & $\begin{array}{l}\text { PSf substrate, PA active } \\
\text { layer }\end{array}$ & $\begin{array}{l}\text { Incorporation of } \\
\text { MWCNTs nanoparticles } \\
\text { onto PA layer }\end{array}$ & $\begin{array}{l}10 \mathrm{mM} \mathrm{NaCl} \\
(2 \mathrm{M} \mathrm{NaCl})\end{array}$ & $\begin{array}{l}95.7(0.1 \mathrm{wt} \% \\
\text { MWCNTs })\end{array}$ & $73(\mathrm{NaCl})$ & {$[88]$} \\
\hline TFC & $\begin{array}{l}\text { PES substrate, PA active } \\
\text { layer }\end{array}$ & $\begin{array}{l}\text { Incorporation of PMAPS } \\
\text { zwitterion onto PES } \\
\text { substrate }\end{array}$ & $\begin{array}{l}1000-10000 \\
\text { ppm Oily } \\
\text { wastewater } \\
(2 \mathrm{M} \mathrm{NaCl})\end{array}$ & $\begin{array}{l}15.79 \quad(1 \% \\
\text { PMAPS- } \\
\text { TFC, AL-DS })\end{array}$ & $99(\mathrm{NaCl})$ & [146] \\
\hline TFC & $\begin{array}{l}\text { PE substrate, PA active } \\
\text { layer }\end{array}$ & $\begin{array}{l}\text { Modification of PE } \\
\text { substrate with PDA } \\
\text { followed by toluene- } \\
\text { based IP process }\end{array}$ & $\begin{array}{l}\text { DI water } \\
(0.5-2.0 \mathrm{M} \mathrm{NaCl})\end{array}$ & $\begin{array}{l}\sim 85 \text { (AL-FS) } \\
\sim 99 \text { (AL-DS) }\end{array}$ & $98.1(\mathrm{NaCl})$ & [89] \\
\hline TFC & $\begin{array}{l}\text { Carboxylated PSf } \\
\text { substrate, PA active layer }\end{array}$ & $\begin{array}{ll}\text { Incorporation } & \text { of } \\
\text { hydrophilic } & \text { carboxylic } \\
\text { acid groups } & \text { onto PSf } \\
\text { substrate } & \end{array}$ & $\begin{array}{l}\text { DI water } \\
(1 \mathrm{M} \mathrm{MgCl}) \\
\text { DI water } \\
\left(2 \mathrm{M} \mathrm{Mel}_{2}\right)\end{array}$ & $\begin{array}{l}18 \\
12 \\
\text { POSS })\end{array}$ & - & [156] \\
\hline TFC & $\begin{array}{l}\text { PSf substrate, PA active } \\
\text { layer }\end{array}$ & $\begin{array}{l}\text { Mixing of SPPO with PSf } \\
\text { substrate }\end{array}$ & $\begin{array}{l}\text { DI water } \\
(2 \mathrm{M} \mathrm{NaCl})\end{array}$ & $\begin{array}{l}25 \text { (AL-DS) } \\
19 \text { (AL-FS) }\end{array}$ & - & [157] \\
\hline TFC & $\begin{array}{l}\text { PSf substrate, PA active } \\
\text { layer }\end{array}$ & $\begin{array}{l}\text { Incorporation of of } \mathrm{TiO}_{2} \\
\text { onto PSf substrate }\end{array}$ & $\begin{array}{l}10 \mathrm{mM} \mathrm{NaCl} \\
(0.5 \text { or } 2 \mathrm{M} \\
\mathrm{NaCl})\end{array}$ & $\begin{array}{lr}31.1 & \\
(\mathrm{TFN} 0.5, \text { AL- } \\
\mathrm{DS}, \quad 0.5 \mathrm{M} \\
\mathrm{NaCl}) \\
17.1 \\
(\mathrm{TFN} 0.5, \mathrm{AL}- \\
\mathrm{FS}, & 0.5 \mathrm{M} \\
\mathrm{NaCl}) & \end{array}$ & $92.7(\mathrm{NaCl})$ & [158] \\
\hline TFC & $\begin{array}{l}\text { PSf substrate, PA active } \\
\text { layer }\end{array}$ & $\begin{array}{l}\text { Double blade casting } \\
\text { technique for } \\
\text { incorporation of silica } \\
\text { nanoparticles onto PSf } \\
\text { substrate }\end{array}$ & $\begin{array}{l}\text { DI water } \\
(1 \mathrm{M} \mathrm{NaCl})\end{array}$ & $\begin{array}{l}60.5 \text { (AL-DS) } \\
31 \text { (AL-FS) }\end{array}$ & $98(\mathrm{NaCl})$ & [159] \\
\hline
\end{tabular}




\begin{tabular}{|c|c|c|c|c|c|c|}
\hline Hollow fiber & PAI substrate & $\begin{array}{l}\text { Immobilization of PAI } \\
\text { substrate with MWCNT } \\
\text { via vacuum filtration } \\
\text { Post-treatment with PEI } \\
\text { solution }\end{array}$ & $\begin{array}{l}\text { DI water } \\
\left(0.5 \mathrm{M} \mathrm{MgCl} \mathrm{Mg}_{2}\right)\end{array}$ & 13 & $87.8\left(\mathrm{MgCl}_{2}\right)$ & [160] \\
\hline Nanofiber TFC & $\begin{array}{l}\text { PVA substrate, PA active } \\
\text { layer }\end{array}$ & $\begin{array}{l}\text { Cross-linking of PVA } \\
\text { substrate using acid } \\
\text { catalyzed glutaraldehyde } \\
\text { in acetone solution }\end{array}$ & $\begin{array}{l}\text { DI water } \\
(0.5 \mathrm{M} \mathrm{NaCl})\end{array}$ & 27.24 & $97(\mathrm{NaCl})$ & [161] \\
\hline TFC & PES substrate & $\begin{array}{l}\text { LBL assembly with } \\
\text { chemical cross-linking } \\
\text { using PDAMAC and } \\
\text { CMCNa }\end{array}$ & $\begin{array}{l}\text { DI water } \\
(0.5 \mathrm{M}-2.0 \mathrm{M} \\
\mathrm{NaCl})\end{array}$ & $\sim 19$ (AL-FS) & - & [71] \\
\hline TFC & PES substrate & $\begin{array}{l}\text { LBL assembly with } \\
\text { chemical cross-linking } \\
\text { using chitosan and } \\
\text { graphene oxide }\end{array}$ & $\begin{array}{l}\text { DI water } \\
(1 \mathrm{M} \mathrm{sucrose} \text { or } \\
\left.1 \mathrm{M} \mathrm{Na}_{2} \mathrm{SO}_{4}\right)\end{array}$ & $\begin{array}{l}\sim 25(10-\mathrm{LbL}, \\
\text { AL-FS) } \\
\sim 30(10-\mathrm{LbL}, \\
\text { AL-DS) }\end{array}$ & $\begin{array}{l}91.11 \\
\left(\mathrm{Na}_{2} \mathrm{SO}_{4}\right)\end{array}$ & [94] \\
\hline TFC & PES substrate & $\begin{array}{l}\text { LBL assembly with } \\
\text { chemical cross-linking by } \\
\text { PDDA, GO and PES }\end{array}$ & $\begin{array}{l}\text { DI water } \\
(1 \mathrm{M} \quad \mathrm{NaCl} \text {, } \\
\mathrm{MgCl}_{2}, \mathrm{Ma}_{2} \mathrm{SO}_{4} \\
\text { or sucrose) }\end{array}$ & $\begin{array}{l}\sim 6 \quad(5-\mathrm{LbL}, \\
\text { AL-FS })\end{array}$ & - & [95] \\
\hline TFC & $\begin{array}{l}\text { CTA substrate with } \\
\text { embedded polyester screen } \\
\text { mesh }\end{array}$ & $\begin{array}{l}\text { LBL assembly with } \\
\text { chemical cross-linking } \\
\text { between P(NIPAAm-co- } \\
\text { SA) and P(NIPAAm) }\end{array}$ & $\begin{array}{l}2 \mathrm{M} \mathrm{NaCl} \\
\text { (hydrogel) }\end{array}$ & $\sim 8$ & - & [96] \\
\hline TFC & PES substrate & $\begin{array}{l}\text { LBL assembly with } \\
\text { chemical cross-linking by } \\
\text { PEI, PAA and } \mathrm{MoS}_{2}\end{array}$ & $\begin{array}{l}\text { DI water } \\
(1 \mathrm{M} \mathrm{NaCl})\end{array}$ & $\begin{array}{l}27.15 \quad(\mathrm{AL}- \\
\mathrm{FS})\end{array}$ & - & [97] \\
\hline TFC & PAN substrate, & $\begin{array}{l}\text { LBL assembly with } \\
\text { chemical cross-linking by } \\
\text { soaking membranes in } \\
\text { glutaraldehyde solution }\end{array}$ & $\begin{array}{l}\text { DI water } \\
\left(3 \mathrm{M} \mathrm{MgCl}_{2}\right)\end{array}$ & 100 (AL-DS) & $\sim 95\left(\mathrm{MgCl}_{2}\right)$ & [162] \\
\hline
\end{tabular}




\begin{tabular}{|c|c|c|c|c|c|c|}
\hline $\begin{array}{l}\text { Double-skinned } \\
\text { TFC }\end{array}$ & PAN substrate & $\begin{array}{l}\text { LBL assembly with } \\
\text { chemical cross-linking by } \\
\text { soaking membranes in } \\
\text { glutaraldehyde solution } \\
\text { on both surfaces of PAN } \\
\text { substrate }\end{array}$ & $\begin{array}{l}\text { DI water } \\
\left(0.5 \mathrm{M} \mathrm{MgCl}_{2}\right)\end{array}$ & $\begin{array}{l}80 \text { (AL-DS) } \\
30 \text { (AL-FS) }\end{array}$ & $\begin{array}{l}94.2\left(\mathrm{MgCl}_{2},\right. \\
\text { top skin) } \\
49.8\left(\mathrm{MgCl}_{2} \text {, }\right. \\
\text { bottom skin })\end{array}$ & {$[163]$} \\
\hline $\begin{array}{l}\text { Thin film } \\
\text { inorganic }\end{array}$ & $\begin{array}{l}\text { Stainless steel mesh (SSM) } \\
\text { substrate }\end{array}$ & $\begin{array}{llr}\text { LBL deposition } & \text { of } \\
\text { microporous } & \text { silica } \\
\text { xerogels onto } & \text { SSM } \\
\text { substrate } & & \\
\end{array}$ & $\begin{array}{l}\text { DI water } \\
(2 \mathrm{M} \mathrm{NaCl})\end{array}$ & 60.3 & - & {$[164]$} \\
\hline $\begin{array}{l}\text { Positively- } \\
\text { charged hollow } \\
\text { fiber }\end{array}$ & PAI substrate & $\begin{array}{l}\text { Post-treatment with } \\
\text { polyelectrolyte PEI }\end{array}$ & $\begin{array}{l}\text { DI water } \\
\left(0.5 \mathrm{M} \mathrm{MgCl}_{2}\right)\end{array}$ & 9.74 (AL-FS) & 49 & {$[165]$} \\
\hline $\begin{array}{l}\text { Double-skinned } \\
\text { TFC }\end{array}$ & PES substrate & $\begin{array}{l}\text { Coating of PMAPS } \\
\text { zwitterion bottom layer }\end{array}$ & $\begin{array}{l}1000-10000 \\
\text { ppm emulsified } \\
\text { oil solution } \\
(2 \mathrm{M} \mathrm{NaCl})\end{array}$ & 13.7 (AL-DS) & $\begin{array}{l}>99.9 \\
\text { (emulsified } \\
\text { oil solution) }\end{array}$ & {$[166]$} \\
\hline $\begin{array}{l}\text { Double-skinned } \\
\text { TFC }\end{array}$ & PAN substrate & $\begin{array}{l}\text { Coating of nexar } \\
\text { copolymer bottom layer }\end{array}$ & $\begin{array}{lr}200000 & \text { ppm } \\
\text { emulsified } & \text { oil } \\
\text { solution } & \\
(0.5 \mathrm{M} \mathrm{NaCl}) & \end{array}$ & 10.9 (AL-DS) & $\begin{array}{l}>99.9 \\
\text { (emulsified } \\
\text { oil solution) }\end{array}$ & [167] \\
\hline $\begin{array}{l}\text { Double-skinned } \\
\text { TFC }\end{array}$ & PSf substrate & $\begin{array}{l}\text { Incorporation of CNTs } \\
\text { onto PA layer and coating } \\
\text { of CNTs-PA layer on the } \\
\text { substrate bottom }\end{array}$ & $\begin{array}{l}\text { DI water } \\
\left(2 \mathrm{M} \mathrm{MgCl}_{2}\right)\end{array}$ & $\begin{array}{l}\sim 8 \text { (TFN0.05, } \\
\text { AL-FS) } \\
\sim 12 \\
\text { (TFN0.05, } \\
\text { AL-DS) }\end{array}$ & - & [101] \\
\hline
\end{tabular}


Table. Summary of membrane development (MD)

\begin{tabular}{|c|c|c|c|c|c|c|}
\hline Membranes & Materials & Modification & $\begin{array}{l}\text { Feed Solution } \\
\text { (Draw Solution) }\end{array}$ & $\begin{array}{l}\text { Water Flux } \\
\left(\mathbf{L ~ m}^{-2} \mathbf{h r}^{-1}\right)\end{array}$ & $\begin{array}{l}\text { Salt } \\
\text { Rejection } \\
\text { (\%) }\end{array}$ & Reference \\
\hline $\begin{array}{l}\text { Flat sheet } \\
\text { membrane }\end{array}$ & $\begin{array}{l}\text { PVDF } \\
\text { membrane }\end{array}$ & $\begin{array}{l}\mathrm{TiO}_{2} \text { nanoparticles electrospray } \\
\text { coating on PVDF membrane }\end{array}$ & $\begin{array}{l}\text { Synthetic algal organic } \\
\text { matter }(10 \mathrm{mg} / \mathrm{L} \text { humic } \\
\text { acid, } 10 \mathrm{mg} / \mathrm{L} \text { sodium } \\
\text { alginate and } 5 \text { mg/L } \\
\text { albumin) }\end{array}$ & 38 & $\begin{array}{l}99.99 \text { (Salt } \\
\text { rejection) } \\
99.99 \text { (DOC } \\
\text { rejection) }\end{array}$ & [105] \\
\hline $\begin{array}{l}\text { Flat sheet } \\
\text { membrane } \\
\text { with } \\
\text { nanofibrous } \\
\text { layers }\end{array}$ & $\begin{array}{l}\text { PVDF } \\
\text { membrane }\end{array}$ & $\begin{array}{l}\begin{array}{l}\text { Hydrophobic modification of } \\
\text { nanosheets } \\
\text { perfluorooctyltriethoxysilane }\end{array} \\
\text { by }\end{array}$ & $\begin{array}{l}35 \mathrm{~g} / \mathrm{L} \text { sodium chloride } \\
(\mathrm{NaCl})\end{array}$ & $18-36$ & 99.9 & {$[168]$} \\
\hline $\begin{array}{l}\text { Tubular } \\
\text { membrane }\end{array}$ & $\begin{array}{l}\mathrm{Al}_{2} \mathrm{O}_{3} \\
\text { membrane }\end{array}$ & $\begin{array}{l}\text { Tubular asymmetric } \mathrm{Al}_{2} \mathrm{O}_{3} \text { membrane } \\
\text { grafted by hexadecyltrimethoxysilane } \\
\text { in ethanol solution }\end{array}$ & $30 \mathrm{~g} / \mathrm{L} \mathrm{NaCl}$ & 30 & 99.9 & [169] \\
\hline $\begin{array}{l}\text { Flat sheet } \\
\text { membrane } \\
\text { with } \\
\text { ominiphobic } \\
\text { surface }\end{array}$ & $\begin{array}{l}\text { Polyester } \\
\text { nonwoven } \\
\text { fabric as } \\
\text { substrate }\end{array}$ & $\begin{array}{l}\text { Fluorination of a fibrous hydrophilic } \\
\text { polymer-nanoparticle composite to } \\
\text { obtain omniphobic surface }\end{array}$ & 3.5 wt. $\%$ sodium chloride & $8.2-13.6$ & 100 & {$[108]$} \\
\hline $\begin{array}{l}\text { Ceramic } \\
\text { hollow fibre } \\
\text { membrane }\end{array}$ & $\begin{array}{l}\text { Alumina } \\
\text { membrane }\end{array}$ & $\begin{array}{l}\text { Phase inversion and sintering for } \\
\text { membrane preparation, followed by } \\
\text { perfluorodecyltriethoxysilane grafting }\end{array}$ & $1.2,3,6.5 \mathrm{NaCl}$ & $25-33$ & 99.985 & {$[170]$} \\
\hline $\begin{array}{l}\text { Hollow } \\
\text { Fibre } \\
\text { Membrane }\end{array}$ & $\begin{array}{l}\text { PVDF } \\
\text { membrane }\end{array}$ & $\begin{array}{l}\text { Dry jet wet spinning for membrane } \\
\text { fabrication, followed by fluorographite } \\
\text { coating. }\end{array}$ & 10 wt. $\% \mathrm{NaCl}$ & $\sim 25$ & 99.99 & {$[171]$} \\
\hline $\begin{array}{l}\text { Dual layer } \\
\text { flat sheet } \\
\text { membrane }\end{array}$ & $\begin{array}{l}\text { PVDF } \\
\text { membrane }\end{array}$ & $\begin{array}{lrr}\begin{array}{l}\text { Membrane } \\
\text { functionalized }\end{array} & \begin{array}{c}\text { modification } \\
\text { graphene }\end{array} & \begin{array}{r}\text { with } \\
\text { oxide }\end{array}\end{array}$ & 3.5 wt. $\% \mathrm{NaCl}$ & 16.7 & 99.9 & {$[172]$} \\
\hline
\end{tabular}




\begin{tabular}{|c|c|c|c|c|c|c|}
\hline & & $\begin{array}{l}\text { chemically modified } \quad \text { with } \\
\text { octadecylamine. }\end{array}$ & & & & \\
\hline $\begin{array}{l}\text { Composite } \\
\text { membrane }\end{array}$ & $\begin{array}{l}\text { PVDF } \\
\text { membrane }\end{array}$ & $\begin{array}{l}\text { Membrane modification via } \\
\text { electrospinning process. }\end{array}$ & $3.5 \mathrm{wt} . \%$ sodium chloride & 49.3 & 99.9 & {$[173]$} \\
\hline $\begin{array}{l}\text { Electrospun } \\
\text { nanofiber } \\
\text { membrane }\end{array}$ & $\begin{array}{l}\text { PVDF } \\
\text { membrane }\end{array}$ & $\begin{array}{l}\text { Membrane modification with } \mathrm{SiO}_{2} \mathrm{NPs} \\
\text { and } \mathrm{f}-\mathrm{SiO}_{2} \mathrm{NPs} \text { via electrospinning }\end{array}$ & Not mention & $5-40$ & $99.5-99.9$ & {$[174]$} \\
\hline $\begin{array}{l}\text { Composite } \\
\text { nanofiber } \\
\text { membrane }\end{array}$ & $\begin{array}{l}\text { PVDF } \\
\text { membrane }\end{array}$ & $\begin{array}{l}\text { Preparation of nanocomposites by } \\
\text { blend electrospinning using Cloisite } \\
\text { 20A }\end{array}$ & 3.5 wt. $\% \mathrm{NaCl}$ & $\sim 6$ & $\sim 99.97$ & {$[175]$} \\
\hline $\begin{array}{l}\text { TFC } \\
\text { membrane }\end{array}$ & $\begin{array}{l}\text { PVDF } \\
\text { membrane }\end{array}$ & $\begin{array}{l}\text { Functionalization of the membrane } \\
\text { using chitosan, ZIF- } 8 \text {, and PEG. }\end{array}$ & 3.5 wt. $\% \mathrm{NaCl}$ & $\sim 7$ & $\sim 99.8$ & {$[176]$} \\
\hline $\begin{array}{l}\text { Hollow fibre } \\
\text { Composite } \\
\text { membrane }\end{array}$ & $\begin{array}{l}\text { MOF/PVDF } \\
\text { membrane }\end{array}$ & $\begin{array}{l}\text { Mixing of MOF with the dope, then } \\
\text { fabricated via dry-jet wet phase } \\
\text { inversion technique. }\end{array}$ & 3.5 wt. $\% \mathrm{NaCl}$ & 15.64 & 99.9 & {$[177]$} \\
\hline $\begin{array}{l}\text { Composite } \\
\text { membrane }\end{array}$ & $\begin{array}{l}\text { PVDF } \\
\text { membrane }\end{array}$ & $\begin{array}{l}\text { Membrane blended with multi-walled } \\
\text { carbon nanotubes (MWCNTs) and } \\
\text { silica. }\end{array}$ & $35 \mathrm{~g} / \mathrm{L}$ sodium chloride & 5.7 & 99.98 & [178] \\
\hline $\begin{array}{l}\text { Flat sheet } \\
\text { ceramic } \\
\text { membrane }\end{array}$ & $\begin{array}{l}\text { Alumina } \\
\text { membrane }\end{array}$ & $\begin{array}{l}\text { Hydrophobic modification } \begin{array}{r}\text { of } \\
\text { membrane } \\
\text { perfluorooctyltrichlorosilane }\end{array} \\
\text { andperfluorodecyltriethoxysilane } \\
\text { (PFDS) }\end{array}$ & $0-3$ wt. $\% \mathrm{NaCl}$ & $10-33$ & 99.9 & [104] \\
\hline $\begin{array}{l}\text { Hollow fibre } \\
\text { ceramic } \\
\text { membrane }\end{array}$ & $\begin{array}{l}\text { Silica } \\
\text { derived from } \\
\text { rice husk } \\
\text { waste }\end{array}$ & $\begin{array}{l}\text { Membrane modification using } \\
\text { fluoroalkylsilane agent in ethanol by } \\
\text { immersion technique }\end{array}$ & $2-10 \mathrm{~g} / \mathrm{L} \mathrm{NaCl}$ & $20-60$ & 99.9 & [134] \\
\hline
\end{tabular}




\section{Highlights}

- $\quad F O$ and MD are emerging technologies for desalination

- A review focuses on fouling mitigation strategies in FO and MD for desalination.

- Membrane modification and operating conditions play important roles in fouling mitigation 